\title{
Markups, International Specialization, and the Gains from Trade
}

\author{
Ahmad Lashkaripour* \\ The Pennsylvania State University \\ July 2014
}

\begin{abstract}
This paper develops a new theory of international specialization that tractably combines all aspects of North-North and North-South trade into one model. The new theory also provides an alternative explanation for many other well-established facts, most notably the "Washington apples" effect. The theory builds upon, and retains the central elements of Krugman [1980]. In the new framework, North-North trade is governed by national product differentiation. North-South trade is governed by a new channel of across product specialization that has been overlooked in the literature. Specifically, there are many products and each product comes in different varieties. Products differ in how (horizontally) differentiated they are. Monopolistically competitive firms charge a higher markup for varieties of highly differentiated products. In equilibrium, rich countries specialize in highly differentiated-high markup products, while poor countries specialize in less differentiated-low markup products. To quantify the gains from trade, I estimate the structural parameters of the model using disaggregated data. Incorporating the new channel of acrossproduct specialization into the Krugman model magnifies the gains from opening to trade by around $200 \%$. Despite trading less, low-income countries experience the largest gains from trade liberalization.
\end{abstract}

\section{JEL-Classification: F12, F14, O15, L25}

Keywords: markups, differentiation, specilization, intraindustry, interindustry, trade, North, South

\footnotetext{
*I owe a debt of gratitude to my advisors Jonathan Eaton and Stephen Yeaple for their invaluable guidance, encouragement, and support. I am also grateful to James Tybout for various discussions on the topic. I wish to thank Russell Cooper, Bernardo Díaz de Astarloa, Alexandros Fakos, Farid Farrokhi, Cecilia Fieler, Paul Grieco, Kala Krishna, Konstantin Kucheryavyy, Felix Tintelnot, and Neil Wallace for helpful comments and suggestions. All errors are my own. Correspondence: azl153@psu.edu, http://www . personal.psu.edu/azl153.
} 


\section{Introduction}

The "Classical trade theories" were developed during the 'first great age of globalization' when trade was mainly North-South trade. They emphasized inter-industry specialization, and were specifically designed to explain North-South trade. Beginning in the 1970s, global trade underwent a major transition. In less than a decade, international trade became predominantly North-North trade: a two-way exchange of similar goods between similar (highly developed) countries. Following this change, the "new trade theories" were born - these theories were specifically designed to explain North-North trade. Recently, international trade has undergone yet another transition. In the past decade North-South and North-North (and even South-South) trade have become equally important (Hanson [2012]; Krugman [2009]). To accommodate this trend, we should revise how we model international trade. More precisely, we need a model that combines North-South and North-North trade-a model that simultaneously incorporates the two-way exchange of autos between US and Canada and the high-volume export of apparels from China to the US.

The past decade also marked a data revolution in the study of international trade. Researchers documented two new features of North-South trade. First, using highly disaggregated data, many studies reported a robust pattern of intraindustry North-South trade. Specifically, North and South exchange goods that belong to the same industry, with north exporting higher price goods within each industry (Schott [2004]; Bernard, Jensen, and Schott [2006a]). Second, many studies documented that (conditional on total GDP) countries with higher per capita GDP, trade more intensely. In other words, export-to-GDP ratio is higher in North relative to South (Fieler [2011]; Waugh [2010]). Neither of these (recently documented) features is captured by "classical theories" of North-South trade.

The goal of this paper is to, first, bridge the gap between "classical trade theory" and the "new trade theory". To this end, I propose an alternative theory of international specialization that tractably combines all aspects of North-South and North-North trade into one model. I take an alternative view from the "classical trade theories," and abstract from non-homotheticity, which is computationally burdensome, but widely used in the contemporary North-South trade literature. Indeed, the alternative theory deviates minimally from the standard assumptions adopted by Krugman [1980], retains the tractability of the "new trade theories," and is straightforward to estimate. Second, the theory developed in this paper is consistent with the recent empirical findings on North-South trade; the new theory simultaneously explains (1) why high-income countries trade more intensely, and (2) why they engage in intra-industry trade with lowincome countries, but export high-price goods within each industry. In fact, this paper presents the first theory of international specialization that reconciles these two recently well-documented features of NorthSouth trade. 
The theory developed in this paper is more than just a theory of North-South (and North-North) trade. It is a comprehensive, multi-country, general equilibrium theory of international specialization; a theory of why (in the global economy) countries with different characteristics specialize in different goods. For example, the new theory provides an alternative explanation for the "Washington apples" effect-a welldocumented fact regarding intra-industry specialization. ${ }^{1}$ Due to its comprehensive nature, the new theory fits aggregate trade data significantly better than the baseline Krugman model. Moreover, the theory yields predictions (about intraindustry and interindustry trade) that are consistent with highly disaggregated US imports data.

The new theory provides a simple framework to quantify the gains from trade across low-income and high-income countries when all directions of trade are taken into account. Previous studies have generally quantified the gains from trade among high-income countries by focusing (exclusively) on North-North trade (Arkolakis, Costinot, and Rodriguez [2012]; Eaton and Kortum [2002]). Quantifying the gains from trade in the new framework reveals two remarkable results: (1) when North-South specialization is embodied into a standard "new trade theory" framework, the gains from trade are magnified (for the average country) by around $200 \%$, and (2) low-income countries experience the largest gains from globalization, even though they trade less. In summary, the new theory introduces an alternative driving force behind (dissimilar) trade that exhibits generality, is highly consistent with disaggregated data, and generates distinct welfare implications. The new theory, therefore, complements the existing theories, and should be separately identified if we wish to attain consistent estimates for the gains from trade.

To model the global economy, I build upon the multi-country monopolistic competition model of trade with homogeneous firms, developed by Krugman [1980]. I modify the baseline Krugman model along two main directions. First, rather than one product, there are many products and each product comes in many different varieties. Varieties of a product are differentiated by country of origin (i.e. national product differentiation), and within every country varieties are differentiated at the firm level. National product differentiation is the driving force behind North-North trade. ${ }^{2}$

Products are characterized by how (horizontally) differentiated they are. Specifically, preferences are nested CES, and each nest represents a product with a unique (product-specific) elasticity of substitution across varieties. Highly differentiated products have a low elasticity of substitution, while less differentiated products are subject to a high elasticity of substitution, e.g. designer handbags are highly differentiated while sandwich bags are less differentiated. In a monopolistically competitive setting, firms charge a higher

\footnotetext{
${ }^{1}$ The "Washington apples" effect states that countries, which face higher trade costs specialize in higher price goods.

${ }^{2}$ In the original Krugman model increasing returns to scale are the driving force behind North-North trade. Increasing returns to scale and national product differentiation are isomorphic in terms of generating North-North trade. However, Head and Ries [2001] suggest that evidence sides with national product differentiation more than the other.
} 
markup for highly differentiated products. Therefore, within every industry, highly differentiated products on average exhibit a higher price due to higher markups. ${ }^{3}$

The second direction in which I modify Krugman [1980] is allowing for countries to be asymmetric in labor skill. A Country that is populated with high-skill labor exhibits superior "national production quality," and is endowed with a larger Armington demand shifter, i.e. varieties produced in high-skill countries are more attractive to consumers all over the world. High-skill labor improves the "quality of production" but not the "quantity of production." For example, a worker in China produces the same quantity of cars as a German worker. However, the German car is more attractive to consumers because it is designed and assembled by high-skill labor. In equilibrium, there is more demand for high-skill labor. Therefore, equilibrium wages and income levels are higher in high-skill countries which exhibit superior "national production quality."

In the trade equilibrium, two factors determine how much a country exports to global markets: (1) price, and (2) national production quality. For highly differentiated products, by definition, demand is less sensitive to price and "national production quality" is the main determinant of trade flows. For less differentiated products, on the other hand, demand is highly sensitive to price, and price is the main determinant of trade flows. As a result, high-wage countries, which have high-skill labor and production quality-advantage, are competitive in highly differentiated-high markup products. Low-wage countries, which have cheap labor and price-advantage, are competitive in less differentiated-low markup products-to put it in a more general context, high-wage countries are competitive in highly differentiated industries, and within each industry they enjoy competitive advantage in the most differentiated products.

Exports are subject to a per-product fixed cost. Exports of highly differentiated products that exhibit high markups, generate high enough profits to cover the (per-product) fixed cost. The least differentiated products that exhibit the lowest markups are not profitable to export. Less differentiated products are, however, profitable to sell domestically since there are no fixed costs associated with domestic sales. Hence, highly differentiated products are the main subject of international trade. Less differentiated products, on the other hand, are mostly purchased from domestic sources.

In summary, firms from low-wage countries have competitive advantage in products that exhibit low markups and are not profitable to export. Firms from low-wage countries, therefore, exploit their competitiveness in less differentiated-low markup products by selling predominantly in the domestic market (where they do not incur fixed costs). Firms from high-wage countries, meanwhile, profitably export a

\footnotetext{
${ }^{3}$ A novel contribution of the new model is presenting an alternative view on (the product space and) prices in international trade. Existing models attribute across-product price differences to across-product quality differences. In the new model, however, a product is (on average) more expensive if it is more differentiated and is subject to a higher markup. I argue that price patterns in international trade can be largely explained with across-product differences in levels of differentiation and markups.
} 
wide range of highly differentiated-high markup products. As a result, in the trade equilibrium, high-wage countries (1) trade more intensively, and (2) specialize in highly differentiated industries, and within each industry they specialize in highly differentiated-high markup products that exhibit higher prices. ${ }^{4}$

The "Washington apples" effect can be explained along the same lines. When firms face high trade costs they have a higher marginal cost and charge a higher price. Demand for highly differentiated products is less sensitive to the high price charged by these firms. Moreover, firms charge a higher markup for highly differentiated products, which allows them to collect profits despite low sales. These two channels encourage firms facing high trade costs to specialize in highly differentiated-high markup products, which exhibit higher unit values.

After developing a unifying model of international specialization, I conduct a two tier empirical analysis to discipline the parameters of the model. First, I fit the model to micro U.S. import data, which is disaggregated at the HS-10 product level. ${ }^{5}$ I use the traditional instrumental variable technique to estimate the structural demand parameters. The estimation quantifies national product differentiation and identifies the elasticity of substitution for more than five thousand product categories. ${ }^{6}$

Patterns of U.S. imports are highly consistent with the new theory. Within every SITC-5 industry, the HS-10 products that have a lower (estimated) elasticity and are more differentiated exhibit significantly higher prices. ${ }^{7}$ This suggest that the higher price of exports from rich countries - within an SITC-5 industry - could be due to the fact that they are net exporters of (i.e. specialize in) highly differentiated-high markup HS10 products. $^{8}$ Patterns of inter-industry specialization are also consistent with the new theory. Low-wage countries penetrate the US market significantly more in less differentiated SITC-5 industries, i.e. low-wage countries are net exporters of (products that belong to) less differentiated industries. ${ }^{9}$

In the second tier of my empirical analysis I take a subset of the elasticities, estimated in the first stage, and use them to calibrate the general equilibrium outcomes of my model to aggregate data on bilateral trade and country wages. The new model significantly improves upon the baseline Krugman model in terms of matching both trade flow data and (out of sample) data on the unit value of traded goods.

\footnotetext{
${ }^{4}$ Specialization in the context of this paper is incomplete specialization; in equilibrium, high-wage countries are net exporters of highly differentiated-high markup products and net importers of less differentiated low-markup products.

${ }^{5}$ An HS-10 product in the data is a 10-digit product classification code belonging to the Harmonized System developed by the World Customs Organization (WCO).

${ }^{6}$ My estimation implies that varieties (of an HS-10 product) produced in the same country are 2.3 times closer substitutes relative to varieties produced in different countries.

${ }^{7} \mathrm{An}$ industry is a set of products that are close substitutes. In the data an industry is characterized by a 5-digit SITC (Standard International Trade Classification) code which comprises of multiple, closely related, HS-10 product categories.

${ }^{8}$ In the literature the higher price of exports are attributed to the higher quality of exported goods. While I find a positive and significant relationship between price and degree of differentiation, the existing literature has struggled to find a positive and significant relationship between price and product quality at the same level of disaggregation. Khandelwal [2010], for example, finds a negative correlation between quality and f.o.b price at the HS-10 product level in the US import data.

${ }^{9}$ By definition, a less differentiated SITC industry is comprised of less differentiated HS-10 products. Demand estimation suggests that the leather and food industries are less differentiated, while the electronics, instruments, and industrial machinery industries are highly differentiated-low-wage countries export relatively more apparel than industrial machinery to the US.
} 
I use the calibrated model to revise our answer to two classic questions in the trade literature: (1) How large are the gains from trade, and (2) how big are the barriers to trade. The gains from trade are larger by a considerable margin in the new model compared to the baseline Krugman model. In the new model, opening to trade from autarky results in a 15\% increase in real wage for the average country. In comparison, the baseline Krugman model estimates only (on average) a 5\% increase in real wages after opening to trade. $^{10}$

To explain the substantially larger gains in the new model, note that the gains from trade depend on two factors: (1) the volume of trade (the more a country trades the more it gains from trade), and (2) the elasticity of substitution (the less substitutable the imported varieties the more one gains from importing them). In the new model after trade liberalization, highly differentiated products are imported more intensively. Since foreign varieties of highly differentiated products are less substitutable with their domestic counterparts, consumers gain considerably more from importing them-this is big step forward in generalizing the existing results about higher gains in the presence of sectoral heterogeneity. ${ }^{11}$

Contrary to what one might expect, low-wage countries gain more from trade even though they trade less. After opening to trade, consumers in low-wage countries gain access to the high-skill labor and the superior "national production quality" in high-wage countries. Low-wage countries are net importers of highly differentiated products, and for highly differentiated products "production quality" matters even more. Pakistan, for example, is one of the biggest gainers (from trade) in the new model. After opening to trade, Pakistani consumers gain access to laptops from Japan and cars from Germany, which are substantially better (per dollar) than their Pakistani counterparts.

In the new model, the iceberg trade costs are estimated to be $51 \%$ larger than the baseline Krugman model-a representative of traditional "new trade theory" models. The underlying reason is that the Krugman model, like most traditional models, is solely a model of North-North trade. The new theory introduces a new driving force behind (North-South) trade in the form of across-product specialization. Therefore, in the light of the new theory there is more incentive to trade-countries engage in trade to utilize from both national product differentiation and across-product specialization. With more incentive to trade in the new model, one can fit trade flow data with larger trade costs. Larger trade costs indicate that potential gains from eliminating them are also larger-in a nutshell, overlooking North-South trade undermines the gains from trade at various levels.

\footnotetext{
${ }^{10}$ In the baseline model, unlike the original Krugman model, trade is driven by national product differentiation. However, national product differentiation and increasing return to scale are isomorphic in terms of trade flows and the gains from trade.

${ }^{11}$ Ossa [2012] and Costinot and Rodríguez-Clare [2013] also show that sectoral heterogeneity (in demand elasticity) can increase the gains from trade. Both studies, however, exogenously fix expenditure shares on highly differentiated sectors by asuming an across-sector Cobb-Douglas utility aggregator. This paper generates even larger gains despite relaxing this, rather restrictive, parametric assumption-I argue that the high intensity of imports in differentiated industries is an equilibrium outcome rather than an assumption.
} 


\section{Related Literature}

This paper complements a flourishing literature on North-South trade. The existing literature can be divided into two distinct blocks. The first block emphasizes inter-industry trade. This block includes the 'Classical theories' (e.g. Hecksier-Ohlin; Ricardian) that rely on factor specialization, and the contemporary models that incorporate non-homothetic demand to explain the higher intensity of trade in North (e.g. Fieler [2011]; Markusen [1986]). ${ }^{12}$ The second block of literature focuses on intra-industry North-South trade. These studies rely on quality differentiation (and usually non-homothetic demand) to explain the patterns of intra-industry North-South specialization (e.g. Schott [2004]; Hallak [2006]; Fajgelbaum, Grossman, and Helpman [2011]). More precisely, they explain the higher price of exports from high-income countries within each industry.

The present paper contributes to the North-South trade literature along two directions. First, it develops a unifying framework that accounts for both inter-industry and intra-industry North-South trade in one model. The new framework tractably accounts for both the lower intensity of trade in South and the higher-price of exports from North within industries. Second, the present paper introduces a new channel of (across-product) specialization that has been overlooked in the literature. While previous theories have emphasized specialization in quality or specialization in factors, the new theory emphasizes a new channel of specialization. Countries specialize in products/industries that exhibit different degrees of differentiation (or alternatively different countries differentiated their products to various degrees). The new channel of specialization unveils a new channel for the gains from trade - a channel that magnifies the gains to a remarkable degree.

This paper builds heavily upon the "new trade theory" models. These models were originally designed to account for patterns of North-North trade in a tractable multi-country general equilibrium setting. Among the "new trade theories," Krugman [1980] emphasizes increasing returns to scale, Armington-like models emphasize national product differentiation, and Eaton and Kortum [2002] rely on comparative advantage. Empirical studies have tested the relative importance of each channel, and have found strong support for national product differentiation among others (Head and Ries [2001]). The first contribution of this paper is incorporating North-South trade into a conventional multi-country "new trade theory" framework with national product differentiation. In doing so, the paper deviates minimally from conventional assumptions - e.g. homothetic CES preferences and symmetric iceberg trade costs. The proposed framework, therefore, retains the tractability of the "new trade theories" and is amenable to straightforward

\footnotetext{
${ }^{12}$ Waugh [2010] accounts for the high intensity of trade in North using an alternative approach. He argues that the higher intensity of trade among rich countries is due to asymmetric trade costs. Specifically, rich countries face systematically lower trade costs than poor countries.
} 
estimation. The second contribution is quantifying (the extent of) national product differentiation.

The new theory (developed in this paper) provides an alternative explanation for the "Washington apples effect." The effect is one of the best-documented facts regarding intra-industry specialization, and states that higher trade costs induce countries to specialize in higher-price goods within each industry. The existing literature accounts for this effect with additive trade costs — generally referred to as the Alchian-Allen conjecture. Contrary to the Alchian-Allen conjecture, the new theory explains the "Washington apples effect" in the context of conventional trade models, in which trade costs are iceberg. As demonstrated by Lashkaripour [2013], the new theory also captures aspects of the "Washington apples effect" that are inconsistent with the Alchian-Allen conjecture.

Finally, this paper contributes to an active area of ongoing research that measures the gains from trade. Recently, Arkolakis et al. [2012] argued that the gains from trade are relatively small in the context of mainstream trade models. In response, Costinot and Rodríguez-Clare [2013] and Ossa [2012] showed that introducing multiple sectors magnifies the gains. Both papers assume a Cobb-Douglas utility aggregator across sectors. Therefore, an endogenously fixed fraction of the consumers' spending will be on sectors/products which exhibit a low elasticity of substitution. This automatically generates sizable gains from trade. This paper takes a big step forward in extending and generalizing their result; it relaxes the exogenous allocation of spending across sectors/products, and introduces a new channel of across-sector specialization that endogenously magnifies the gains from trade.

\section{Theory}

In this section I will introduce the main ingredients of my general equilibrium model. The global economy consists of $N$ asymmetric countries denoted by $C=\{1,2, \ldots, N\}$. Each country $i \in C$ is populated with a mass $L_{i}$ of identical agents. Each agent is endowed with one unit of labor, and labor is the only factor of production. Countries differ in terms of their population and their production techniques. Varieties produced in countries with superior production technique are more appealing and carry more weight in the consumers' utility function. Geography is reflected in two kinds of barriers between countries: variable iceberg trade costs, and the fixed cost of exporting in a product category. There is a continuum of differentiated products and each product comes in different varieties. Firms in every country are multi-product and homogenous. I assume a market structure characterized by monopolistic competition and free entry.

In the following sections I will further lay out the environment; I start with a description of the commodity space and demand in the next subsection. Then, I turn to supply and the problem of the firms. 


\subsection{Product Space}

There are two types of goods: (i) manufactured goods that are differentiated and tradable, and (ii) nonmanufactured goods that are homogenous and non-tradable. The manufactured good comes in different varieties. A variety is characterized by (i) the product category it belongs to , (ii) the country it was manufactured in, and (iii) the firm that manufactured it. Mathematically, the commodity space can be expressed as

$$
\Xi=\underbrace{H}_{\text {Product }} \times \underbrace{C}_{\text {Country }} \times \underbrace{\Omega_{c}}_{\text {Firm }}
$$

where $H=[0, \bar{H}]$ denotes the (continuous) set of products, $C=\{1,2, \ldots, N\}$ is the set of countries, and $\Omega_{j}$ is the continuum of firms in country $j \in C$. Variety $\omega j h$ denotes a manufactured good that belongs to product category $h \in H$, is manufactured in country $j \in C$, by firm $\omega \in \Omega_{j}$ (e.g. a 40" Samsung TV is a variety that belongs to the 40 " TV product category, is manufactured by Samsung, in Korea. ) A simple illustration of the commodity space is provided in figure $1 .{ }^{13}$

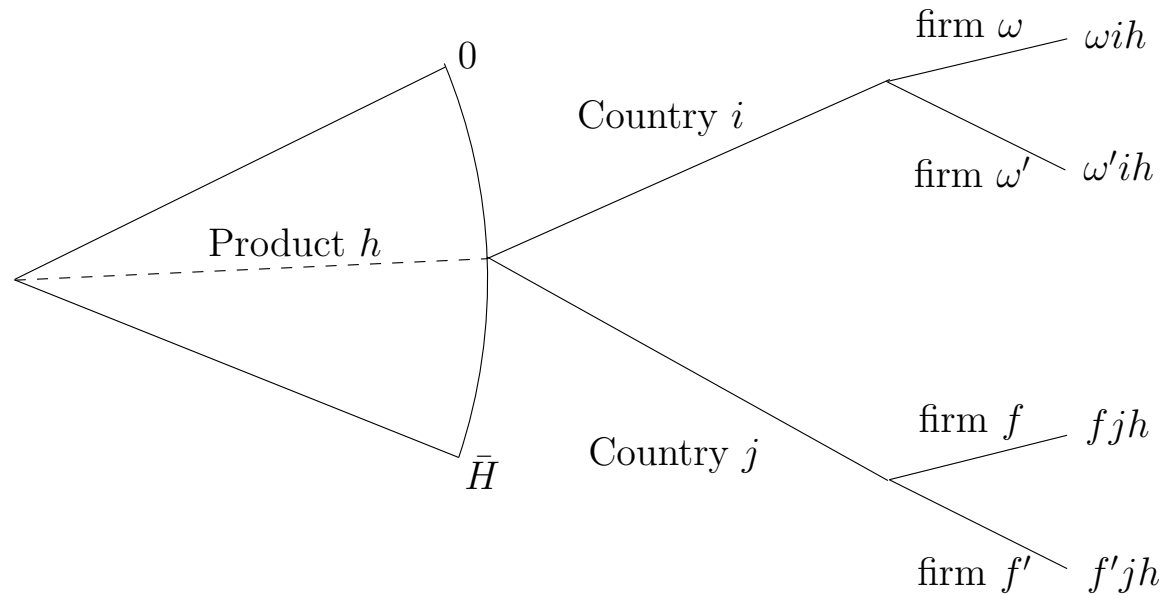

Figure 1: The commodity space. There is a continuum of differentiated products. Each differentiated product comes in different varieties. Varieties of a product are differentiated by country of origin (i.e. national product differentiation). Within a country, varieties are differentiated at the firm level.

In the background, product space $H$ can be broken down into industries. Precisely, $H=\cup_{s \in S} H_{s}$ where $S$ is the set of industries and $H_{s} \subset H$ is a subset of products that belong to industry $s \in S-$ an industry comprises of products that are comparable. In this paper, whenever I compare unit values across products I confine my comparison to products within an industry. In other words, I am comparing the price of apples to apples (e.g. the price of luxury cars to economy cars).

\footnotetext{
${ }^{13}$ A product category in the data is defined as a 10-digit HS-10 code belonging to the Harmonized System developed by the World Customs Organization (WCO). A group of closely substitutable products constitute an industry. In trade data, an industry is classified by a 5-digit SITC-5 (Standard International Trade Classification) code. Figure 15 (in appendix D) displays an example of an SITC-5 industry in the US import data (compiled by Feenstra, Romalis, and Schott [2002]) - the industry displayed in figure 15 is classified as (the 5-digit number) 71620 and comprises of various categories of DC generators and motors.
} 


\subsection{Demand}

As noted earlier, each country is populated with a mass $L_{i}$ of identical consumers. Preferences are a generalized version of the Dixit-Stiglitz preferences (Dixit and Stiglitz [1977]). Each individual maximizes the following utility function

$$
V=U_{M}^{\alpha} Q_{N}^{1-\alpha}
$$

where $Q_{N}$ is the quantity consumed of the non-manufactured good. A share $1-\alpha$ of expenditure is, therefore, allocated to the non-manufactured good and the remaining share $(\alpha)$ is spent on manufactured products. $U_{M}$, the utility consumers derive from manufactured products, is characterized by a nested CES function

$$
U_{M}=\left[\int_{h \in H} C_{h}^{\frac{\epsilon-1}{\epsilon}} d h\right]^{\frac{\epsilon}{\epsilon-1}}
$$

where $C_{h}$ is the sub-utility derived from the consumption of manufactured product $h \in H$, and $\epsilon$ is the elasticity of substitution between any two composite products in set $H .{ }^{14}$ Sub-utility $C_{h}$ is characterized by the following (lower-tier) CES aggregator

$$
C_{h}=\left[\sum_{j \in C} \mu_{j}^{\frac{1}{\sigma_{h}}} Q_{j h}^{\frac{\sigma_{h}-1}{\sigma_{h}}}\right]^{\frac{\sigma_{h}}{\sigma_{h}-1}}
$$

where $\mu_{j}$ is a country-specific (Armington) demand shifter that represents "national production quality." Countries that are endowed with superior "national production quality" produce varieties that are universally more attractive to consumers. "National production quality" $\mu_{j}$ is, essentially, a function of some underlying characteristic like labor-skill (or human capital) in country $j-i . e$ high-skill countries posses superior "national production quality." 15

$\sigma_{h}>1$ is the elasticity of substitution between country-level aggregate varieties of product $h$. I will refer

\footnotetext{
${ }^{14}$ In the background, products are implicitly nested within various industries with the assumption that $\epsilon_{s}=\epsilon$ for all $s \in S$ where $S$ is the set of industries (i.e. the across-product elasticity of substitution is the same for all industries). Specifically, suppose the set of industries, $S$, is discrete. Every product $h \in H$ belongs to some industry $s \in S$ (i.e. $h \in H_{s}$ ) and the upper-tier utility can be written as

$$
U_{M}=\left[\sum_{s \in S}\left\{\int_{h \in H_{s}} C_{h}^{\frac{\epsilon_{s}-1}{\epsilon_{s}}} d \epsilon\right\}^{\frac{\epsilon_{s}}{\epsilon_{s}-1} \frac{\epsilon-1}{\epsilon}}\right]^{\frac{\epsilon}{\epsilon-1}}
$$

where $\epsilon_{s}$ is the elasticity of substitution within industry $s$ and $\epsilon$ is the elasticity of substitution across industries. $H_{s} \subset H$ is the set of products in industry $s$. Assuming $\epsilon_{s}=\epsilon$ for all $s \in S$, then

$$
U_{M}=\left[\sum_{s \in S}\left\{\int_{h \in H_{s}} C_{h}^{\frac{\epsilon-1}{\epsilon}} d \epsilon\right\}^{\frac{\epsilon}{\epsilon-1} \frac{\epsilon-1}{\epsilon}}\right]^{\frac{\epsilon}{\epsilon-1}}=\left[\int_{h \in H} C_{h}^{\frac{\epsilon-1}{\epsilon}} d \epsilon\right]^{\frac{\epsilon}{\epsilon-1}}
$$

${ }^{15}$ Generally speaking, sub-utility $C_{h}$ has the following form
} 
to $\sigma_{h}$ as the across-country elasticity for product $h$. $\sigma_{h}$ determines the scope of differentiation for product $h$. Precisely, if $\sigma_{h}$ is low consumers perceive various varieties of product $h$ to be highly differentiated from one another. The country-level aggregate variety $Q_{j h}$ is itself a CES aggregator across firm-level varieties within country $j$ and product $h$

$$
Q_{j h}=\left[\int_{\omega \in \Omega_{j}} q_{\omega j h}^{\frac{\gamma_{h}-1}{\gamma_{h}}} d \omega\right]^{\frac{\gamma_{h}}{\gamma_{h}-1}}
$$

where $q_{\omega j h}$ is the quantity of variety $\omega j h$ consumed directly by consumers. $\gamma_{h}>1$ is the elasticity of substitution across firm-level varieties of product $h$ within country $j$. I will refer to $\gamma_{h}$ as the within-country elasticity. Figure 2 displays patterns of substitution across varieties.

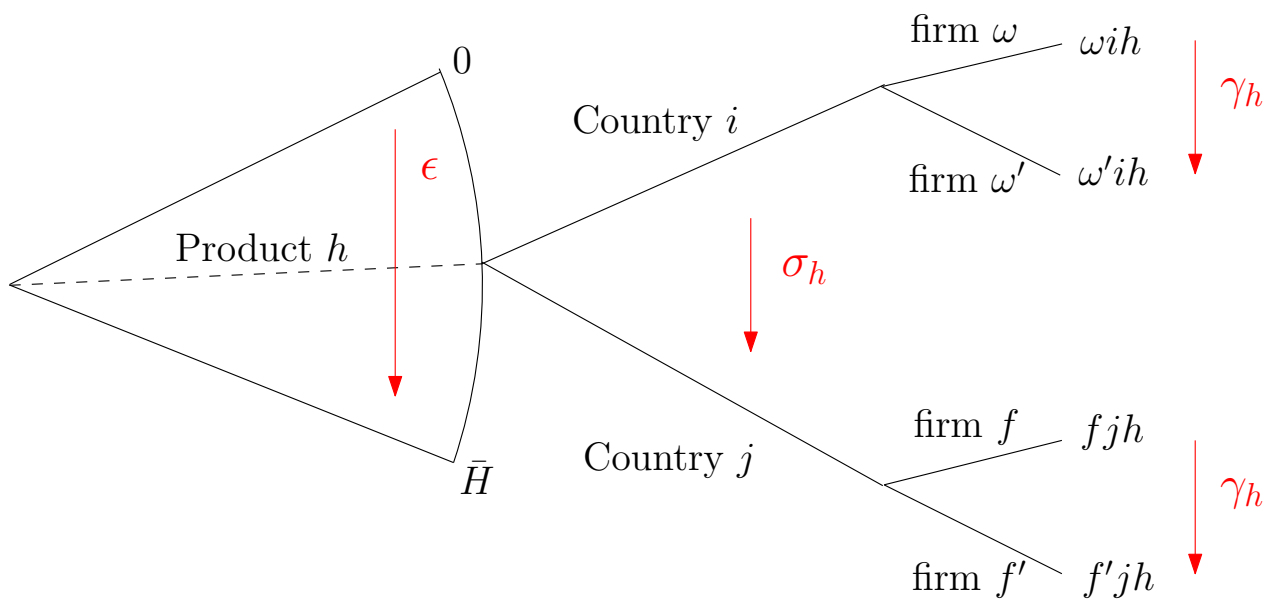

Figure 2: Elasticity of substitution across products and varieties. $\epsilon$ is the elasticity of substitution between two different products. $\sigma_{h}$ is the elasticity of substitution between two different (composite) country-level varieties of the same product. $\gamma_{h}$ is the elasticity of substitution between two different firm-level varieties of the same product from the same country.

Krugman [1980] assumes $\epsilon=\sigma_{h}=\gamma_{h}$ for all $h \in H$. This assumption implies that all products are identical to the consumer and there is no national product differentiation. I partially relax the restrictions imposed by Krugman. I allow for different products that exhibit different degrees of differentiation, and I also allow for national product differentiation. To introduce national product differentiation, I restrict the within-country elasticity of substitution to be greater than the across-country elasticity: $\gamma_{h}>\sigma_{h}$ for

$$
C_{h}=\left[\sum_{j \in C} \mu_{j h}^{\frac{1}{\sigma_{h}}} Q_{j h}^{\frac{\sigma_{h}-1}{\sigma_{h}}}\right]^{\frac{\sigma_{h}}{\sigma_{h}-1}}, h \in H_{s}
$$

Where $s \in S$ is an industry consisting of narrowly defined products that are comparable (the above formulation is similar to Hallak and Schott [2011] with the exception that they assume a common elasticity for all products belonging to same 2-digit sector). In this paper, I will introduce a new channel of international specialization that does not depend on North having better technology when producing certain goods - this channel is already well-explored in the literature. Most existing models of North-South trade assume that $\mu_{j h}$ depends on the quality assigned to product $h\left(\alpha_{h}\right)$ and human capital in country $j\left(H_{j}\right)$. If $\mu_{j h}=\mu\left(\alpha_{h}, H_{j}\right)$ is super-modular, then the technological gap between countries with low human capital and countries with high human capital is more prominent for products that are perceived as high-quality. In this paper I shut down this, already well-explored, channel by assuming $\mu_{j h}=\mu_{j}$ for all $h \in H_{s}$. This assumption assures that the technological gap between North and South is product-independent. 
all $h \in H$. Putting it differently, varieties produced in the same country are closer substitutes. ${ }^{16}$ National product differentiation will induce similar countries to trade with each other - similar to any Armingtontype model. In Krugman [1980], similar countries trade due to economies of scale. ${ }^{17}$

I also allow for different products (in $H$ ) to be subject to different elasticities of substitution: $\sigma_{h} \neq \sigma_{h^{\prime}}$, and $\gamma_{h} \neq \gamma_{h^{\prime}}$ for every $h, h^{\prime} \in H$. However, the within-country elasticity $\left(\gamma_{h}\right)$ is restricted to have the same ordering as the cross-country elasticity $\left(\sigma_{h}\right): \sigma_{h}>\sigma_{h^{\prime}} \Longrightarrow \gamma_{h}>\gamma_{h^{\prime}}$ for every $h, h^{\prime} \in H$. This restriction rules out the (counter-intuitive) possibility that for some products there is a great scope for national product differentiation, but little or not scope for differentiation between firms within a country.

To tractably incorporate both restrictions, I parametrically assume that $\left\{\gamma_{h}\right\}_{h \in H}$ is a linear transformation of $\left\{\sigma_{h}\right\}_{h \in H}$ :

Parametric assumption 1. $\left\{\gamma_{h}\right\}_{h \in H}=\left\{\eta \sigma_{h}\right\}_{h \in H}$, with $\eta>1$

Later, I will estimate the elasticities non-parametrically and show that this parametric assumption is highly consistent with data.

I will refer to $\frac{1}{\sigma_{h}}$ as the degree of differentiation of product $h-$ the higher $\frac{1}{\sigma_{h}}$ the greater the scope for differentiation. Each product in $H$ exhibits a unique degree of differentiation. Hence, there is a one-to-one mapping from the product space to the degree of differentiation

$$
\frac{1}{\sigma_{h}}:[0, \bar{h}] \rightarrow\left[0, \frac{1}{\bar{\sigma}}\right]
$$

Each of the $L_{i}$ consumers in country $i$ are endowed with one unit of labor and therefore will have an income equal to the wage in $i$, which I denote by $w_{i}$. Utility maximization implies that the quantity demanded in country $i$ of variety $\omega j h$ at price $p_{\omega j h}^{i}$ is

$$
q_{\omega j h}^{i}=\mu_{j}\left(\frac{p_{\omega j h}^{i}}{P_{j h}^{i}}\right)^{1-\eta \sigma_{h}}\left(\frac{P_{j h}^{i}}{P_{h}^{i}}\right)^{1-\sigma_{h}}\left(\frac{P_{h}^{i}}{P^{i}}\right)^{1-\epsilon} \frac{\alpha w^{i} L^{i}}{p_{\omega j h}^{i}}
$$

where $P^{i}$ is the aggregate price index, $P_{h}^{i}$ is the price index associated with product $h$, and $P_{j h}^{i}$ is the price index associated with country $j$ varieties of product $h$, all in country $i$ 's market. The price indices are given by

$$
P_{j h}^{i}=\left\{\int_{\omega^{\prime} \in \Omega_{j h}^{i}}\left(p_{\omega^{\prime} j h}^{i}\right)^{1-\eta \sigma_{h}} d \omega^{\prime}\right\}^{\frac{1}{1-\eta \sigma_{h}}}
$$

\footnotetext{
${ }^{16}$ If $\gamma_{h} \leq \sigma_{h}$ the model will generate trade equilibria with only one country supplying to each market - firms from the lowest price country will absorb all the revenues in any given market.

${ }^{17}$ Head and Ries [2001] find support for both economies of scale and national product differentiation. However, the preponderance of the evidence supports national product differentiation.
} 


$$
\begin{aligned}
P_{h}^{i} & =\left\{\sum_{k \in C} \mu_{k}\left(P_{k h}^{i}\right)^{1-\sigma_{h}}\right\}^{\frac{1}{1-\sigma_{h}}} \\
P^{i} & =\left\{\int_{h \in H}\left(P_{h}^{i}\right)^{1-\epsilon} d h\right\}^{\frac{1}{1-\epsilon}}
\end{aligned}
$$

where $\Omega_{j h}^{i}$ is the set of firms exporting product $h$ from country $j$ to country $i$. As a general rule, the superscripts refer to the country that is importing the variety while the subscripts index the variety (e.g. $\omega j h)$ that is being traded. In the following subsection, I turn to describing the supply side of the global economy.

\subsection{Supply}

Every country is populated with a large pool of homogenous multi-product firms. ${ }^{18}$ Each firm can potentially enter various markets, and sell its own (differentiated) variety of every product. Entry and exports are, however, subject to the following fixed costs:

i. Every firm pays a local (per-market) entry cost $f^{e}$, separately for every market $j \in C$-including the domestic market. For example, if a firm enters both the domestic market and one foreign market, it has to pay the local entry cost twice.

ii. After entering a foreign market, the firm has to pay a local per-product fixed cost $f$ for every product it exports to that market (e.g. if a multi-product firm exports two products to a foreign market it pays the fixed cost twice). The per-product fixed cost is only for exports; domestic sales are not subject to the per-product fixed cost. ${ }^{19}$

Both fixed and entry costs are paid in terms of labor in the country of origin. ${ }^{20}$ Also note that, the fixed and entry costs are not product or country-specific — in terms of magnitude, they are the same for all markets and all products. Paying the entry cost per market rules out economies of scale. Unlike the Krugman model (which relies on economies of scale), in the present framework North-North trade is driven by national

\footnotetext{
${ }^{18}$ In the data, multi-product firms dominate domestic production and international trade. In the United States, firms manufacturing more than one product account for more than 90 percent of total manufacturing shipments, while firms that export multiple products represent more than 95 percent of total exports (Bernard, Redding, and Schott [2006b]). Apart from multi-production being a realistic stance, the reason I assume multi-product firms is two-folded. First, the "Washington apples" effect, is documented as a within-firm effect, and one goal of the model is to account for this within-firm regularity. Second, multi-production gives rise to economies of scope which (as we will see later) creates some rents for firms in wealthy countries. Trade data suggests that trade activity is much more intense among rich countries. From the perspective of my model, economies of scope could be one channel, among others, that magnifies the dissimilarity between North and South in the international trade scene.

${ }^{19}$ Paying the entry cost per market rather than once (for all markets) is not critical for the results of the paper. The per-market entry cost is a conservative assumption in terms of the gains from trade (shown later) - it results in less entry into foreign markets.

${ }^{20}$ Eaton, Kortum, and Kramarz [2011] make a similar assumption regarding entry costs. The second assumption on the per-product fixed cost is also adopted by Arkolakis and Muendler [2010]. However, unlike these studies, both the per-market entry cost $\left(f^{e}\right)$ and the per-product exporting cost $(f)$ are paid in terms of labor in the country of origin.
} 
product differentiation. When I fit the model to data in section 4, I find strong empirical support for national product differentiation in the US import data.

All firms in a country share the exact same production technology. For firms in country $j$, the cost of producing $q$ units of product $h$ and selling them in country $i$ is

$$
c_{\omega j h}^{i}(q)=c_{j}^{i}(q)=\tau_{j i} w_{j} q+w_{j} f, \quad \forall \omega \in \Omega_{j}, \forall h \in H
$$

$\tau_{j i} w_{j}$ is the marginal cost of production, which is the same for all products/industries - products are costlessly differentiated and the marginal labor requirement for producing each product is unity. $\tau_{j i}$ is the iceberg transportation cost from country $j$ to $i$; and $\tau_{i i}=1$. The marginal labor requirement (for producing one unit of a differentiated product) is also the same across countries. However, high-skill countries are more productive in terms of producing utils (a standard assumption in Armington models).

For domestic firms in country $i$ the cost of producing $q$ units and selling them domestically is

$$
c_{\omega i h}^{i}(q)=w_{i} q, \quad \forall \omega \in \Omega_{i}, \forall h \in H
$$

Domestic firms pay neither the local per-product fixed cost nor the iceberg transportation cost, but incur a local entry cost. As noted before, the local entry cost is paid upfront. Post entry, firms decide on which products to sell and what prices to charge. Potentially, firms from country $j$ can sell all the products (in set $H$ ) after entry. The (incremental) product-specific profit they collect (conditional on selling product $h$ in country $i$ ) will be

$$
\pi_{\omega j h}^{i}=\max _{p_{\omega j h}^{i}}\left[p_{\omega j h}^{i}-\tau_{j i} w_{j}\right] q_{\omega j h}^{i}-w_{j} f
$$

where $p_{\omega j h}^{i}$ is the price that firm $\omega$ from $j$ charges for variety $\omega j h$ in country $i$. The profit maximizing firms would charge a product-specific markup over the marginal $\operatorname{cost}^{21}$

$$
p_{\omega j h}^{i}=p_{j h}^{i}=\frac{\eta \sigma_{h}}{\eta \sigma_{h}-1} \tau_{j i} w_{j}, \quad \omega \in \Omega_{j h}^{i}, j \in C, h \in H
$$

Markup $\left(\frac{\eta \sigma_{h}}{\eta \sigma_{h}-1}\right)$ is increasing in the degree of differentiation $\left(\frac{1}{\sigma_{h}}\right)$, i.e. firms charge a higher markup for highly differentiated products. Therefore, within industries, more differentiated products exhibit (on average) higher prices. The higher price of highly differentiated products is a purely endogenous outcome.

\footnotetext{
${ }^{21}$ Demand for a variety is determined by its pure price rather than nominal price. The pure price - as Hallak and Schott [2011] define it - of variety $\omega j h$ is $\frac{p_{\omega j h}^{i}}{\mu_{j}^{1 /\left(\sigma_{h}-1\right)}}$. Pure price is price per unit of util rather than price per unit of quantity. Similarly, $\frac{\tau_{j i} w_{j}}{\mu_{j}^{1 /\left(\sigma_{h}-1\right)}}$ is the effective pure wage of country $j$ in production and export of product $h$. The effective pure wage is product-specific and determines a country's competitiveness in the global markets.
} 
The current literature attributes higher prices to higher product-specific qualities. In this model, however, a higher price reflects a higher markup, and a higher markup implies a higher degree of (horizontal) differentiation. I argue that patterns of intra-industry trade can be largely explained with across-product differences in markups.

Firms from country $j$ all charge the same price and make the same product-specific profit conditional on selling the product: $\pi_{\omega j h}^{i}=\pi_{\omega^{\prime} j h}^{i}=\pi_{j h}^{i} \forall \omega, \omega^{\prime} \in \Omega_{j h}^{i}$ where $\Omega_{j h}^{i}$ is the set of firms from $j$ who who enter market $i$ and sell product $h$ (among other products). The total profits collected by firm $\omega$ from country $j$ gross of entry cost will then be $\int_{h \in H_{\omega j h}^{i}} \pi_{j h}^{i} d h$, where $H_{\omega j h}^{i}$ is the set of products firm $\omega$ export to market $i$ after (local) entry-in the next subsection I will describe the free entry and characterize set $H_{\omega j h}^{i}$.

Finally, The market for the non-manufactured good is assumed to be perfectly competitive. The marginal labor requirement for producing one unit of the non-manufactured good is one. Hence, the price of the (non-traded) non-manufactured good in country $i$ is $w_{i}$. In equilibrium, $(1-\alpha)$ share of the labor in country $i$ will be allocated to the production of the non-manufactured good.

\subsection{Equilibrium}

Free Entry. I denote the mass of firms that enter country $i$ 's market from country $j$ as $M_{j}^{i}$. When a firm pays the per-market entry cost it can sell each product in that market conditional on paying an additional per-product exporting fixed cost. Of the mass $M_{j}^{i}$ of firms who pay to enter market $i$ from $j$, some or all of them will sell product $h$ up to point that there are either no profits left for additional firms or all the entrants are already selling. Let $M_{j h}^{i}$ denotes the measure of firms who sell $h \in H$ in country $i$ from $j$. It is very clear that $M_{j h}^{i}<M_{j}^{i}$ given that there can not be more firms selling a product than the measure of firms who paid the entry cost. If $M_{j h}^{i}$ firms sell product $h$ in $i$ then each of them will collect a product-specific profit equal to

$$
\pi_{j h}^{i}=\frac{1}{\eta \sigma_{h}}\left(M_{j h}^{i}\right)^{\frac{\sigma_{h}-1}{\eta \sigma_{h}-1}}\left(\frac{p_{j h}^{i}}{P_{h}^{i}}\right)^{1-\sigma_{h}}\left(\frac{P_{h}^{i}}{P^{i}}\right)^{1-\epsilon} \alpha w_{i} L_{i}-w_{j} f
$$

where $p_{j h}^{i}$ is the monopolistic competitive price given by equation (5). I would like to reiterate that after paying the per-market entry cost for market $i$, firms from $j$ will sell the products in $H$ to the point that either (1) no profits are left for extra sales (i.e. $\pi_{j h}^{i}=0$ ), or (2) all the mass $M_{j}^{i}$ of entrants are already selling. Hence, from equation (6) the mass of firms from country $j$ selling product $h$ in market $i$ will be 


$$
M_{j h}^{i}=\min \left\{M_{j}^{i},\left[\frac{\mu_{j}\left(\frac{p_{j h}^{i}}{P_{h}^{i}}\right)^{1-\sigma_{h}}\left(\frac{P_{h}^{i}}{P^{i}}\right)^{1-\epsilon} \alpha w_{i} L_{i}}{\eta \sigma_{h} w_{j} f}\right]^{\frac{\eta \sigma_{h}-1}{\sigma_{h}(\eta-1)}}\right\}
$$

the above equation implies that for some products in $H$, firms from $j$ collect positive profits and $M_{j h}^{i}=M_{j}^{i}$, while for some others the firms crowd the market to the point that profits are zero and $M_{j h}^{i} \leq M_{j}^{i}$. The mass of entrants $M_{j}^{i}$ is itself pinned down by the free entry (FE) condition

$$
\int_{h \in H} \pi_{j h}^{i} \nu_{j}^{i}(h) d h=w_{j} f^{e}(F E)
$$

where $\int_{h \in H} \pi_{j h}^{i} \nu_{j}^{i}(h) d h$ is the expected profits from entry to market $i$ (gross of entry cost) for a typical firm from country $j . \nu_{j}^{i}(h)$ is the fraction of mass $M_{j}^{i}$ (of firms that enter market $i$ from $j$ ) that sell product $h^{22}$

$$
\nu_{j}^{i}(h)=\frac{M_{j h}^{i}}{M_{j}^{i}} \in[0,1]
$$

I will refer to $\nu_{j}^{i}(h)$ as the participation rate. ${ }^{23}$ I will use the following terminology in this paper: if all the entrants from $j$ are selling product $h$ in $i$ (i.e. $\nu_{j}^{i}(h)=1$ ) I will say that country $j$ is exporting $h$ at full intensity. There are products that only a small fraction of entrants from country $j$ will sell; in this case I will say that $j$ exports those products to $i$ at low-intensity.

Labor Market. Wages in country $i$ are pinned down by labor market clearing (LMC) condition

$$
\alpha L^{i}=\left(M_{i}^{i} f^{e}+\int_{h \in H} q_{i h}^{i} M_{i}^{i} \nu_{i}^{i}(h) d h\right)+\left(\sum_{k \neq i} M_{i}^{k} f^{e}+\int_{h \in H}\left(\tau_{i k} q_{i h}^{k}+f\right) M_{i}^{k} \nu_{i}^{k}(h) d h\right)
$$

The product market clearing condition is the following and clears by Walras' law

\footnotetext{
${ }^{22}$ In the product categories that a fraction of firms sell, i.e. $\nu_{j}^{i}(h)<1$, profits net of per-product fixed cost are zero, therefore, the expected profits from entry are the same for all firms from $j$. In other words, only the product that all the entrants from $j$ sell yield positive profits gross of entry cost.

${ }^{23}$ The free entry condition can be rewritten as

where

$$
\int_{h \in H_{j}^{i}} \pi_{j h}^{i} d h=w_{j} f^{e}(F E)
$$

$$
H_{j}^{i}=\left\{h \in H \mid \pi_{j h}^{i}>0\right\}=\left\{h \in H \mid \nu_{j}^{i}(h)=1\right\}
$$

Thus, when solving for equilibrium one can first solve for the mass of entrants, i.e. $M_{j}^{i}$, independent of $\nu_{j}^{i}(h)$ from the above (FE) condition-because only products for which $\nu_{j}^{i}(h)=1$ yield positive profits net of per-product fixed cost. After solving for $M_{j}^{i}$, I can solve for $\nu_{j}^{i}(h)$ and $H_{j}^{i}$ using equation (7). Then, I can iterate over this until convergence is achieved.
} 


$$
\sum_{k \in C} \int_{h \in H_{k}^{i}} p_{k h}^{i} q_{k h}^{i} M_{k}^{i} \nu_{k}^{i}(h) d h=\alpha w^{i} L^{i}(P M C)
$$

Given the market clearing conditions, I can now define the global equilibrium.

Definition. Given $\left\{L_{i}\right\}_{i \in C},\left\{\tau_{i j}\right\}_{i, j \in C^{\prime}}\left\{\mu_{j}\right\}_{j \in C^{\prime}} f, f^{e}, \alpha, \eta, \epsilon$ and $\left\{\sigma_{h}\right\}_{h \in H^{\prime}}$ a global equilibrium is a set of wages $w_{i}$, mass of firms $M_{j}^{i}$, a participation rate $\nu_{j}^{i}(h)$, price indices $P_{h}^{i}, P^{i}$, prices $p_{j h}^{i}$, and consumer allocations $q_{\omega j h}^{i}$ profits $\pi_{j h}^{i}$ and scope of production $H_{j}^{i}$ such that

(i) Equation (1) is the solution of the consumer's optimization problem.

(ii) $p_{j h}^{i}$ solves the firms' profit maximization problem-equation (5).

(iii) $\nu_{j}^{i}(h)=\frac{M_{j h}^{i}}{M_{j}^{i}}$ where the mass of sellers $M_{j h}^{i}$ is given by equation (7).

(iv) $P_{h}^{i}$ and $P^{i}$ are given by equations (3) and (4) respectively.

(v) The free entry condition (FE) holds.

(vi) The labor market clearing condition (LMC) holds.

\subsection{Gravity}

In equilibrium, bilateral trade is governed by a two-tier gravity equation. Let $X_{j h}^{i}$ denote total spending in country $i$ on varieties of product category $h$ that are manufactured in country $j-X_{j h}^{i}=p_{j h}^{i} q_{j h}^{i} M_{j h}^{i}$. The lower tier gravity equation, describing bilateral trade of product $h$, is the following

$$
\lambda_{j \mid h}^{i}=\frac{X_{j h}^{i}}{\sum_{k \in C} X_{k h}^{i}}=\frac{\mu_{j}\left(M_{j h}^{i}\right)^{\frac{\sigma_{h}-1}{\eta \sigma_{h}-1}}\left[w_{j} \tau_{j i}\right]^{\left(1-\sigma_{h}\right)}}{\sum_{k \in C} \mu_{k}\left(M_{k h}^{i}\right)^{\frac{\sigma_{h}-1}{\eta \sigma_{h}-1}}\left[w_{k} \tau_{k i}\right]^{\left(1-\sigma_{h}\right)}}, \quad i, j \in C
$$

$\lambda_{j \mid h}^{i}$ is the share of total expenditure in country $i$ allocated to varieties of product $h$ that are manufacture in country $j$. In the equation above, trade elasticity (specifically, elasticity of trade volumes with respect to iceberg trade costs) is lower for products that exhibit higher degrees of differentiation.

The upper-tier gravity equation characterizes relative spending on each product $h \in H$. Let $X_{h}^{i}$ denote total spending in country $i$ on product $h\left(X_{h}^{i}=\sum_{k \in C} X_{k h}^{i}\right)$, and let $X^{i}$ be total spending in country $i$ on manufactured products (i.e. $X^{i}=\int_{h} X_{h}^{i} d h=\alpha w^{i} L^{i}$ ). The share of total expenditure spent on product $h$ in country $i$ is

$$
\lambda_{h}^{i}=\frac{X_{h}^{i}}{X^{i}}=\frac{\left[\frac{\eta \sigma_{h}}{\eta \sigma_{h}-1}\right]^{(1-\epsilon)}\left\{\sum_{k \in C} \mu_{k}\left(M_{k h}^{i}\right)^{\frac{\sigma_{h}-1}{\eta \sigma_{h}-1}}\left(w_{k} \tau_{k i}\right)^{\left(1-\sigma_{h}\right)}\right\}^{\frac{\epsilon-1}{\sigma_{h^{-1}}}}}{\int_{h^{\prime}}\left[\frac{\eta \sigma_{h^{\prime}}}{\eta \sigma_{h^{\prime}}-1}\right]^{(1-\epsilon)}\left\{\sum_{k^{\prime} \in C} \mu_{k^{\prime}}\left(M_{k^{\prime} h^{\prime}}^{i}\right)^{\frac{\sigma_{h^{\prime}}-1}{\eta \sigma_{h^{\prime}-1}}}\left(w_{k^{\prime}} \tau_{k^{\prime} i}\right)^{\left(1-\sigma_{h^{\prime}}\right)}\right\}^{\frac{\epsilon-1}{\sigma_{h^{\prime}-1}}} d h^{\prime}}, h \in H
$$


A novel future of equation (9) is that love of variety is stronger the more differentiated the product. Therefore, as the number of available varieties in a market rise, to benefit from the extra variety, consumers redirect spending from less-differentiated products to highly differentiated products. This result, explained thoroughly in appendix B, induces wealthy countries with big markets and many incumbent varieties to spend relatively more on highly differentiated (and high-price) products.

\subsection{Patterns of International Specialization}

\subsubsection{North-South Trade (the Big Divide)}

Two well-established facts characterize North-South trade:

i. North and South engage intra-industry (and inter-industry) trade. Within each industry, high-income countries (in North) export goods that exhibit higher prices compared to (goods exported by) lowincome countries (Schott [2004]; Hallak and Schott [2011]; Hummels and Klenow [2005]). ${ }^{24}$

ii. High-income countries export (and import) a higher share of their GDP relative to low-income countries (Fieler [2011]; Waugh [2010])

Various theories have confronted these two features individually, but have not provided a simple framework that captures both. Here, I demonstrate how the present model reconciles both features. To this end, consider two countries $n$ (North) and $s$ (South) that share the same geography. North, however, is endowed with higher-skill labor and, therefore, superior "national production quality:" $\mu_{n}>\mu_{s}$. South is more populated $L_{s}>L_{n}$. In equilibrium, there would be more demand for high-skill labor, which results in higher equilibrium wages in North relative to South: $\mu_{n}>\mu_{s} \Longrightarrow w_{n}>w_{s}$. Suppose, however, that the parameters of the model are such that total income (GDP) is the same in North and South

$$
\left\{\begin{array}{l}
w_{n}>w_{s} \\
w_{n} L_{n}=w_{s} L_{s}
\end{array}\right.
$$

For any product $h \in H$, spending in country $i$ on varieties manufactured in North relative to South is

\footnotetext{
${ }^{24}$ Hallak [2006], Hallak and Schott [2011] look at variations within 2 and 3-digit SIC sectors.Hummels and Klenow [2005] looks at within HS-6 product variations in export prices across exporters. Each SIC sector, SITC industry, and HS-6 product consists of many narrowly defined HS-10 products. This suggests that part of the across-exporter variation in export prices could be due to some exporters exporting more expensive HS-10 codes (rather than more expensive varieties of the same HS-10 product). Khandelwal [2010] and Schott [2004] analyze within HS-10 variations in unit values. Khandelwal [2010], however, finds that the estimated quality and f.o.b unit values move in significantly opposite directions. My view is that within a class of products, say an SITC-5 industry, exporters from high-income countries are selectively exporting more differentiated and expensive HS-10 products, rather than higher quality products.
} 


$$
\frac{\lambda_{n \mid h}^{i}}{\lambda_{s \mid h}^{i}}=\frac{\mu_{n}}{\mu_{s}}\left(\frac{M_{s h}^{i}}{M_{n h}^{i}}\right)^{\frac{\sigma_{h}-1}{\eta \sigma_{h}-1}}\left[\frac{w_{s}}{w_{n}}\right]^{\left(\sigma_{h}-1\right)}, \quad h \in H, i \neq n, s
$$

Two factors control the competitiveness of North relative to South: relative wage $\frac{w_{s}}{w_{n}}$, and relative "national production quality" $\frac{\mu_{n}}{\mu_{s}}$ - North has production quality-advantage over South while South has price-advantage over North. The degree of differentiation $\frac{1}{\sigma_{h}}$ controls the relative importance of these two factors. In highly differentiated products/industries, wage is relatively less important and "national production quality" is the main determinant of trade flows. Hence, North has competitive advantage (over South) in highly differentiated industries and within each industry North has competitive advantage in highly differentiated-high markup products. ${ }^{25}$ South, on the other hand, has competitive advantage in less differentiated-low markup industries/products. ${ }^{26}$ As a result, firms from North specialize in highly differentiated industries and within industries, they are net exporters of highly-differentiated-high markup products that exhibit higher prices. ${ }^{27}$

The pattern I discussed above is illustrated in figure 3. Figure 3 plots the product-specific pure wage ( $\left.\frac{w_{i}}{\mu_{i}^{1 /\left(\sigma_{h}-1\right)}}\right)$ in North and South against the of the degree of differentiation within that product/industry. The product-specific pure wage determines the competitiveness of a country for a given product. Specifically, the lower the product-specific pure wage the more competitive a country in the global markets. In the baseline model (where all products/industries are differentiated to the same degree), pure wage is the same across all products. Moreover, in the baseline, pure wage equalizes across countries conditional on geography. A product-specific pure wage that varies across countries and products is the main driving force behind international specialization and dissimilar trade - an element that us absent in the original Krugman model.

The pattern of North-South specialization combined with fixed exporting costs lead to higher export-toGDP ratios in rich countries. South is competitive in less-differentiated-low markup products/industries. Exports of less differentiated-low markup products do not generate high enough profits to cover to fixed exporting cost. Specifically, exporters charge lower markups for less-differentiated products, but pay the same (per-product) fixed cost. Poor countries, therefore, have competitive advantage in products that are not profitable to export. Figure 3 demonstrates this result - the scope of competitive advantage for South

\footnotetext{
${ }^{25}$ Mathematically, I can show that for every pair of countries $i$ and $j$ where $\mu_{i}>\mu_{j}$, there exists a cutoff $\frac{1}{\tilde{\sigma}}$ such that country $i$ has competitive advantage over to $j$ in products with a degree of differentiation above the cut-off.

${ }^{26}$ This pattern is mirrored by the mass of entrants. Precisely, there are relatively more firms from North exporting highly differentiated products to country $i$, i.e. $\frac{M_{n h}^{i}}{M_{s h}^{i}}$ is non-decreasing in $\frac{1}{\sigma_{h}}$.

${ }^{27}$ In data terms, within each SITC- 5 industry, rich countries export HS-10 products that (on average) exhibit higher markups and higher prices. This result is in line with the existing literature in open macro about rich countries having comparative advantage in more differentiated sectors (Kraay and Ventura [2007]). However, in that literature there is no direct link between price and degree of differentiation.
} 


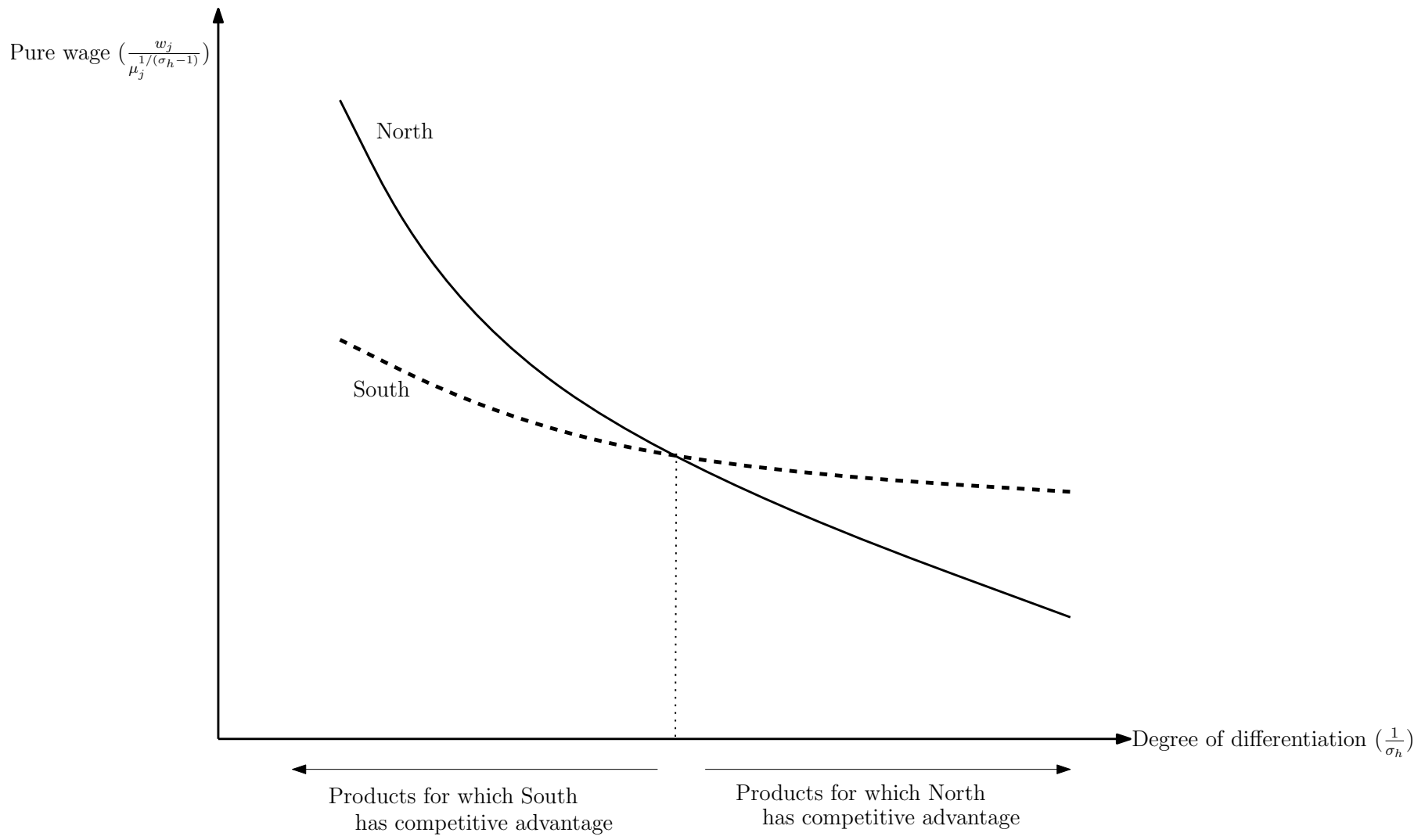

Figure 3: Patterns of competitive advantage between North ( $n$ ) and South (s). Note that $\mu_{n}>\mu_{s}$ and $w_{n}>w_{s}$.

(low-wage countries) is very narrow when considering the set of products that are traded intensively. In fact, the majority of sales by firms from low-wage countries are domestic sales, since domestic sales are not subject to fixed exporting costs (when a firm enters the domestic market every product is profitable to sell domestically). Proposition 1 summarizes the above results. ${ }^{28}$

Proposition. Consider two countries $n$ (North) and $s$ (south); all else being equal, if $\mu_{n}>\mu_{s}$ (North has better production technique relative to South) then

(i) $w_{n}>w_{s}$ : wages in North are higher than South.

(ii) North exports a larger share of its GDP relative to South

(iii) North is a net exporter of highly differentiated-high markup products to South, and South is a net exporter of less differentiated-low markup products to North - within every industry North exports product that exhibit higher

\footnotetext{
${ }^{28}$ Another important implication of the model is how trade openness affects employment in the North. It is well understood that the public's fear of globalization is often rooted in the vulnerability of US jobs to low-wage competition. Bernard et al. [2006a] provide evidence that the probability of US plant survival and employment growth are negatively associated with an industry's exposure to import penetration, particularly from low-wage countries. Khandelwal [2010] argues that low-wage import penetration in the US will have less impact on employment and wages in industries where the quality ladder is long. Patterns of competitive advantage in my model suggest that industries with a high degree of differentiation (i.e. low elasticity) will be largely insulated from wage movements in low-wage countries. Lower wages in the apparel sector in China can largely affect employment in the apparel sector in the US, but lower wages in the industrial machinery sector in China will have much less of an impact on employment in the US (given the high quality of US varieties). I will explore this implication of the model in more detail when I take the model to data in section 4.
} 
prices.

Proof. see Appendix A.3

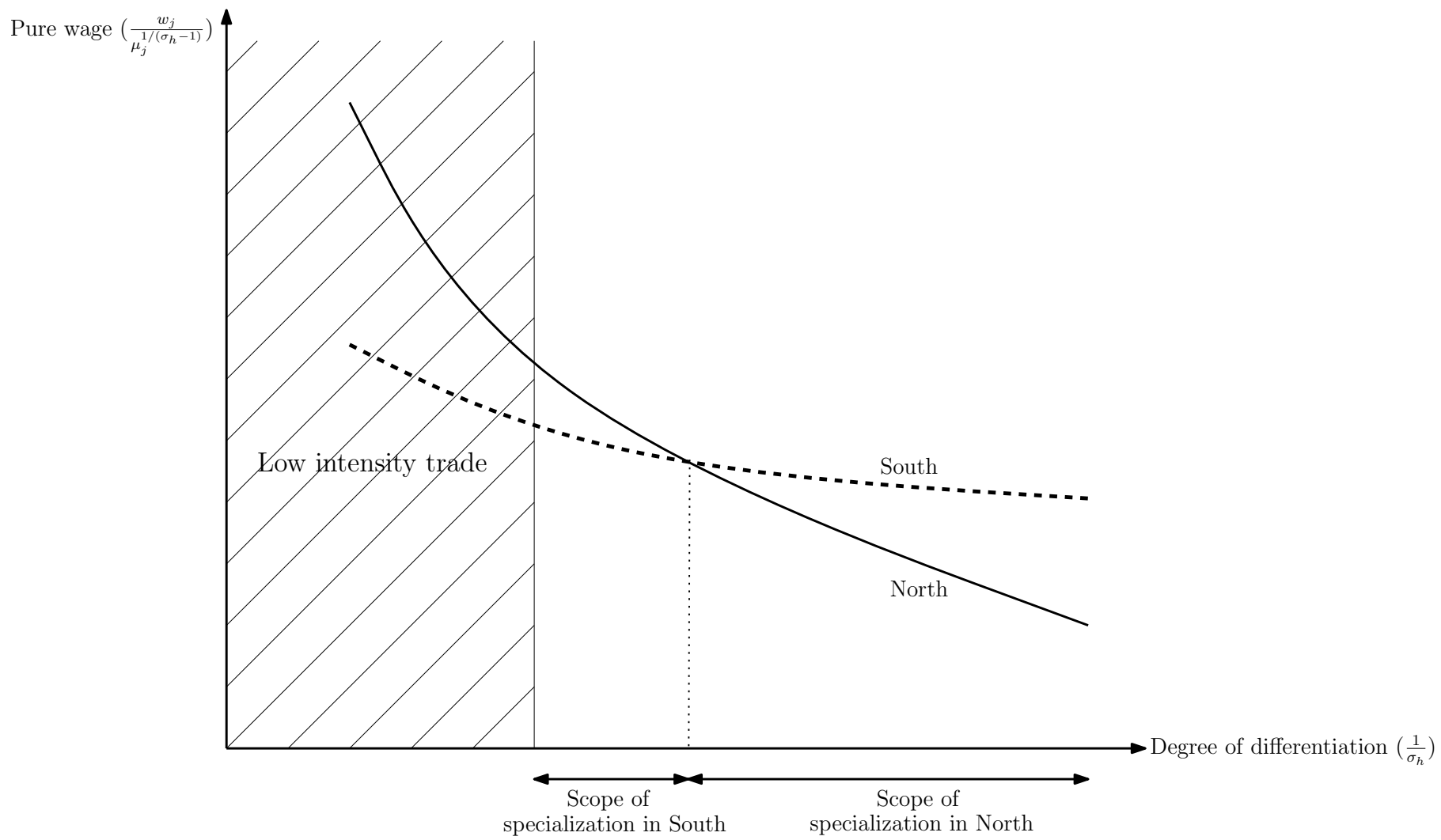

Figure 4: The narrow scope of competitive advantage for South (s). Note that $\mu_{n}>\mu_{s}$ and $w_{n}>w_{s}$.

\subsubsection{The "Washington Apples" Effect.}

The "Washington Apples" effect is a well-documented regularity in the empirical literature. The effect states that within a narrowly defined set of goods, the (free on board) unit value of exported goods are higher from countries that face higher trade costs - that is to say, in response to high trade costs exporters selectively export goods that posses higher unit values. Surprisingly, even though the effect is highly documented, conventional gravity models do not account for it. ${ }^{29}$ The standard explanation in the literature is due to Alchian and Allen [1983], and relies on trade costs being per-unit rather than iceberg. ${ }^{30}$

The present model provides a novel explanation for the "Washington apples" that does not require any restriction on trade costs. Specifically, consider two countries $i$ and $j$ that are endowed with similar

\footnotetext{
${ }^{29}$ Baldwin and Harrigan [2011] survey the mainstream trade literature and show that all leading models generate results that are inconsistent with this empirical regularity.

${ }^{30}$ Lashkaripour [2013] analyzes highly disaggregated US import data and argues that additive trade costs alone cannot explain the "Washington apples" effect.
} 
qualities $\left(\mu_{i}=\mu_{j}\right)$ and, hence, pay the same wage in equilibrium $\left(w_{i}=w_{j}\right) .{ }^{31}$ Suppose, however, that firms in country $j$ incur larger trade costs (relative to firms in $i$ ) when exporting to (a third) country $k: \tau_{i k}<\tau_{j k}$. From equation (8), the value of imports from $i$ relative to $j$ of product $h$ is

$$
\frac{\lambda_{i \mid h}^{k}}{\lambda_{j \mid h}^{k}}=\left(\frac{M_{i h}^{k}}{M_{j h}^{k}}\right)^{\frac{\sigma_{h}-1}{\eta \sigma_{h}-1}}\left[\frac{\tau_{j k}}{\tau_{i k}}\right]^{\left(\sigma_{h}-1\right)}, \quad h \in H, k \neq i, j
$$

In the above equation, two factors determine trade shares: the mass of exporters (that engage in exporting product $h$ to country $k$ ) and the iceberg trade costs. Due to higher trade costs, relatively less firms from country $j$ would export to country $k: M_{j h}^{k} \leq M_{i h}^{k}$ for each $h \in H$. Hence, country $j$ is at a disadvantage both dues to higher trade costs and due to a lower number of firms exporting. However, for products that exhibit higher degrees of differentiation (have a lower $\sigma_{h}$ ), the disadvantage diminishes - both $\left(\frac{M_{i h}^{k}}{M_{j h}^{k}}\right)^{\frac{\sigma_{h}-1}{\eta \sigma_{h}-1}}$ and $\left[\frac{\tau_{j k}}{\tau_{i k}}\right]^{\left(\sigma_{h}-1\right)}$ fall as $\frac{1}{\sigma_{h}}$ increases. $^{32}$

The intuition is the following. Since firms from country $j$ face higher trade costs they incur a higher marginal cost and charge a higher price. Demand for highly differentiated products is less sensitive to the high price charged by country $j$ firms. Moreover, country $j$ firms charge a higher markup for highly differentiated products, which allows them to collect profits despite low sales. These two channels encourage firms exporting from country $j$ to specialize in highly differentiated-high markup products, which exhibit higher f.o.b unit values.

\subsubsection{Discussion}

Inter-industry versus intro-industry specialization. The theory developed in this paper generates predictions regarding both intra-industry and inter-industry specialization. High-income countries specialize in highly differentiated industries, and within each industry they specialize in highly differentiated products. Specialization is incomplete, rather than complete as in Ricardian models. Moreover, unlike classical models of incomplete specialization (e.g. Hecksier-Ohlin), high-income countries are not the sole exporters of highly differentiated products. Both high-income and low-income countries export highly differentiated products - even though high-income countries are strictly better at highly differentiated products, they would still import them from low-income countries to benefit from national product differentiation. Highincome countries are, however, net exporters in highly differentiated products/industries and net importers in less differentiated products/industries. This pattern of intra-industry specialization is consistent with

\footnotetext{
${ }^{31}$ This will be the case if, for example, one country has a smaller population while the other country enjoys a better geographical location and lower trade costs.

${ }^{32}$ This argument will still hold if I allow for product-specific quality differences between the product categories in $H$. In this case, I will need the extra assumption that high quality products are also more differentiated.
} 
the findings of Schott [2004].

The new theory can also be extended to incorporate within-product specialization. Suppose every product consists of sub-products that exhibit different degrees of differentiation, i.e. a product $h$ can be costlessly differentiated to various degrees. High-income countries would specialize in a more differentiate version of the products and will charge a higher markup, whereas low-wage countries would specialize in less differentiated-low markup versions of the same product. This could serve as an (alternatively) explanation for within product variations in f.o.b. export prices across exporters. Until now, within product export-price variations have been exclusively attributed to quality.

Comparison to the existing theories. The theory presented in this paper is both a theory of why nations trade and a theory of what they trade. the theory introduces a new driving force behind North-South trade and provides an alternative explanation for the "Washington apples" effect. It relies on across-product differences in degree of differentiation and monopolistic competition. The are many competing theories in the trade literature-e.g. non-homothetic demand and factor specialization explain certain aspects of NorthSouth trade; additive trade costs explain the "Washington apples" effect. The theory developed in this paper stands out among competing theories for several reasons. First, it exhibits generality. The theory tractably combines two basic features of North-South trade that were previously explained only in isolation. At the same time, the theory also accounts for patterns of North-North and South-South trade. Second, the theory achieves generality with minimal deviation from conventional modeling assumptions. As a result the theory retains the analytical tractability of standard gravity models and is amenable to straightforward estimation. ${ }^{33}$ Competing theories, in contrast, impose computational and analytical burden in a general equilibrium multi-country setting.

Most importantly, the new theory raises questions about how big of a role the competing mechanisms play. To identify the effect of say additive trade costs or non-homothetic preferences, researchers have shut down across-product heterogeneity in (degree of) differentiation. If one allows for products to exhibit different degrees of differentiation, estimation would imply a weaker role for the competing theories.

\footnotetext{
${ }^{33}$ The goal of this paper is to match these first order facts simultaneously with minimal deviation from the assumptions that make new trade theories tractable and easy to quantify. To this end, my model preserves the assumptions that demand is homothetic and trade costs are symmetric and of the iceberg type. However, there is more structure imposed on demand than in the baseline Krugman model. Some results of the model are immune to the extra structure and some are not. The "Washington apples" effect depends only on heterogeneity in elasticities across products. It actually holds regardless of whether trade costs are additive or iceberg. Rich countries exporting high-price products relies on both heterogeneity in elasticities and inclusion of country-specific demand shifters. The result on rich countries trading a higher share of their GDP relies on heterogeneity in elasticities, country-specific demand shifters and the per-product fixed cost of exporting - The result, however, does not depend on how the country-specific quality (demand shifter $\mu_{j}$ ) enters the utility function.

The results in this paper rely on firms incurring an entry cost. The results, however, do not depend on the entry cost being incurred per-market (as apposed to once for all markets).Also, the fact that entry and fixed costs are paid in terms of labor in the country of origin is not key to the results of the model; it magnifies the self-selection of firms from rich countries into highly differentiated products. However, the assumption is not necessary for the self-selection to happen.
} 
Precisely, estimations would imply preferences that are less non-homothetic and trade costs that are less additive. If that is the case, and as I will demonstrate in the empirical section, the welfare gains from trade would be sizable. If countries trade according to the theory presented in this paper - and disaggregated data suggest that they do - the gains from trade would be considerably larger than traditional estimates.

\section{Mapping the Model to Data}

This section maps the model presented in Section 3 to data. First, I will describe the data and provide some preliminary evidence on product differentiation. Second, I will identify the core demand parameters by estimating a micro-gravity equation for individual manufactured product categories. Third, I will plug the estimated demand parameters into my general equilibrium model and calibrate it to global bilateral trade flows. I will then compare the explanatory power of the new model relative to the baseline ArmingtonKrugman model. Finally, I will analyze the predictions of the calibrated model and perform a counterfactual welfare analysis to quantify the gains from trade.

\subsection{Step 1: Estimating Demand Parameters}

\subsubsection{Data description and preliminary evidence}

This paper uses the publicly available US import data, which is compiled by Schott [2008]. The data documents the value and quantity of imported goods from various countries in various 10-digit HS10 product codes. Every HS-10 product belongs to a 5-digit SITC-5 industry, and every SITC-5 industry belongs to a two-digit SIC-2 sector. Since the original data does not report SITC-5 industry codes, I use the data compiled by Feenstra et al. [2002] to map the HS-10 codes into SITC-5 industries, and map SITC-5 industries into SIC-2 sectors. This paper uses data from 1989 to 2011.

An observation in the data set is an import record for an HS-10 product, from a particular exporting country, in a given year to a given U.S. city. ${ }^{34}$ Each observation documents import quantities, values, and the number of individual export cards (invoices) associated with that observation. In addition, the data includes tariff and freight charges and the units in which the reported quantity was measured. For my estimation, I consider only manufacturing industries (SITC 5-8) that are differentiated according to the classification developed by Rauch [1999]. I take the aggregate economic variables (population, GDP, etc.) from the Penn world tables and distance data from the CEPII data set compiled by Morey and Waldman [1998].

\footnotetext{
${ }^{34}$ The layout of the data is illustrated in table 9 in appendix D.
} 
I trim the data along two different dimensions. First, I drop all the observations reporting varieties in which the quantity imported is one unit or the imported value is less than $\$ 5000$ in 1989 dollars. Second, since the sample stretches over 22 years, to identify $\sigma_{h}$ and $\gamma_{h}$ I need sufficient cross-country variation to avoid the incidental parameters problem. To achieve this, I drop all HS-10 products, which report less than five exporting countries. In total, I'm left with for 5,847 HS-10 products for which I estimate the demand parameters.

For the estimation I need the number of firms that export to the U.S. from each country in every HS10 code. I do not directly see the number of firms, but I see the total number of firm-specific invoices, i.e. individual export cards filled in by individual firms, associated with each observation. ${ }^{35}$ I use the total number of export cards from country $j$ in HS-10 code $h$ as a proxy for $M_{j h}$ (the number of firms exporting to the U.S. from country $j$ in that HS-10 code). Since higher number of export cards can be due to more quantity sold, I rerun the estimation with the number of export cards (of product $h$ ) per quantity exported (from country $j$ ) as a proxy for $M_{j h} \cdot{ }^{36}$

The above proxy is quite crude and I use it due to lack of access to better data. There are two issues that can arise from using the above proxy. First, the proxy does not differentiate between one firm shipping to multiple US cities, and multiple firms selling to the same US city. Second, a firm might export to the US multiple times during the year. As noted, the second concern can be partially addressed by running the estimation with the number of invoices per quantity sold, as a proxy for the number of firms. One way of assessing the proxy is merging import data with firm-level export data. In Figure 17 (in the appendix) I do so by plotting the number of cards reported in the public US import data against the number of exporting firms as reported in the Bangladesh firm-level export data. The correlation between the number of firms and the proxy is 0.415 - the correlation is high but not perfect, partly due to imperfect concordance between HS codes in the two data sets.

Even though approximating the number of firms with the number of export invoices is not a perfect step forward, but it is a big step forward compared to the existing literature. Khandelwal [2010] uses population of the exporting country to control for the number of firms / varieties. Other studies that estimate gravity at the product-level (e.g. Broda and Weinstein [2006]) usually do not account for the extensive margin of trade altogether. These studies basically assume a representative firm/variety in each country, i.e. $M_{j h}=$

\footnotetext{
${ }^{35}$ In the words of Hummels and Schaur [2012]: “When a firm exports into the US they electronically file a Shipper's Export Declaration Form, and the data on that form constitute one record. The public use imports data remove firm identifiers and aggregate over all the records with the same characteristics (i.e. same exporter, HS10 product, US customs district, month, and transportation mode), but include a count of records as a variable in the data. At the most disaggregated level of the imports data, most monthly observations consist of a single shipment, though some have multiple records."

${ }^{36}$ The results of the estimation of very robust to both specifications.
} 
$1 \forall j, h .^{37}$

\subsubsection{Estimating $\sigma_{h}$ and $\gamma_{h}$}

In this section I will identify and estimate demand elasticities $\sigma_{h}$ and $\gamma_{h}$, where $h$ denotes an HS-10 product code. ${ }^{38}$ In the theory section, I parametrically assumed that $\gamma_{h}=\eta \sigma_{h}$ for all $h \in H$, to achieve tractability. Here, I will identify and estimate $\gamma_{h}$ and $\sigma_{h}$ non-parametrically for each HS-10 product $h$. This, in turn, will enable me to evaluate the parametric assumption in imposed in theory. After estimating the elasticities, I can get a sense of which products are highly differentiated. I can also investigate how degree of differentiation and f.o.b price are correlated across HS-10 product codes.

From equation (1), total U.S. spending on varieties from country $j$ in HS-10 code $h$ is given by

$$
X_{j h}=\mu_{j} M_{j h}^{\frac{\sigma_{h}-1}{\gamma_{h}-1}}\left(\frac{p_{j h}}{P_{h}}\right)^{1-\sigma_{h}}\left(\frac{P_{h}}{P}\right)^{1-\epsilon} \alpha w_{U S} L_{U S}
$$

where $M_{j h}$ is the number of firms from country $j$ exporting product $h$ to the U.S. market. $p_{j h}$ is the c.i.f unit value set by these firms for variety $j h . P_{h}$ is the price index of HS-10 code $h$ given by equation (3), and $P$ is the aggregate price index in the US given by equation (4). Log-linearizing equation (14) and adding a time subscript, we will have

$$
\ln X_{j h t}=\frac{\sigma_{h}-1}{\gamma_{h}-1} \ln M_{j h t}-\left(\sigma_{h}-1\right) \ln p_{j h t}+\underbrace{\ln \frac{1}{P_{h t}^{1-\sigma_{h}}}\left(\frac{P_{h t}}{P_{t}}\right)^{1-\epsilon} \alpha w_{U S, t} L_{U S, t}}_{\psi_{h, t}}+\ln \mu_{j h t}
$$

where $t$ refers to a year from 1989 to $2011 . \psi_{h, t}$ is a year-product fixed effect. $\ln \mu_{j h t}$ is the Armington demand shifter attached to varieties of product $h$ produced in country $j$ in year $t$ - the demand shifters reflect differences in production technique across countries. In theory, I assumed that production technique (or the demand shifter) is country-specific, but not product-specific: $\mu_{j h t}=\mu_{j t}, \forall h$, i.e. Corr $\left[\mu_{j h t}, \mu_{j h t^{\prime}}\right]=$ 1. The theory, however, requires that either (1) $\mu_{j h t}$ 's for each country $j$ to be sufficiently correlated across different HS-10 products, or (2) the gap in production technique $\left(\mu_{j h t}\right)$ between rich and poor countries to widen as products become more differentiated. After estimating the demand parameters, data confirms the latter scenario. I allow for Heteroskedasticity in $\mu_{j h t}$ across countries, and I also allow for $\mu_{j h t}$ 's to be correlated within a (exporter) country across time, i.e. $\operatorname{Cov}\left[\mu_{j h t}, \mu_{j h t^{\prime}}\right]>0$ for all $t$ and $t^{\prime}$ in the sample. ${ }^{39}$

For every HS-10 product I have a separate equation to estimate, but since the production technique

\footnotetext{
${ }^{37}$ Helpman, Melitz, and Rubinstein [2008] use aggregate bilateral trade data and control for the extensive margin of trade by imposing theoretical structure on firms entry. They find that not accounting for the extensive margin (or hidden varieties) can significantly bias the trade elasticity estimates.

${ }^{38} \epsilon$ can be estimated looking at cross-HS10 variations; I perform this estimation in the appendix.

${ }^{39}$ Broda and Weinstein [2006] do not allow for the country-specific qualities $\mu_{j h t}$ 's to be clustered by country across time.
} 
$\ln \mu_{j h t}$ is (likely) correlated across products I a system of seemingly unrelated regressions (SUR). Nevertheless, because the explanatory variables are the same across the equations, estimating each equation separately at the HS-10 product level will yield consistent and efficient estimates (Greene [2003] p.343). ${ }^{40}$ I also would not be able to identify $\epsilon$ (i.e. the elasticity of substitution across HS-10 codes) with equation (15) since I would be looking at only within HS-10 code variations. In appendix D, I estimate an alternative demand equation by looking at across HS-10 and within-SITC-5 variations, which allows me to identify and estimate $\epsilon$.

\subsubsection{Identification}

To identify $\sigma_{h}$ and $\gamma_{h}$, I will take the standard approach, which requires using supply-shifters to identify the demand curve. The strategy is to find a vector of instruments $z$ that is uncorrelated with the country-specific demand shifter $\ln \mu_{j h t}$. In theory, I imposed the parametric assumption that $\gamma_{h}=\eta \sigma_{h}$ with $\eta>1$. Here, I non-parametrically estimate $\gamma_{h}$ (for every HS-10 product $h$ ), which enables me to evaluate the validity of the parametric restriction I imposed in theory - as we will see later, the non-parametric estimates confirm the validity of imposed restriction.

Let $\Theta_{h}=\left(\gamma_{h}, \sigma_{h}\right)$ denote the vector of parameters to be estimated, and $Y_{h}$ denote data on $X_{j h t}, M_{j h t}$, and $p_{j h t}$. The moment condition will, then, be the following ${ }^{41}$

$$
\mathrm{E}\left[z G\left(\Theta_{h} ; Y_{h}\right)\right]=0
$$

where $z$ denotes the vector of instruments and

$$
G\left(\Theta_{h} ; Y_{h}\right)=\ln X_{j h t}-\frac{\sigma_{h}-1}{\gamma_{h}-1} \ln M_{j h t}+\left(\sigma_{h}-1\right) \ln p_{j h t}-\psi_{h, t}
$$

The above identification strategy is also adopted by Khandelwal [2010], while Broda and Weinstein [2006] identify elasticities (by assuming a constant elasticity supply curve) under the assumption that the supply shock (productivity) is uncorrelated with the demand shifter and by allowing for Heteroskedasticity. I estimate the $\Theta_{h}$ parameters, for each $h$ in my sample, using a GMM procedure

\footnotetext{
${ }^{40}$ Estimating each equation separately regardless of whether or not the explanatory variable are the same across equations will yield consistent estimates. However, in some cases one has to use all the information in the cross equation variance-covariance matrix to achieve efficient estimates. In the present case however, the independent estimates are both consistent and efficient.

${ }^{41}$ Prices (c.i.f) are calculated as value of shipment plus freight charges and duty charges divided by the quantity reported (in terms of the primary unit of measurement). Iceberg trade costs $\left(\tau_{i j}\right)$ in theory include more than just freight and tariff charges. In my estimation if iceberg trade costs are tariff and freight plus some other unobserved costs (like information frictions) then, they will cancel out in the estimation if I assume they affect all exporters the same. This is because I am not including data on domestic sales when estimating equation (15)-I only include import data.
} 


$$
\hat{\Theta}_{h}=\arg \min _{\Theta} \hat{G}\left(\Theta_{h} ; Y_{h}\right)^{\prime} z^{\prime} \hat{W}_{2} z \hat{G}\left(\Theta_{h} ; Y_{h}\right)
$$

The optimal weighting matrix $\hat{W}_{2}$ is calculated in the conventional two-step procedure. As noted before, in constructing $\hat{W}_{2}$ (i.e. variance-covariance matrix) I allow $\ln \mu_{j h t}$ 's to be clustered by source country. I impose no extra restriction on the parameters when running the above estimation. ${ }^{42}$

Since $\ln M_{j h t}$ and $\ln p_{j h t}$ are endogenous and correlated with $\ln \mu_{j h t}$, I should find instruments that are correlated with these two variables but uncorrelated with $\ln \mu_{j h t}$. To identify the price coefficient, I will instrument price with the tariff rate associated with each observation. As shown in section 3.6, ad-valorem trade cost (which include tariffs) are correlated with the degree of differentiation $\frac{1}{\sigma_{h}}$ which is constant across all observations when I'm estimating parameters for each $h$ separately. ${ }^{43}$ Therefore, within an HS-10 category tariff rate is not correlated with the demand shifter $\mu_{j h t}$. I also include exchange rates and the interaction of distance to the US with oil prices as additional instruments; these instruments vary at the country-year level.

For $M_{j h t}$, I use an additional instrument, which is population of country $j$ in year $t{ }^{44}$ I also use the total number of export cards documented in year $t$ in product $h$ from all sources, and the number of exporting countries of product $h$ in year $t$ as additional instruments. ${ }^{45}$

Table 1 summarizes the estimation result. For $72 \%$ of the HS-10 products the price coefficient is statistically significant (at the $90 \%$ confidence level) and has the correct sign, i.e. $\sigma_{h}>1$. For around $91 \%$ of the HS-10 products, the estimated $\gamma_{h}$ is bigger than $\sigma_{h}$ and statistically significant (at the $90 \%$ confidence level). This implies that for the vast majority of the HS-10 products, varieties produced in the same country are more substitutable which is in-line with assumption 1 in the theory section - I the following section I will verify assumption 1 more closely. As demonstrated in table 2, there is sizable heterogeneity in the estimated (within and across-country) elasticity across HS-10 products.

Figure 5 displays the relative ranking of various SIC-2 sectors in terms of the estimated elasticity. A low elasticity indicates that either consumers allocate their spending more evenly across different varieties of a product, or that imports are less sensitive to price and more sensitive to the country-specific demand shifters. A high elasticity, in contrast, implies that consumers spend mostly on the cheapest variety and are highly sensitive to price. The ranking of sectors (in terms of the within-country and cross-country elasticity)

\footnotetext{
${ }^{42}$ Broda and Weinstein [2006] perform a restricted grid search to estimate $\sigma_{h}$ 's. In particular, they evaluate the GMM objective function for values of $\sigma_{h} \in[1.05,131.5]$ at intervals that are 5 percent apart.

${ }^{43}$ Higher tariff would result in firms selecting into highly differentiated HS-10 codes, regardless of the demand shifter $\mu_{j h t}$ they face.

${ }^{44}$ In my model, everything else the same, a larger population lowers the wages and increase the number of exporting firms from a country-due to the lower entry and fixed costs.

${ }^{45}$ Khandelwal [2010] uses the number of exporting countries of product $h$ as an instrument (for conditional nest share) which proxies competition in code $h$.
} 


\begin{tabular}{ccccc}
\hline Statistic & Mean & Median & First quartile & Third quartile \\
\hline \hline$\sigma_{h}$ & 1.675 & 1.524 & 1.344 & 1.818 \\
$\frac{\gamma_{h}-1}{\sigma_{h}-1}$ & 3.464 & 3.300 & 2.731 & 3.999 \\
Two-step GMM p-value, $\sigma_{h}$ & .011 & .001 & .000 & .012 \\
Two-step GMM p-value, $\gamma_{h}$ & .008 & .000 & .000 & .004 \\
& & & & \\
Observations per estimation & 336 & 262 & 167 & \\
Estimation with stat. sig. $\sigma_{h}>1$ & & .72 & & \\
Observations with stat. sig. $\sigma_{h}>1$ & & .78 & & \\
Observations with stat. sig. $\gamma_{h}>1$ & & .91 & & \\
Total estimations & & 5,847 & & \\
Total observations across all estimations & & $1,980,018$ & & \\
\hline
\end{tabular}

Table 1: Summary of statistics from estimating equation (15) for 5,847 manufacturing HS-10 products.

\begin{tabular}{ccccccc}
\hline Parameter & Mean & Median & percentile 5 & percentile 10 & percentile 90 & percentile 95 \\
\hline \hline $\begin{array}{c}\text { Within-country elasticity: } \gamma_{h} \\
\text { Confidence interval (95\%) }\end{array}$ & 3.344 & 2.787 & 1.502 & 1.678 & 5.424 & 7.151 \\
& & $(1.997,3.577)$ & $(1.273,1.730)$ & $(1.248,2.109)$ & $(4.051,6.796)$ & $(6.053,8.250)$ \\
$\begin{array}{c}\text { Across-country elasticity: } \sigma_{h} \\
\text { Confidence interval (95\%) }\end{array}$ & 1.675 & 1.524 & 1.175 & 1.226 & 2.236 & 2.578 \\
\hline
\end{tabular}

Table 2: The variation of elasticities across HS-10 product codes.

are subjectively sensible. However, the ranking based on my estimation is different from the one in Broda and Weinstein [2006] (left panel in figure 18). For example, my estimation suggests that food and paper are relatively less differentiated than machinery and electronics. In Broda and Weinstein [2006], paper is more differentiated than industrial machinery, and food is more differentiated than electronics.

Evaluating the Theoretical Assumptions The theory developed in this paper relies on two conditions:

i. $\gamma_{h}>\sigma_{h}$ for all $h \in H$.

ii. $\sigma_{h}>\sigma_{h^{\prime}} \Longrightarrow \gamma_{h}>\gamma_{h^{\prime}}$ for any $h, h^{\prime} \in H$ (i.e. $\left\{\sigma_{h}\right\}_{h \in H}$ and $\left\{\gamma_{h}\right\}_{h \in H}$ have the same order type).

In table 1 , I already demonstrated that condition 1 holds for $91 \%$ of the HS-10 manufacturing products. To check condition 2, I rank HS-10 products both in terms of the magnitude of $\hat{\sigma}_{h}$ and in terms of the magnitude of $\hat{\gamma_{h}}$. Then, I plot these two ranks against one another for all HS-10 products. Figure 6 displays 

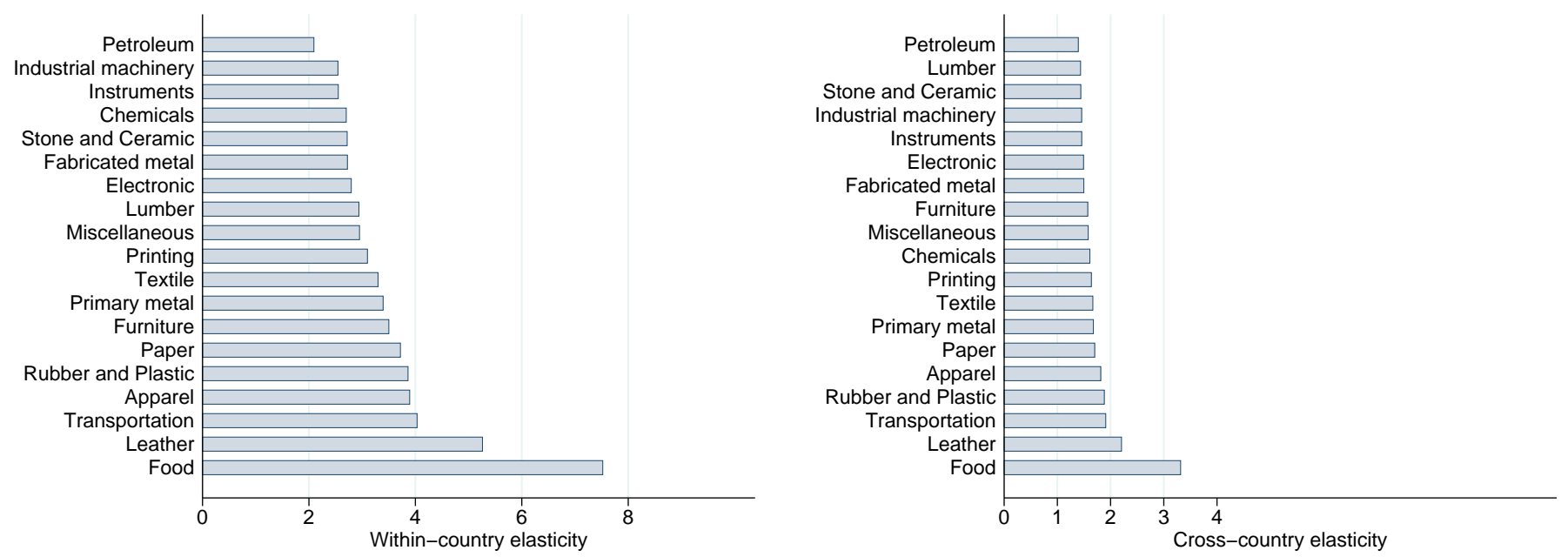

Figure 5: This Table reports the average elasticity by manufacturing SIC-2 sector (the average is across HS-10 products within an SIC-2 sector). The top panel is my estimates for the cross-country elasticity $\sigma_{h}$ and within-country elasticity $\gamma_{h}$. The estimates are for a sample of differentiated manufacturing products as classified byRauch [1999].

the outcome. If $\left\{\gamma_{h}\right\}_{h \in H}$ and $\left\{\sigma_{h}\right\}_{h \in H}$ had the exact same ordering, then all the dots should lie on the 45-degree line. The points are tightly scattered around the 45-degree line which implies that $\left\{\sigma_{h}\right\}_{h \in H}$ and $\left\{\gamma_{h}\right\}_{h \in H}$ are ordered near identically. That is to say, if an HS-10 product exhibits a relatively high crosscountry elasticity of substitution it also subject to a relatively high within-country elasticity.

In theory, to tractably incorporate conditions 1 and 2, I parametrically restricted $\left\{\gamma_{h}\right\}_{h \in H}$ to be a linear transformation of $\left\{\sigma_{h}\right\}_{h \in H}$, i.e. $\gamma_{h}=\eta \sigma_{h}$ for all $h$. In this section, however, I non-parametrically estimated $\gamma_{h}$ and $\sigma_{h}$ for various HS-10 products. This, allows me to verify the parametric restriction I imposed in theory. To compare the ordering of $\left\{\gamma_{h}\right\}_{h \in H}$ to $\left\{\sigma_{h}\right\}_{h \in H}$, I plot the estimated $\gamma_{h}$ against the estimated $\sigma_{h}$ for each HS-10 product in my sample. The resulting scatter plot is displayed in figure 7, and implies a tight linear relationship between $\gamma_{h}$ and $\sigma_{h}$.

Now I turn my attention to the assumption that production technique is not product-specific. In particular, I assumed the production technique to be country-specific, but common across all products

$$
\mu_{j h t}=\mu_{j h^{\prime} t}=\mu_{j t} \forall h, h^{\prime} \in H
$$

In the context of the new theory, countries with superior production techniques are more competitive in highly-differentiated. Suppose now that production technique is both country and product-specific. Specifically, suppose production technique depends on both human capital in country $j$ (denoted by $H_{j}$ ) and degree of differentiation of product $h: \mu_{j h}=\mu\left(H_{j}, \frac{1}{\sigma_{h}}\right)$. If $\mu\left(H_{j}, \frac{1}{\sigma_{h}}\right)$ is log super-modular $-\frac{\partial^{2} \mu\left(H, \frac{1}{\sigma_{h}}\right)}{\partial \frac{1}{\sigma_{h}} \partial H}>0-$ then the channel of across-product specialization introduced in this paper will be amplified. That is to say, 


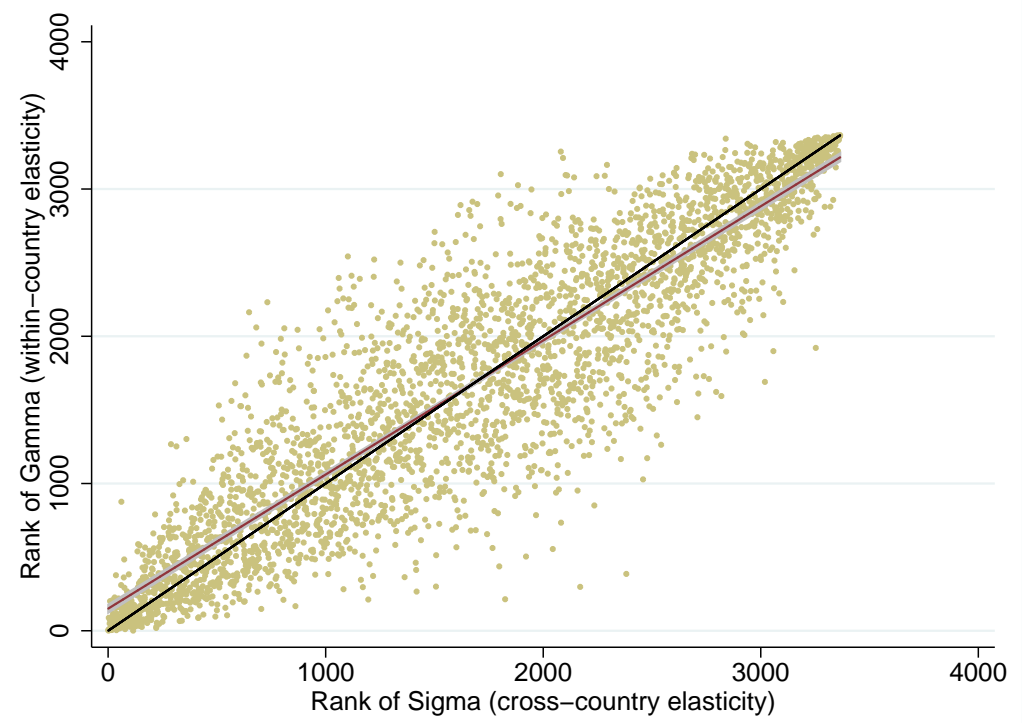

Figure 6: Scatter plot of the rank of an HS-10 code in terms of the estimated $\sigma_{h}$ against its rank in terms of the estimated $\gamma_{h}$. Each point refers to one HS-10 code. The black line represents the 45-degree line. The red line is the best linear fit and the shaded gray area indicates $95 \%$ confidence intervals for the best-fitted linear relationship.

the gap in competitiveness between North and South will be even larger for highly differentiated products (relative to the main model).

It is straightforward to verify that $\mu_{j h}$ is indeed log super-modular. To demonstrate this, I regress $\ln \hat{\mu}_{j h t}$ (the estimated demand shifter for country $j$ in product $h$ ) on per capita GDP $\left(w_{j t}\right)$ - as a proxy for human capital - and the degree of differentiation in product category $h\left(\ln \frac{1}{\hat{\sigma}_{h}}\right)$. I also include the interaction of these two variables as an additional regressor ${ }^{46}$

$$
\ln \hat{\mu}_{j h t}=\underset{(.006)}{.0157} \ln w_{j t}+\underset{(.086)}{.8600} \ln \frac{1}{\hat{\sigma}_{h}}+\underset{(.010)}{.0576 \ln w_{j t}} \times \ln \frac{1}{\hat{\sigma}_{h}}
$$

There are 1,320,268 observations in total, and the results are robust to including SITC-5 and year fixed effects. All the coefficients are significant at the 99\% confidence level (the standard errors are reported in the parenthesis). $\mu_{j h}$ is $\log$ super-modular because the coefficient on the interaction term $\left(\ln w_{j t} \times \ln \frac{1}{\hat{\sigma}_{h}}\right)$ is positive. In other words, the technical gap between rich and poor countries widens as products become more differentiated. Hence, enforcing $\mu_{j h}=\mu_{j}$ (for all $h$ ) is a rather conservative restriction in terms of generating the patterns of North-South trade that I am interested in. All the theoretical results not only would go through, but would be magnified if $\mu_{j h}$ was assumed to be log super-modular, as suggested by data.

\footnotetext{
${ }^{46} \ln \hat{\mu}_{j h t}$ is the residual from the micro-gravity estimation.
} 

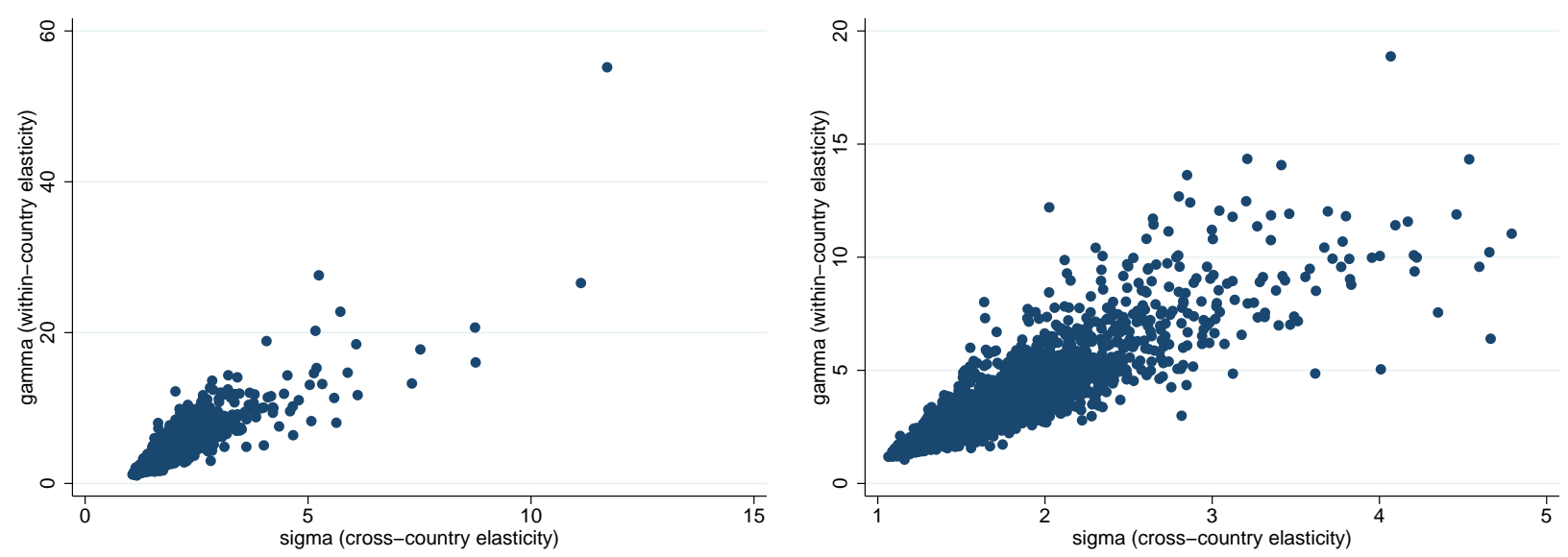

Figure 7: The scatter plot of the estimated $\gamma_{h}$ against the estimated $\sigma_{h}$. The right graph contains only a subset of HS-10 codes for which the estimated $\sigma_{h}$ is less than 5. The slope of the best-fitted line (i.e. $\eta$ ) is 2.15 with $R^{2}=0.9$.

\subsubsection{Product Differentiation and the Patterns of US Imports}

Before I take the model to aggregate data and perform a cross-country welfare analysis, I will illustrate two micro-data patterns that confirm the theory. First, when looking at intra-industry trade, high price is accompanied with a higher degree of differentiation. Hence, to explain export-prices one should account for the differentiation margin beside the more standard quality margin. Second, countries do specialize in industries based on the degree of differentiation that industry; low-income countries are net exporters in industries with a low a scope for horizontal differentiation.

Pattern 1. Within an SITC-5 industry, HS-10 products that are more differentiated exhibit higher f.o.b unit-values

The new theory suggests that across-product within-industry differences in unit values can be attributed to differences in markups that stem form differences in the degree of differentiation. Data reveals that this is well the case; higher unit values are significantly associated with lower demand elasticities (note that lower demand elasticity implies higher markup). To illustrate this association, I plot the estimated degree of differentiation $\left(\frac{1}{\sigma_{h}}\right)$ for each HS-10 product against the average f.o.b unit value of varieties of that HS-10 product (the unit values are normalized by the average of the SITC-5 industry to which the HS-10 product belongs to). The result is displayed in figure 8. HS-10 products that are more differentiated exhibit on average a higher f.o.b unit value.

As noted earlier, in the literature, across-product price differences are attributed to quality differences. However, a positive association between f.o.b unit value and quality at the same level of disaggregation (used in this paper) has yet to be established. Khandelwal [2010] (who, to my knowledge, is the only study that structurally estimates quality at the HS-10 level of disaggregation) finds a negative correlation between 
quality and f.o.b unit value. The theory proposed in this paper, therefore, has at least one advantage over the quality theory: it is consistent with highly disaggregated data. ${ }^{47}$

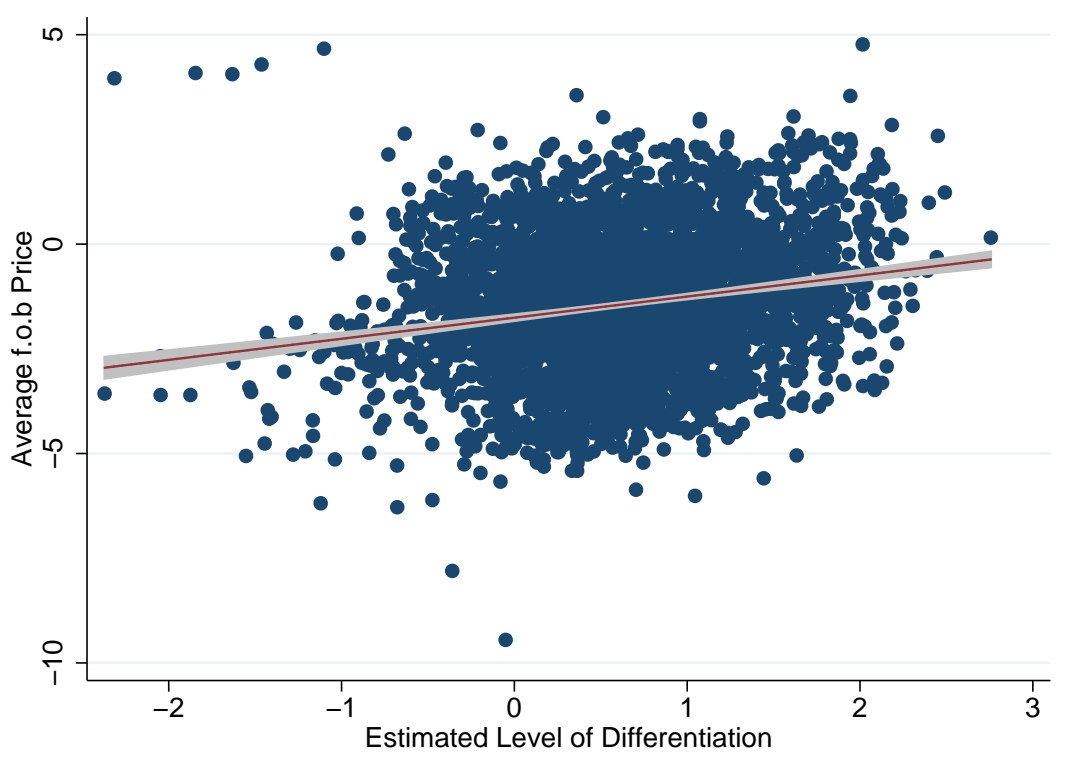

Figure 8: The positive relationship between degree of differentiation (in logs) and f.o.b prices (in logs). Each point in the graph corresponds to an HS-10 product code. The shaded area indicates 95\% confidence intervals for the best-fitted linear relationship. Average prices in every HS-10 code are normalized by the SITC-5 industry average. The estimated degree of differentiation for HS-10 code $h$ is measured as $\frac{1}{\hat{\sigma}_{h}}$.

Pattern 2. Low-wage countries penetrate the US market significantly more in less differentiated industries

The new theory claims that the US, imports relatively less of the highly differentiated product from lowwage countries - highly differentiated products are mostly imported from other advanced nations. ${ }^{48}$ To assess this claim I look at how import penetration from low-wage countries varies across different product categories. Low-wage import penetration is calculated as the total value share of imports (in percentage terms) from low-wage countries. Varieties from low-wage countries comprise a higher share of the US import basket in less-differentiated industries (figure 9) - I am using industry-level data because I observe import penetration only at the industry level. The pattern is consistent with the new theory of international specialization developed in this paper.

The pattern serves importance because As Khandelwal [2010] puts it, "fear of globalization is often rooted in the vulnerability or, to use Edward Leamer's terminology, the contestability of jobs. According to Leamer, the contestable jobs are those where "wages in Los Angeles are set in Shanghai."' Khandelwal

\footnotetext{
${ }^{47}$ In an earlier version of the paper (available upon request) I estimate demand allowing for quality to vary across HS-10 products and find that product quality and product differentiation co-move in the trade data at the HS-10 product level, i.e. demand elasticity is significantly lower in high-quality HS-10 product codes.

${ }^{48}$ The list of low-wage countries is reported in appendix D.
} 
[2010] shows that in industries with a long quality ladder, labor markets in developed countries will be insulated from wage movements in low-wage countries. My analog argument is that labor markets in developed countries will be insulated in differentiated industries. In appendix D.2 I show that this argument is indeed consistent with data.

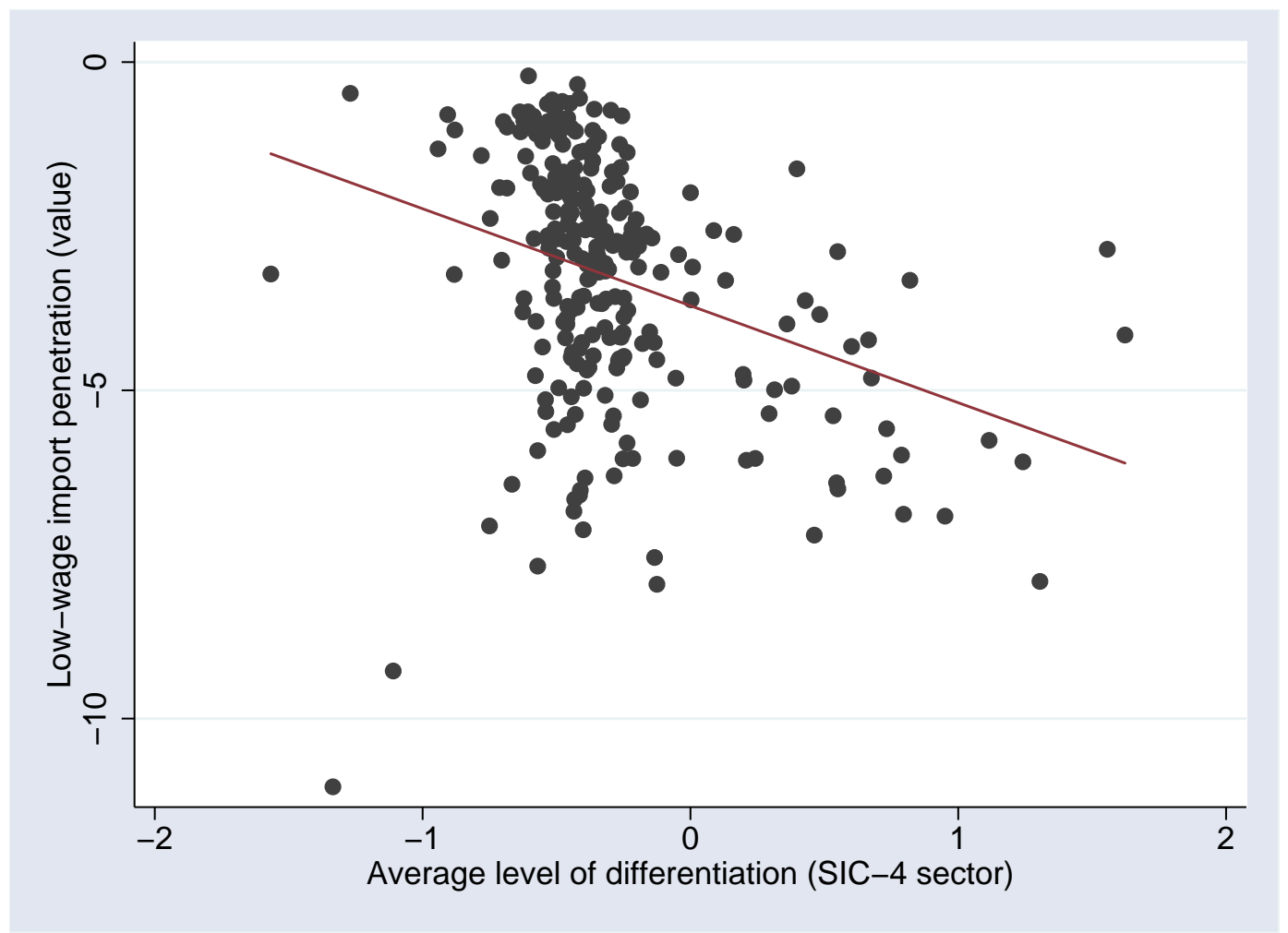

Figure 9: Scatter plot of import penetration from low-wage countries (\% value of total imports in logs) against the average degree of differentiation for various SIC-4 industries (in logs). The average degree of differentiation is the inverse of the average estimated elasticity $\left(\sigma_{h}\right)$ within the SIC-4 industry.

\subsection{Step 2: Fitting the General Equilibrium Model to Aggregate Trade Flows}

In the second stage of my empirical inquiry, I will fit my model to global trade flows to explore the general equilibrium properties of the model. In this section, I calibrate the key parameters to the general equilibrium outcomes of the model using data for many countries. Specifically, I calibrate iceberg trade costs, country-specific qualities, fixed costs of exporting varieties, and market entry cost to data on bilateral trade flows, and per capita GDP/wages. I solve for the endogenous (relative) wages, price indices, and mass of firms in every country. The results indicate that traditional assumptions in trade models can result in underestimating both trade costs and the gains from trade. 


\subsubsection{Data}

I use data on bilateral merchandise trade flows in 2000 from the U.N. Comtrade database (Comtrade [2010]), and data on population and GDP from the World Bank database (World-Bank [2012]). I only consider the 50 largest economies (in terms of real GDP) that account for more than $80 \%$ of world trade in 2000 . Each observation contains the total value of trade for an importer-exporter country pair. Data specific to country pairs-distance, common official language, and borders-are compiled by Mayer and Zignago [2011].

\subsubsection{Calibration Strategy}

Trade shares, $\left\{\lambda_{j}^{i}\right\}_{i, j \in C^{\prime}}$ are a function of the set of $N$ countries, each with its population $L_{i}$, wage $w_{i}$, "national production quality" $\mu_{i}$, and iceberg trade costs $\tau_{j i}$; parameters $\left\{\gamma_{h}\right\}_{h \in H}, \epsilon$, and $\left\{\sigma_{h}\right\}_{h \in H}$ that control the elasticity of substitution across varieties; local entry cost parameter $f^{e}$ that govern entry decision of firms into different markets, and per-product (local) fixed exporting cost $f$ that governs the decision of firms to export individual HS-10 products post entry; parameter $\alpha$, which determines the expenditure share on manufactured products. ${ }^{49}$ I take the set of countries, their population $L_{i}$, and wages $w_{i}$ from the data, and I calibrate $\left\{\tau_{j i}\right\}_{j, i=1}^{N},\left\{\mu_{i}\right\}_{i=1}^{N}, f, f^{e},\left\{\sigma_{h}\right\}_{h \in H}, \alpha, \epsilon$, and $\eta$ to match trade flow and wage data. ${ }^{50}$

Parameters set without solving the model Parameters $\alpha, \epsilon, \eta$, and $\left\{\sigma_{h}\right\}_{h \in H}$ are set from the estimation in step 1 or external sources. In the previous section I estimated demand elasticities for 5,847 HS-10 products. In the calibration I confine my analysis to inter-industry specialization and trade. There are five industries, and each industry is characterized by an elasticity of substitution estimated in step 1. Every industry is assumed to comprise of one product - a step back from the main model, but a step forward relative to the literature. The (five) industries are chosen to represent different degrees of differentiation. In particular, food, leather and apparel represent the less differentiated industries, while electronics and industrial machinery represent highly differentiated industries. Each industry is described in table 3. I calibrate the elasticity within each industry using the demand estimation results from step 1 . I also calibrate $\eta$ to 2.15 , again from the demand estimation in step 1. $\epsilon$ is calibrated to 1.2 from the cross HS-10 within-industry demand estimation, implemented in an earlier version of the paper. ${ }^{51}$ From Dekle, Eaton, and Kortum [2007]

${ }^{49}$ The equilibrium trade shares can be calculated using the two tier gravity represented by equations (8) and (9)

$$
\lambda_{j}^{i}=\sum_{h \in H} \lambda_{j \mid h}^{i} \lambda_{h}^{i}
$$

where $\lambda_{j \mid h}^{i}$ and $\lambda_{h}^{i}$ are given by equations (8) and (9) respectively. Also, since in practice I have a discrete set of products instead of a continuum I sum up over all the products instead of integrating over the product space.

${ }^{50}$ I already showed that the linear relationship between $\sigma_{h}$ and $\gamma_{h}$ is a very reasonable approximation based on my estimation results. Thus, in my calibration exercise I will allow for $\gamma_{h}=\eta \sigma_{h} \forall h$.

${ }^{51}$ The paper is available upon request 
I calibrate the share of spending on manufactured products, $\alpha$, to 0.188 .

\begin{tabular}{cccc}
\hline & SIC code & $\begin{array}{c}\text { No. of HS-10 } \\
\text { industries }\end{array}$ & $\begin{array}{c}\text { Average estimated } \\
\text { elasticity } \sigma_{h}\end{array}$ \\
\hline \hline Industrial machinery & 35 & 1,632 & 2.3 \\
Electronics & 36 & 1,325 & 2.5 \\
Apparel & 23 & 2,560 & 2.8 \\
Leather & 30 & 403 & 3.3 \\
Food & 20 & 37 & 4.2 \\
\hline
\end{tabular}

Table 3: Representative industries in my calibration

Next, I will describe my strategy for identifying iceberg trade costs $\left\{\tau_{j i}\right\}_{j, i=1}^{N}$, country-specific demand shifters $\left\{\mu_{i}\right\}_{i=1}^{N}$, and per-product fixed cost of exporting $f$. I normalize $f^{e}$ to one since the scale of $f^{e}$ only affects the scale of firm entry $\left\{M_{j}^{i}\right\}_{i, j \in C}$, but not the relative mass of firms in the market.

Trade costs. I assume that iceberg trade costs take the following form

$$
\tau_{j i}=\kappa_{\text {const }}\left(\text { dist }_{j i}\right)^{\kappa_{\text {dist }}}\left(\kappa_{\text {border }}\right)^{d_{\text {border }}}\left(\kappa_{\text {lang }}\right)^{d_{\text {lang }}}\left(\kappa_{\text {agreement }}\right)^{d_{\text {agreement }}}
$$

Variable $d_{i s t} t_{j i}$ is the distance (in thousands of kilometers) between countries $j$ and $i . d_{b o r d e r}$ is a border dummy and $\left(\kappa_{\text {border }}\right)^{d_{b o r d e r}}$ equals 1 if countries $j$ and $i$ do not share a border, and $\kappa_{\text {border }}$ otherwise. If $\kappa_{\text {border }}$ is, say, 0.8 , sharing a border reduces trade costs by $20 \%$; if $\kappa_{\text {border }}>1$, sharing a border increases trade costs. Similarly, parameters $\kappa_{\text {lang }}$ an $\kappa_{\text {agreement }}$ refer, respectively, to whether countries $j$ and $i$ share a language, and whether they have a trade agreement. Henceforth, $\Upsilon=\left\{\kappa_{\text {const }}, \kappa_{\text {dist }}, \kappa_{\text {border }}, \kappa_{\text {lang }}, \kappa_{\text {agreement }}, f, f^{e}\right\}$ refers to the set of trade cost parameters and $\bar{\Upsilon}$ refers to the set of data on countries' pairwise geopolitical characteristics-distance, common border, language, and trade agreement.

National production quality. I solve for the vector of "national production qualities" (or country-specific demand shifters) in an inner-loop by matching data on per capita GDP, using the following algorithm. ${ }^{52}$ Given parameters $\left\{\Upsilon, \eta,\left\{\sigma_{h}\right\}_{h \in H}, \epsilon, \alpha\right\}$, data on population $L=\left\{L^{i}\right\}_{i=1}^{N}$, and geopolitical characteristics $\bar{\Upsilon}$, the product market clearing condition (PMC) pins down a relation between country-specific demand shifters $\left\{\mu_{i}\right\}_{i=1}^{N}$ and market clearing wages $\left\{w^{i}\right\}_{i=1}^{N}$. Therefore, fixing other parameters, I can uses wages directly to back out "national production qualities" $\left\{\mu_{i}\right\}_{i=1}^{N}$. I take per capita income from the data as a proxy for wages. Then, for each guess of the parameters, I simulate the whole economy, generating trade shares $\lambda_{j}^{i}$ until I find a vector of country-specific demand shifters $\left(\left\{\mu_{i}\right\}_{i=1}^{N}\right)$ that satisfies equilibrium

\footnotetext{
${ }^{52}$ Fieler [2011] uses the same strategy to pin down the technology parameters in a Ricardian model.
} 
conditions. ${ }^{53}$

After substituting fixed and variable trade costs and the implicit solutions for "national production qualities," $\left\{\mu_{i}\right\}_{i=1}^{N}$, the moment condition (minimized in the outer-loop) can be written as

$$
\min _{\Upsilon}\left[\lambda_{j}^{i}\left(\Upsilon ; \bar{\Upsilon}, w, L, \eta,\left\{\sigma_{h}\right\}_{h \in H}, \epsilon, \alpha\right)-\lambda_{j}^{i}\right]_{i \neq j=1}^{N}
$$

where, $\lambda_{j}^{i}$ is total share of spending on varieties from country $j$ in country $i$. Each element in the above $(N-1) \times(N-1)$ vector characterizes the distance between the respective model outcome (given the parameters) and the outcome in the data. The calibration's objective is to search for a set of parameters $\Upsilon=$ $\left\{\kappa_{\text {const }}, \kappa_{\text {dist }}, \kappa_{\text {border }}, \kappa_{\text {lang }}, \kappa_{\text {agreement }}, f, f^{e}\right\}$ that minimize the sum of the squared differences between the model outcomes and the data targets for these outcome. ${ }^{54}$ I normalize wage in the US and taste parameter for US varieties to 1 and 100 respectively.

Results. The calibrated value of parameters and the goodness of fit are displayed in table 4. I also calibrate the model under two alternative baseline specifications. First, I shut down across industry heterogeneity in degree of differentiation (reported in column two of table 4). By doing so, I partially shut down interindustry North-South trade - which is also absent in a standard Krugman or Armington model. Second, I calibrate a model with little-to-no national product differentiation (reported in column three of table 4). ${ }^{55}$ In the absence of national product differentiation there is no incentive for similar trade (e.g. North-North trade). As expected, the main model outperforms both baseline models in terms of fitting aggregate trade data. The improved fit of the model is mostly due to incorporating inter-industry North-South trade (by allowing for across-industry heterogeneity in the degree of differentiation).

$f=0.05$ implies that exporters have to pay a fixed cost per-product (inclusive of entry costs) that is $25 \%$ higher than that paid by domestic firms. Table 11 (in the Appendix) reports the estimated "national

\footnotetext{
${ }^{53}$ I solve for the trade shares along the following steps

i. Start with a guess of the vectors $\left\{M_{j}^{i}\right\}_{j, i \in C}^{0}$ and $\left\{P_{h}^{i}\right\}_{i, j \in C ; h \in H^{\prime}}^{0}$;

ii. Calculate the vector of product-specific profits of firm $\left\{\pi_{j h}^{i}\right\}^{0} i, j \in C ; h \in H$;

iii. Solve for the new vector of the mass of firms $\left\{M_{j}^{i}\right\}_{j, i \in C}^{1}$ using the free entry (FE) condition;

iv. Calculate the new vector of price indexes $\left\{P_{h}^{i}\right\}_{i, j \in C ; h \in H}^{1} ;$ and

v. Start over from 1 and iterate until convergence is achieved up to a pre-assigned degree of accuracy .

After the convergence in the above loop I can calculate trade shares using the prices indices and mass of firms from equations (8) and (9).

${ }^{54}$ To find the global minimum, I first perform a global search using the Genetic Algorithm. Then, I use the Nelder-Mead algorithm to perform a local search. Chelouah and Siarry [2003] Show that this approach is more efficient in finding the global optimum than implementing either algorithm independently.

${ }^{55}$ In the baseline calibration, I lower $\eta$ to be as close to one as possible (i.e. $\eta=1.1$ ). When I let $\eta$ to be exactly one the nested fixed-point algorithm does not converge, because the condition gives rise to knife edge equilibria.
} 
production quality" $\left(\mu_{i}\right)$ for each country. As one would expect, the rank of countries in terms of "national production quality" $\left(\mu_{i}\right)$ is similar to their productivity $\left(T_{i}\right)$ rank in Eaton and Kortum [2002]. This is quite intuitive given that, in the present gravity model, technology $\left(T_{i}\right)$ is replaced with two elements: (1) "national production quality" $\left(\mu_{i}\right)$, and (2) the mass exporters $\left(M_{i h}^{k}\right)$ from country $i$ (mass of firms that export is endogenously determined by $\mu_{j}$ and other country-specific characteristics). ${ }^{56}$

\begin{tabular}{cccc}
\hline Parameters & Main model & $\begin{array}{c}\text { No across-product } \\
\text { specialization } \\
\left(\sigma_{h}=4.2, \forall h ; \eta=2.15\right)\end{array}$ & $\begin{array}{c}\text { No national product } \\
\text { differentiation } \\
\left(\sigma_{h}=4.2, \forall h ; \eta \rightarrow 1\right)\end{array}$ \\
\hline \hline$\kappa_{\text {const }}$ & 0.292 & 0.804 & 0.666 \\
$\kappa_{\text {dist }}$ & 0.275 & 0.117 & 0.100 \\
$\kappa_{\text {lang }}$ & 0.955 & 0.961 & 0.971 \\
$\kappa_{\text {border }}$ & 0.939 & 0.958 & 0.966 \\
$\kappa_{\text {agreement }}$ & 0.961 & 0.964 & 0.967 \\
$f$ & 0.049 & 0.051 & 0.059 \\
$f$ f & 1 & 1 & 1 \\
Goodness of fit & 0.39 & 0.33 & 0.31 \\
\hline (R-squared) & & & \\
\hline
\end{tabular}

Table 4: The calibrated trade cost parameters

\subsection{Pattern of Competitive Advantage (North vs. South)}

This section illustrates patterns of competitive advantage across industries. According to the gravity equation, country $k^{\prime}$ s imports from country $i$ industry $h$ (or product $h$ ) are characterized by

$$
\lambda_{i \mid h}^{k}=\frac{\mu_{i}\left(M_{i h}^{k}\right)^{\frac{\sigma_{h}-1}{\eta \sigma_{h}-1}}\left[\tau_{i k} w_{i}\right]^{\left(1-\sigma_{h}\right)}}{\sum_{j \in C_{h}^{k}} \mu_{j}\left(M_{j h}^{k}\right)^{\frac{\sigma_{h}-1}{\eta \sigma_{h}-1}}\left[\tau_{j k} w_{j}\right]^{\left(1-\sigma_{h}\right)}}=\frac{\left(M_{i h}^{k}\right)^{\frac{\sigma_{h}-1}{\eta \sigma_{h}-1}}\left[\frac{\tau_{i k} w_{i}}{\mu_{i}^{1 /\left(\sigma_{h}-1\right)}}\right]^{\left(1-\sigma_{h}\right)}}{\sum_{j \in C_{h}^{i}}\left(M_{j h}^{k}\right)^{\frac{\sigma_{h}-1}{\eta \sigma_{h}-1}}\left[\frac{\tau_{j k} w_{j}}{\mu_{j}^{1 /\left(\sigma_{h}-1\right)}}\right]^{\left(1-\sigma_{h}\right)}}
$$

As evident in the above equation, Pure wage $-\frac{w_{i}}{\mu_{i}^{1 /\left(\sigma_{h}-1\right)}}$ - determines the market share of country $i$ in global markets. The lower the pure wage the more competitive the firms from country $i$, and the higher the market

\footnotetext{
${ }^{56}$ The rank of countries in terms of their estimated "national production quality" $\mu_{i}$ is also similar to their quality-rank in Hallak and Schott [2011]. This can be seen in figure 19 where I compare the estimated "national production quality" in this paper to countryspecific qualities estimated by Hallak and Schott [2011] — the use disaggregated US imports data to estimate the country-specific qualities.
} 
share they absorb in global markets. Pure wage is industry-specific; a country could pay a relatively high pure wage in one industry and a relatively low pure wage in another. To illustrate this, I plot pure wage against per capita income once for machinery (that are highly differentiated) and then for the food industry (that is less differentiated).

Figure 10 (upper panel) displays the relationship between pure wage and per capita income in the food industry. As seen, rich countries pay a higher pure wage and are competitively disadvantage in the food industry. For industrial machinery, however, the trend is the opposite (lower panel in figure 10). As 10 displays, rich countries have clear competitive advantage over poor countries in industrial machinery they pay a much lower pure wage to workers who manufacture machinery and consequently charge a lower pure price for their variety of machinery.

To elaborate further, I can compare China with the US. In the least differentiated industry (food) China pays a pure wage (or marginal cost per unit of util) that is less than half of the US. In the most differentiated industry (industrial machinery) the pure wage in China is 33.8 times higher than the US. Clearly, US has tremendous advantage over China in industrial machinery. The advantage stems from differences in "national production quality," and is largely immune to tariff reduction or any other policy that targets price rather than production-quality.

\subsection{A Gated Globe-the Large Scale of Iceberg Trade Costs}

As noted earlier, across-product heterogeneity in differentiation is the driving force behind North-South trade, while national product differentiation is driving force behind North-North and South-South trade. Shutting down either channel leads to an aggregation bias when estimating the iceberg trade costs. Specifically, when both channels are taken into account, the estimated iceberg trade costs are larger in magnitude. When I impose $\sigma_{h}$ to be the same for all five products (and equal to 4.2), the estimated trade costs are around $34 \%$ lower than the main model. When national product differentiation is also shut down, trade costs are under-estimated by an additional 53\%.

The estimated trade costs are higher in the new model compared to the baseline setting (and also compared to traditional estimates) due to the following. In the new model, there is more incentive for bilateral trade compared to traditional models of international trade. Across-product heterogeneity in differentiation, induces dissimilar countries to trade. In traditional models of trade (and in the baseline model) this direction of trade is absent. Hence, the new model can match the observed bilateral trade flows conditional on higher trade costs. This implies that in the context of the new model the gains from eliminating trade costs could be much greater than thoe predicted by traditional models. 

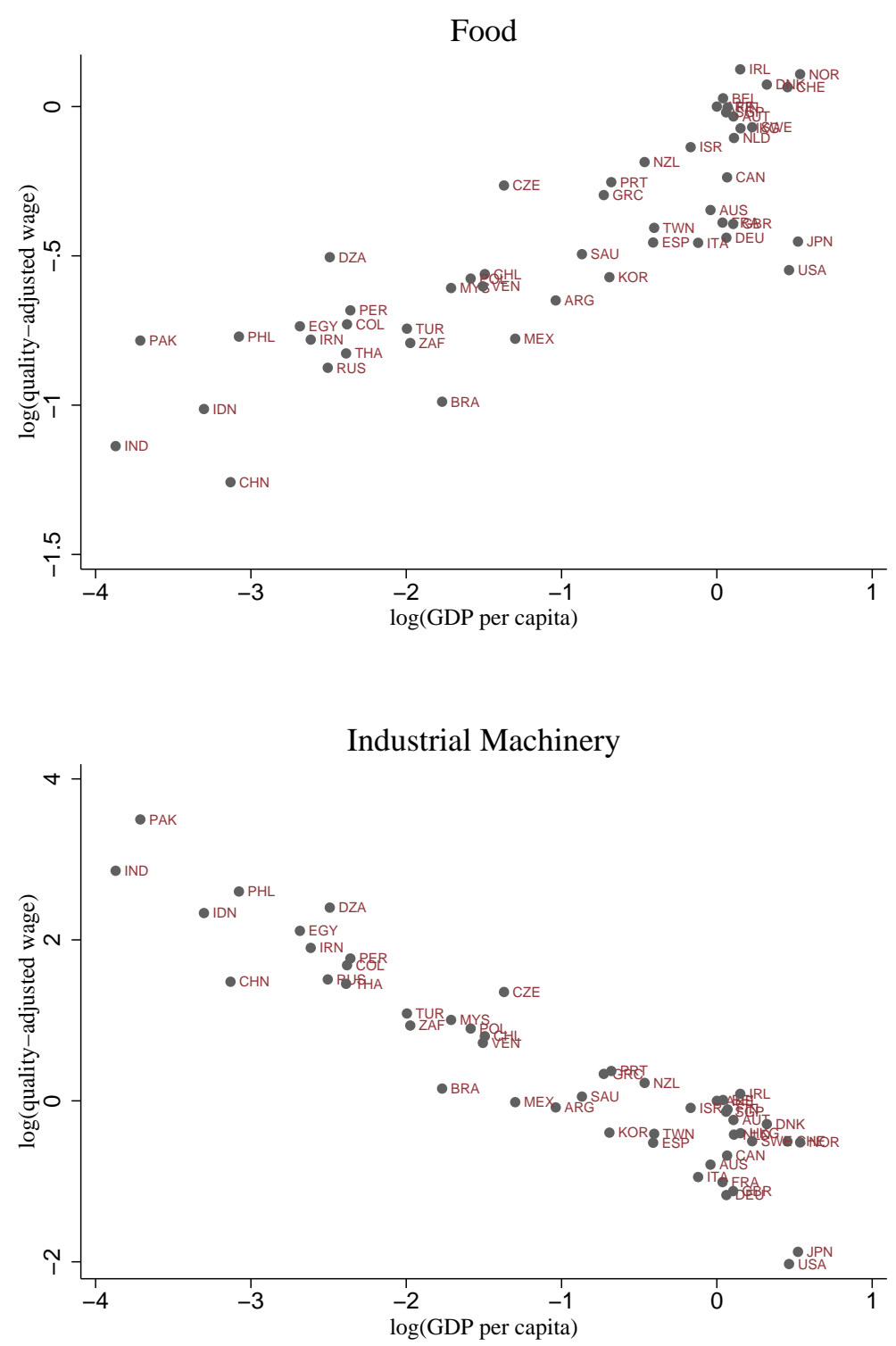

Figure 10: The relationship between pure wage and per capita income (in logs) for the most and least differentiated products. Low-wage countries enjoy competitive advantage in food products (the least-differentiated product), while high-wage countries enjoy competitive advantage in machinery products (the most differentiated). Pure wage is calculated as the quality-adjusted wage in each country, i.e. $\ln \frac{w_{i}}{\mu_{i}^{1 /\left(\sigma_{h}-1\right)}}$. 


\begin{tabular}{ccc} 
& Average $\tau_{j i}$ & $\begin{array}{c}\text { \% difference compared to } \\
\text { new model }\end{array}$ \\
\hline \hline Main model & 3.28 & $\ldots$ \\
$\quad$ No across-product specialization \\
$\quad\left(\eta=2.15 ; \sigma_{h}=4.2, \forall h\right)$ \\
$\begin{array}{c}\text { No national product differentiation } \\
\text { and no across-product specialization } \\
\left(\eta \rightarrow 1 ; \sigma_{h}=4.2, \forall h\right)\end{array}$
\end{tabular}

Table 5: Comparison of calibrated iceberg trade costs under different specifications.

\subsection{The Sizable Gains From Trade}

Highly differentiated products exhibit higher markups, are more profitable to export, and, therefore, are traded more intensely. After a country opens to trade, imports will mostly consist of highly differentiated products. The import bias towards highly differentiated products is even bigger in poor countries. Taking this into account, the gains from trade would be sizable. Precisely speaking, the gains from trade depend on the volume of trade (which is observed in the data), and the elasticity of substitution across varieties of the product that is imported. In the new model when trade is liberalized, countries import predominantly foreign varieties of highly differentiated products. Since foreign varieties of highly differentiated products are not easily substitutable with their domestic counterparts, the gains from importing them are immense - appendix A.1 demonstrates this result analytically.

To quantify the gains from trade, I preform a counter-factual welfare analysis. I analyze the welfare effects of opening to trade from autarky (i.e. $\tau_{i j} \rightarrow \infty \forall i \neq j$ ). Welfare in each country is characterized by real wage $\left(\frac{w_{i}}{P^{i}}\right)$. In the counterfactual experiment the general equilibrium is resolved for the new trade values, and the new measure of real wage is calculated using the counterfactual (autarky) wage and price index. The change in real wage form the trade to autarky measures the gains from trade. I perform the same counterfactual experiment for two alternative (baseline) models. As before, in the first baseline I restricted the elasticity of substitution to be 4.2 for all products. In the second baseline, I also shut down national product differentiation, i.e. I enforce $\eta \rightarrow 1$.

The estimated gains from trade are displayed in table 11 - and in more detail in table6. The results suggest that the gains from trade are, by far, larger in the new model. In the new model countries gain on average \%15.2 in terms of real wage when opening to trade (from autarky). In the two baseline settings the gains are on average $4.9 \%$ and $1 \%$ in real wage terms - these numbers are closer to traditional estimates (to 


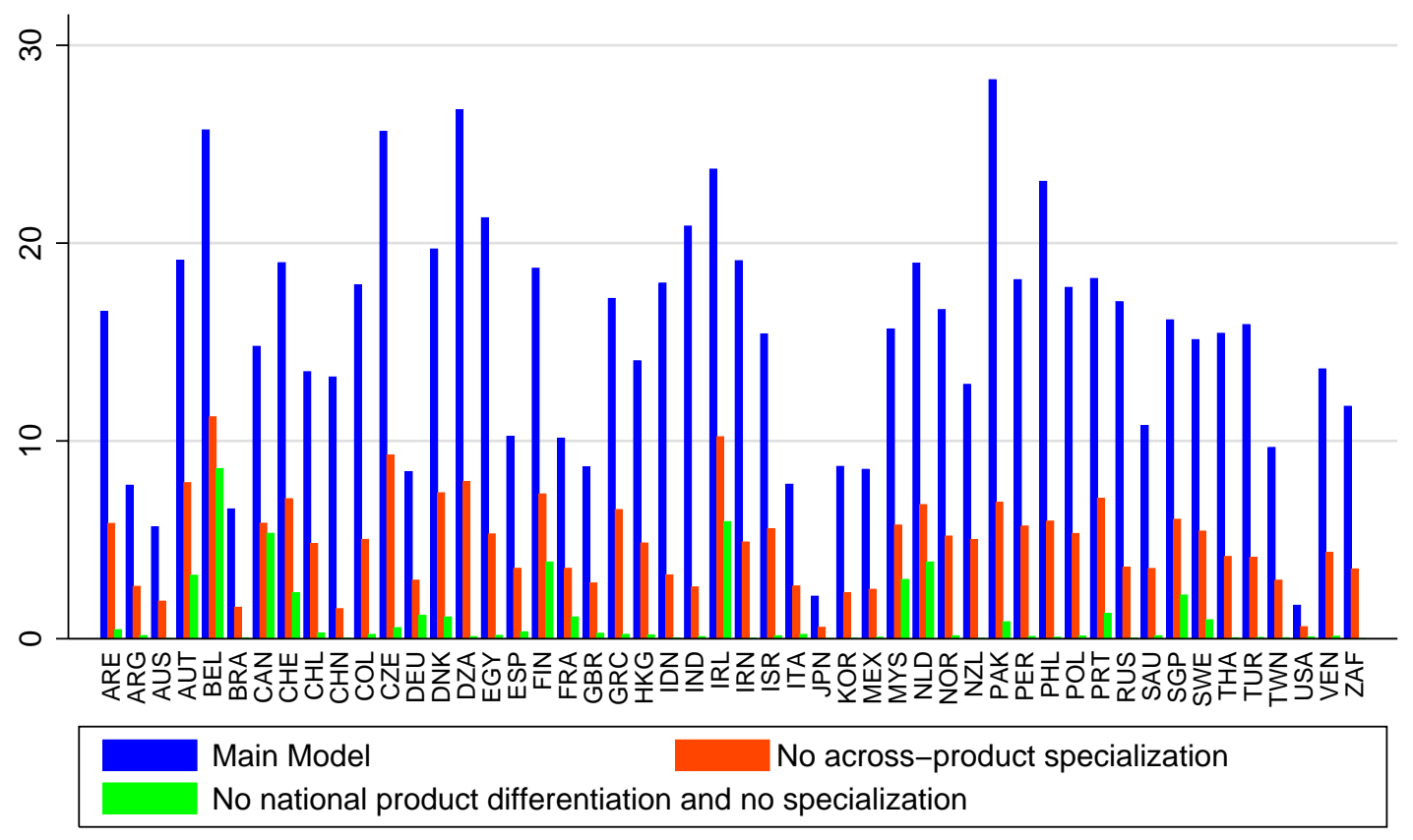

Figure 11: Comparison of the gains from opening to trade from autarky in the new model relative to the two baseline specifications.

illustrate this, in table 6, I report the gains from trade quantified by Eaton and Kortum [2002]). Note that in the new model trade costs are supposedly larger, and the immense gains from trade are happening even though countries are moving from autarky to a highly-gated global economy. ${ }^{57}$

I can also decompose the gains from trade and back out the product-specific gains. Figure 12 displays the effect of trade on purchasing power (nominal wage relative to prices index of good $h$ ) for all five products. Every dot displays the change in purchasing power for a given product in one of the 50 countries after opening to the trade from autarky. Each product is indexed by degree of differentiation (x-axis) such that every vertical set of dots (in figure 12) reference one product. As expected, trade increases purchasing power significantly more for the highly differentiated products (e.g. electronics and machinery). For food products, which are the least differentiated, the gains are small and occasionally negative.

The drop in purchasing power of food product (after trade) happens mostly in low-wage countries (table 12). This is due to low-wage countries not being a profitable market for exporters of food products. In low-wage countries, domestic firms supply food products at a very low price, and absorb all the market share. When low-wage countries open to trade, multi-product foreign firms enter the market, crowd out

\footnotetext{
${ }^{57}$ In the new model the trade equilibrium resembles autarky more than free trade. Under the baseline characterization, however, the trade equilibrium resembles more closely a free trade environment.
} 


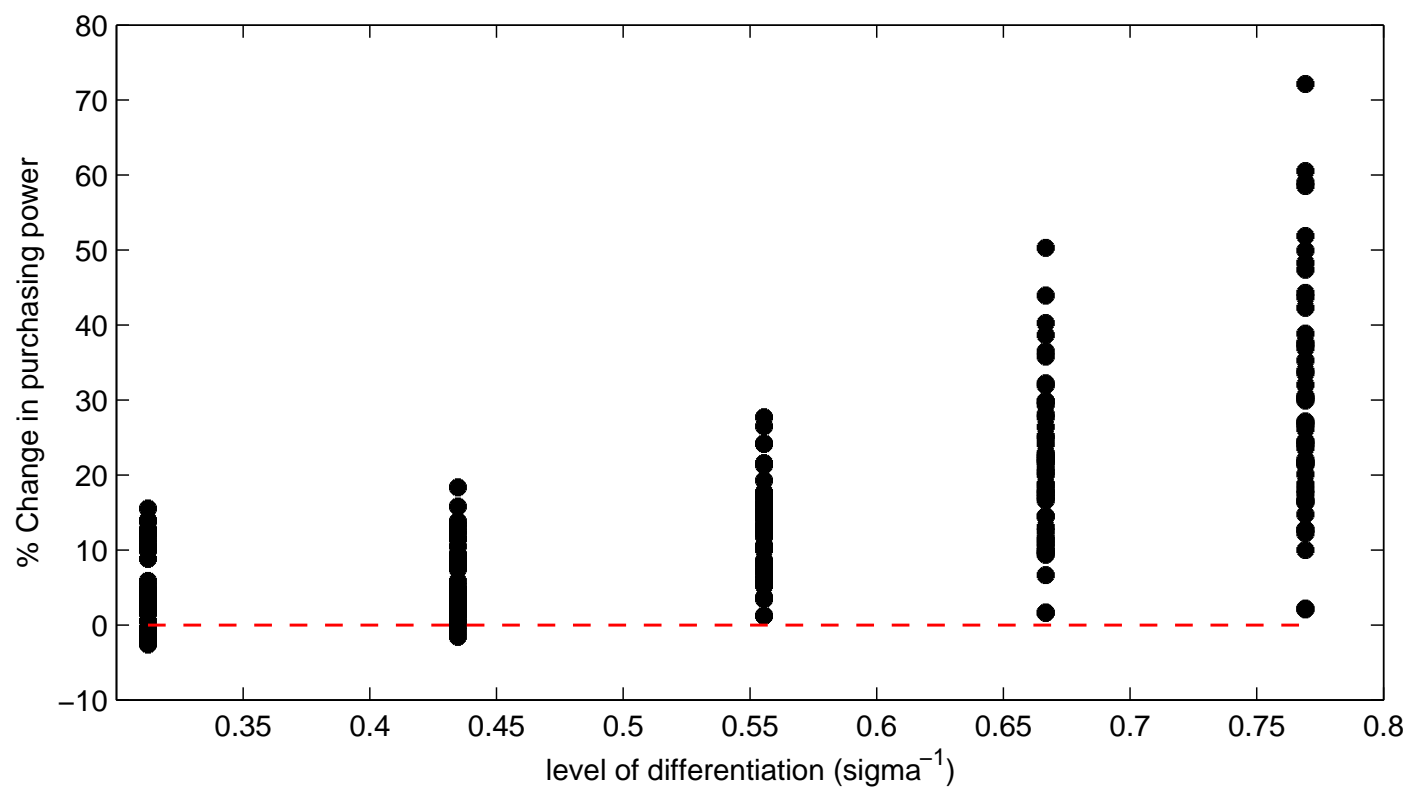

Figure 12: The gains from trade for different countries in different products (characterized by the degree of differentiation-x axis). The numbers on the vertical axis are changes in nominal wage relative to the price of the product (i.e. $\left.\frac{w_{i}}{P_{h}^{i}}\right)$ when switching from the calibrated trade equilibrium to the counter-factual autarky equilibrium.

some of the domestic firms, but only supply the most-differentiated products (e.g. electronics and machinery). When domestic firms (that are the main suppliers of food products) leave the market, there is less variety of food products. As a result, the purchasing power (of food) goes down. Consumers are, however, compensated by a disproportionally large increase in their purchasing power of highly differentiated products. ${ }^{58}$

Finally, poor countries gain more from trade even though they conduct less trade. The reason is that by engaging in trade, poor countries gain access to the superior production techniques and high-quality labor in rich countries. For highly differentiated products (that are the main subject of imports in poor countries) production technique plays an important role-consumers of highly-differentiated products are more concerned about quality than quantity. Thus, importing differentiated products that are produced by high-quality labor in rich countries, generate sizable welfare gains. Pakistan, for example, is one of the main beneficiaries of trade in the new model. After trade is liberalized, Pakistani consumers gains access to electronics from Japan and machinery from Germany, both of which are massively superior (per dollar price) to there Pakistani counterparts. Despite being very intuitive, this direction of gain has never been

\footnotetext{
${ }^{58}$ In the CES framework consumers are identical and purchase all the varieties. The asymmetric gains in purchasing power, i.e. product-specific real wage, are of not of much interest in this setting. However the exact same aggregate demand and model could be generated with a nested logit demand structure, which is isomorphic to nested CES. If the underlying demand structure were nested logit, where everyone buys only one variety, the above result implies asymmetric gains from trade across consumers. Consumers of low-price less-differentiated products could lose from trade, specially in low-wage countries. Nevertheless, the average consumer in low-wage countries always gains from trade.
} 
formally characterized in the existing literature.

\section{Conclusion}

This paper develops a new theory of international specialization that simultaneously captures all the fundamental features of North-North and North-South trade. The explanatory power of the theory spans beyond patterns of North-South (or North-North) trade; it provides an alternative explanation for a host of other well-document facts, most notably the "Washington apples" effect. The theory reconciles facts that previous theories have explained in isolation. Moreover, unlike the existing theories of North-South trade, it requires minimal deviation form conventional assumptions. The pattern of (across-product) specialization emphasized by the new theory are unlike any other in the literature. The new theory is consistent with disaggregated trade data, and generates gains from trade that are substantially larger than traditional models.

I fit the model to data in two steps. First, I estimate the structural demand parameters using disaggregated data. Then, I use the first the step estimates to calibrate the model to aggregate trade flows, and to quantify the gains from trade. The main empirical findings are the following: (2) low-income countries specialize in less-differentiated products while high-income countries specialize in highly differentiated products; (1) the gap in competitiveness between high and low-income countries is strikingly large in highly differentiated sectors; (3) US employment in highly differentiated (i.e. low elasticity) industries is largely insulated from import penetration by low-wage countries; (4) the realized gains from trade (relative to autarky) are immense when we account for all directions of trade; and (5) in the main model (with North-South trade), the estimated trade costs are 51\% larger than the baseline Krugman model (without North-South trade).

The new theory provides a tractable framework to analyze trade policy. In contrast to the "new trade theories" (e.g. Krugman, Melitz, Eaton-Kortum), the present framework is well-suited to analyze trade between the US and developing nations like China. Meanwhile, the framework retains both tractability of the "new trade theories", and their explanatory power regarding North-North trade. A simple extension of the theory will provide a framework to analyze the unequal gains from trade (across consumers). Specifically, if trade costs are lowered, purchasing power of highly differentiated products would rise dramatically at the expense of lower purchasing power for less differentiated products. The effect is more prominent in lowincome countries. This would imply unequal gains from trade across consumers if the underlying demand structure were nested logit rather than nested CES. Specifically, trade liberalization would greatly benefit the average consumer, but would harm consumers that buy (only) the least-differentiated of the products. 


\section{References}

Christopher H Achen. The statistical analysis of quasi-experiments. Univ of California Press, 1986.

Armen Alchian and William Allen. Exchange and production: Competition. Coordination, and Control, 193, 1983.

Simon P Anderson, Andre De Palma, and Jacques-Francois Thisse. Discrete choice theory of product differentiation. MIT press, 1992.

C Arkolakis, A Costinot, and A Rodriguez. Clare, 2012, new trade models, same old gains. American Economic Review, 102(1):94, 2012.

Costas Arkolakis and Marc-Andreas Muendler. The extensive margin of exporting products: A firm-level analysis. Technical report, National Bureau of Economic Research, 2010. URL http: / /www . nber . org/ papers/w16641.

K Arkolakis, Pete Klenow, Svetlana Demidova, and Andres Rodriguez-Clare. The gains from trade with endogenous variety. In American Economic Review Papers and Proceedings, volume 98, pages 444-450, 2008.

R Baldwin and J Harrigan. Zeros, quality and space: trade theory and trade evidence. The American Economic Journal: Microeconomics, forthcoming, 2011.

Robert J Barro and Jong-Wha Lee. International data on educational attainment: updates and implications. Oxford Economic Papers, 53(3):541-563, 2001. URL http://oep.oxfordjournals.org/content/ $53 / 3 / 541$. short.

Andrew B Bernard, J Bradford Jensen, and Peter K Schott. Survival of the best fit: Exposure to lowwage countries and the (uneven) growth of us manufacturing plants. Journal of International Economics, 68(1):219-237, 2006a. URL http://www.sciencedirect.com/science/article/pii/ S0022199605000498.

Andrew B Bernard, Stephen J Redding, and Peter K Schott. Multi-product firms and product switching. Technical report, National Bureau of Economic Research, 2006b. URL http://www. nber.org/ papers/w12293.

Steven Berry, James Levinsohn, and Ariel Pakes. Automobile prices in market equilibrium. Econometrica: Journal of the Econometric Society, pages 841-890, 1995. URL http://www.jstor.org/stable/10. 2307/2171802. 
Christian Broda and David E Weinstein. Globalization and the gains from variety. The Quarterly Journal of Economics, 121(2):541-585, 2006. URL http://qje.oxfordjournals.org/content/121/2/541. short.

Rachid Chelouah and Patrick Siarry. Genetic and nelder-mead algorithms hybridized for a more accurate global optimization of continuous multiminima functions. European Journal of Operational Research, 148(2):335-348, 2003. URL http://www.sciencedirect.com/science/article/pii/ S0377221702004010.

UN Comtrade. United nations commodity trade statistics database. URL: http://comtrade. un. org, 2010.

Arnaud Costinot and Andrés Rodríguez-Clare. Trade theory with numbers: Quantifying the consequences of globalization. Technical report, National Bureau of Economic Research, 2013. URL http://www . nber.org/papers/w18896.

Robert Dekle, Jonathan Eaton, and Samuel Kortum. Unbalanced trade. Technical report, National Bureau of Economic Research, 2007. URL http: //www. nber.org/papers/w13035.

Avinash K Dixit and Joseph E Stiglitz. Monopolistic competition and optimum product diversity. The American Economic Review, 67(3):297-308, 1977. URL http://www.jstor.org/stable/10.2307/ 1831401.

Jonathan Eaton and Samuel Kortum. Technology, geography, and trade. Econometrica, 70(5):1741-1779, 2002. URL http://onlinelibrary.wiley.com/doi/10.1111/1468-0262.00352/abstract.

Jonathan Eaton, Samuel Kortum, and Francis Kramarz. An anatomy of international trade: Evidence from french firms. Econometrica, 79(5):1453-1498, 2011. URL http://onlinelibrary.wiley.com/doi/ 10.3982 /ECTA8318/abstract.

Pablo Fajgelbaum, Gene M Grossman, and Elhanan Helpman. kincome distribution. Product Quality, and International Trade, lJournal of Political Economy, 118(4):721, 2011.

Robert C Feenstra, John Romalis, and Peter K Schott. Us imports, exports, and tariff data, 1989-2001. Technical report, National Bureau of Economic Research, 2002. URL http: / /www . nber . org / papers / w9387.

Robert C Feenstra, Maurice Obstfeld, and Katheryn N Russ. In search of the armington elasticity. University of California-Davis, unpublished mimeo, 2012. 
Ana Cecilia Fieler. Nonhomotheticity and bilateral trade: evidence and a quantitative explanation. Econometrica, 79(4):1069-1101, 2011. URL http://onlinelibrary.wiley.com/doi/10.3982/ ECTA8346/abstract.

William H Greene. Econometric analysis, 5th. Ed.. Upper Saddle River, NJ, 2003.

Juan Carlos Hallak. Product quality and the direction of trade. Journal of International Economics, 68(1):238-265, 2006. URL http://www.sciencedirect.com/science/article/pii/ S0022199605000516.

Juan Carlos Hallak and Peter K Schott. Estimating cross-country differences in product quality*. The Quarterly Journal of Economics, 126(1):417-474, 2011. URL http: / / qje.oxfordjournals.org/content/ 126/1/417. short.

Gordon H Hanson. The rise of middle kingdoms: Emerging economies in global trade. Technical report, National Bureau of Economic Research, 2012.

Keith Head and John Ries. Increasing returns versus national product differentiation as an explanation for the pattern of us-canada trade. American Economic Review, pages 858-876, 2001.

Elhanan Helpman, Marc Melitz, and Yona Rubinstein. Estimating trade flows: Trading partners and trading volumes. The Quarterly Journal of Economics, 123(2):441-487, 2008. URL http://qje. oxfordjournals.org/content/123/2/441. short.

David Hummels and Peter J Klenow. 9the variety and quality of a nation s exports9. The American Economic Review, 95(3), 2005.

David Hummels and Georg Schaur. Time as a trade barrier. Technical report, National Bureau of Economic Research, 2012. URL http: //www . nber.org/papers/w17758.

Jean Imbs and Isabelle Méjean. Trade elasticities. Paris School of Economics, unpublished mimeo, 2010.

Amit Khandelwal. The long and short (of) quality ladders. The Review of Economic Studies, 77(4):1450-1476, 2010. URL http://restud.oxfordjournals.org/content/77/4/1450.short.

Aart Kraay and Jaume Ventura. Comparative advantage and the cross-section of business cycles. Journal of the European Economic Association, 5(6):1300-1333, 2007. URL http://onlinelibrary•wiley •com/ doi/10.1162/JEEA.2007.5.6.1300/abstract.

Paul Krugman. Scale economies, product differentiation, and the pattern of trade. The American Economic Review, 70(5):950-959, 1980. URL http://www. jstor.org/stable/10.2307/1805774. 
Paul Krugman. The increasing returns revolution in trade and geography. The American Economic Review, pages 561-571, 2009.

Ahmad Lashkaripour. Apples and oranges: The alchian-allen conjecture revisited. Pennsylvania State University, unpublished mimeo, 2013.

James R Markusen. Explaining the volume of trade: an eclectic approach. The American Economic Review, pages 1002-1011, 1986. URL http://www.jstor.org/stable/10.2307/1816465.

Thierry Mayer and Soledad Zignago. Notes on cepii's distances measures: The geodist database. 2011. URL http://papers.ssrn.com/sol3/papers.cfm?abstract_id=1994531.

Daniel McFadden et al. Modelling the choice of residential location. Institute of Transportation Studies, University of California, 1978.

Marc Melitz. The impact of trade on aggregate industry productivity and intra-industry reallocations. Econometrica, 71(6):1695-1725, 2003.

Edward R Morey and Donald M Waldman. Measurement error in recreation demand models: the joint estimation of participation, site choice, and site characteristics. Journal of Environmental Economics and Management, 35(3):262-276, 1998. URL http://www.sciencedirect.com/science/article/pii/ S0095069698910294.

Ralph Ossa. Why trade matters after all. Technical report, National Bureau of Economic Research, 2012. URL http://www.nber.org/papers/w18113.pdf.

James E Rauch. Networks versus markets in international trade. Journal of international Economics, 48(1):7-35, 1999. URL http://www.sciencedirect.com/science/article/pii/ S0022199698000099.

Peter K Schott. Across-product versus within-product specialization in international trade. The Quarterly Journal of Economics, 119(2):647-678, 2004. URL http: / / qje . oxfordjournals . org/content/119/ 2/647. short.

Peter K. Schott. The relative sophistication of chinese exports. Economic Policy, 23:5-49, 01 2008. URL http://ideas.repec.org/a/bla/ecpoli/v23y2008ip5-49.html.

Ina Simonovska and Michael E Waugh. The elasticity of trade: Estimates and evidence. Technical report, National Bureau of Economic Research, 2011. URL http://www. nber. org/papers/w16796. 
Michael Waugh. International trade and income differences. The American Economic Review, 100(5): 2093-2124, 2010. URL http://www.ingentaconnect.com/content/aea/aer/2010/00000100/ $00000005 / \operatorname{art} 00006$.

World-Bank. World Development Indicators 2012. World Bank-free PDF, 2012. 


\section{A Proofs and Additional Results}

\section{A.1 Trade Liberalization: More Gain than Pain}

In this section I will briefly discuss the effects of trade liberalization on the number of varieties in different markets. Then, I will analyze the welfare implications of the model in some depth.

Lowering iceberg trade costs will lead to more foreign entry. Multi-product foreign firms will enter the market and crowd out a portion of the multi-product domestic firms. Consider a baseline setting in which $\sigma_{h}=\sigma, \forall h$ and $\eta \rightarrow 1 .{ }^{59}$ The total number of varieties in a given market will either drop or remain the same after lowering the trade costs in the baseline setting. ${ }^{60}$ In the main model, on the other hand, trade would always be more pro-variety relative to the baseline (I demonstrate the pro-variety effects of trade in the new model in detail in appendix A.1). As noted earlier, the market-entry procedure adopted in this paper is conservative in terms of the gains from variety. Adopting a conventional entry scheme (paying an entry cost once and for all markets) will assure that the total number of varieties do not drop after trade liberalization even in the baseline model. ${ }^{61}$ The results of the paper do not rely on the per-market entry procedure and the main reason I assume it, is to demonstrate how the model generates big gains from trade even under conservative entry assumptions.

To analyze the gains from trade I implement the approach proposed by Arkolakis et al. [2012]. ${ }^{62}$ Small changes in real wage (i.e. indirect utility) as a result of slightly lowering the iceberg trade costs (or any exogenous shock) will be given by ${ }^{63}$

$$
d \ln \frac{w_{i}}{P^{i}}=\int_{h} \frac{-d \ln \lambda_{i \mid h}^{i} \lambda_{h}^{i}}{\sigma_{h}-1} d h+\left[\int_{h} \frac{1}{\eta \sigma_{h}-1} \lambda_{h}^{i} d h\right] d \ln M_{i}^{i}
$$

Using the free entry condition and some algebra the above equation can be re-written as ${ }^{64}$

\footnotetext{
${ }^{59}$ The outcomes of the model can be no-trade when $\eta \leq 1$. From here on by $\eta \rightarrow 1$, I mean $\eta$ approaches 1 from the right: $\eta \rightarrow 1^{+}$.

${ }^{60}$ In the absence of per-market fixed exporting costs $(f)$ the total number of varieties in the baseline model does not change after lowering the iceberg trade costs. However, when fixed exporting costs are present the number of varieties in the market drops after lowering the iceberg costs. Finally, when entry cost is payed once and for all markets (which is the case in Krugman [1980] andMelitz [2003]) the total number of varieties in every market would increase after lowering the iceberg trade costs. See appendix ?? for a formal argument on this.

${ }^{61}$ The intuition is simple; when the entry cost is paid multiple times instead of once and for all markets, there would be less incentive for firm entry.

${ }^{62}$ In this section when I talk about the gains from trade I am referring to the change in the indirect utility from consumption of the manufactured goods, i.e. $d \ln \tilde{U}_{M}$. The total change in welfare will therefore be $d \ln V=\alpha d \ln \tilde{U}_{M}$ where $\alpha$ is the share of spending on manufactured goods.

${ }^{63}$ For a derivation of equations (11) and (12) see appendix A.4. The second term, i.e. $\left[\int_{h} \frac{1}{\eta \sigma_{h}-1} \lambda_{h}^{i} d h\right] d \ln M_{i}^{i}$, is negative in my model and would be zero if entry cost was paid once and for all markets as in Arkolakis et al. [2012]. What makes the entry procedure adopted in this paper more conservative in terms of the gains from trade, is allowing for the second term to be non-zero.

${ }^{64}$ As $\eta \rightarrow 1$ the model gives rise to special case equilibria with the possibility of no trade. For example, if the economy is symmetric such that the domestic varieties are the cheapest then $d \ln \lambda_{i \mid h}^{i} \rightarrow 0$. The other possibility that could arise is switching to cheapest alternative that could possibly be non-domestic and in that case $d \ln \lambda_{i \mid h}^{i} \rightarrow \infty$. The term in the braces disappears under two circumstances: (1) if $\eta \rightarrow \infty$ in which case every country would be one firm, or (2) when entry is once and for all markets (as in Arkolakis et al. [2012]) rather than per-market.
} 


$$
d \ln \frac{w^{i}}{P^{i}}=\int_{h} \frac{-d \ln \lambda_{i \mid h}^{i} \lambda_{h}^{i}}{\sigma_{h}-1} d h\left\{1-\left[\frac{\int_{h} \frac{1}{\eta \sigma_{h}-1} \lambda_{h}^{i} d h}{\int_{h} \frac{1}{\sigma_{h}-1} \lambda_{h}^{i} d h}\right]\right\}
$$

I can then break down the change in welfare an examine the effect per product. In particular, for every product $h$ small changes in purchasing power will be given by ${ }^{65}$

$$
d \ln \frac{w_{i}}{P_{h}^{i}}=\frac{-d \ln \lambda_{i \mid h}^{i}}{\sigma_{h}-1}+\frac{d \ln M_{i}^{i}}{\eta \sigma_{h}-1}
$$

When trade costs are lowered, some multi-product domestic firms leave to create room for the multiproduct foreign firms. The multi-product domestic firms sell all the products at full intensity because they do not pay the per-product fixed cost after entry. The multi-product foreign firms, on the other hand, only sell the expensive and differentiated products after they enter (only a very small portion of them will sell the less differentiated products). ${ }^{66}$ In the highly differentiated product categories the loss of domestic varieties (the second term on the RHS in equation (13)) is offset by extensive foreign entry in those products (the first term on the RHS in equation (13)). The overall gains are larger in the new model relative to the baseline (or the general setting proposed by Arkolakis et al. [2012]) for the following reason: in equation (12) if $\sigma_{h}<\sigma_{h^{\prime}}$ then $-d \ln \lambda_{i \mid h}^{i}>-d \ln \lambda_{i \mid h^{\prime}}^{i}{ }^{67}$ Therefore, changes in the import flows (i.e. $-d \ln \lambda_{i \mid h}^{i}=\sum_{j \neq i} d \lambda_{j \mid i}^{i}$ ) are larger in more differentiated products where consumers benefit more from having the foreign varieties. Putting it differently, foreign varieties are concentrated where consumers want them to be.

The above result is closely related to two studies. Arkolakis, Klenow, Demidova, and Rodriguez-Clare [2008] argue that the gains from variety are not that much. ${ }^{68}$ What my theory suggests is that after opening to trade, foreign varieties crowd the highly differentiated product categories (i.e. trade happens relatively more in differentiated products), and that is where consumers benefit the most from their availability. More precisely, observed aggregate trade flows are not sufficient statistics for measuring the gains from trade. We should break down aggregate flows into product-specific flows and weight them according to the degree of differentiation in each product category. If one restricts elasticity to be the same across all products, the new foreign varieties that arrive (post trade liberalization) are evenly spread out across all categories.

\footnotetext{
${ }^{65}$ note that if entry was once and for all markets (as in Arkolakis et al. [2012]) rather than per-market, then $\frac{d \ln M_{i}^{i}}{\eta \sigma_{h}-1}=0$.

${ }^{66} \mathrm{~A}$ reminder about the terminology I use in this paper: The firms from a country sell product $h$ at full intensity if all of them participate in selling $h$ after entry: $\nu_{j}^{i}(h)=1$. If firms from a country are not selling at full intensity, it means a fraction of entrants from that country sell until the product-specific profit for product $h$ is drawn down to zero.

${ }^{67}$ This is true in the symmetric equilibrium. In an asymmetric equilibrium this is true for two disconnected intervals on $H$ (i.e. if $H=[0, \bar{h}]$ is sorted in terms of the degree of differentiation then there exists a $\tilde{h}$ such $\int_{0}^{\tilde{h}}-d \ln \lambda_{i \mid h}^{i}>\int_{\tilde{h}}^{\bar{h}}-d \ln \lambda_{i \mid h^{\prime}}^{i}$ ), and the argument will still go through.

${ }^{68}$ Arkolakis et al. [2008] use import data from Costa Rica, to show that the number of varieties increased a lot in Costa Rica when trade was liberalized. However, they claim that since the new varieties absorb very low market shares, the gains from variety are not significant. My theory suggests that the results in Arkolakis et al. [2008] are driven by weighting the new varieties with a high aggregate elasticity.
} 
Consequently, the gains from these new varieties would measure up to be small. Ossa [2012] makes a similar argument, but the contribution of this paper is that it generalizes his result. Ossa [2012] fixes expenditure shares on industries to an exogenous number by assuming a cross-industry Cobb-Douglas utility aggregator-which is very special case of the CES aggregator used in this paper.

To dig deeper, I look at what happens underneath the large aggregate gains from trade. As note earlier, the number of varieties in less differentiated product categories slightly drops when trade costs are lowered. This imposes a loss of purchasing power in those categories. In equation (13) if $\sigma_{h}$ is very large then $d \ln \lambda_{i}^{i} \simeq 0$ since there will be barely any foreign entry (in those products) and changes in welfare will be

$$
d \ln \frac{w_{i}}{P_{h}^{i}} \simeq \frac{d \ln M_{i}^{i}}{\eta \sigma_{h}-1}<0
$$

where $d M_{i}^{i}<0$ is the small drop in the number of domestic firms in market $i$ (as a result of lowering trade costs). Even though consumers' purchasing power drops for the least-differentiated products, overall the consumers gain substantially from trade. ${ }^{69}$ A simple depiction of how lowering iceberg trade costs affect purchasing power (i.e. $\frac{w_{i}}{P_{h}^{i}}$ for product $h$ ) along the product differentiation ladder is displayed in figure 13.

To conclude this section, I should note that $\eta$ also affects the gains from trade; the larger $\eta$ the bigger the gains from trade for two reasons. First, as $\eta$ increases the consumers will care less about the loss in domestic varieties after trade-the second term on the RHS in equation (11). Also, a higher $\eta$ would magnify the concentrated foreign entry in highly differentiated products which I discussed earlier. These effects are captured in equation (12) and it is easy to see that as $\eta$ approaches one, the welfare gains from trade approach zero. If $\eta=1$ then if iceberg trade cost are sufficiently large there will be no foreign entry at all. ${ }^{70}$ The intuition is that if there are many firms from one source country in a market, when $\eta=1$ consumers do not care if the next firm which enters the market is also from the same country. Thus, they will buy everything from the cheapest source.

In the next section I fit the model to data and quantify the gains from trade (relative to autarky). My results show that the gains associated with opening to trade from autarky are around \%15 of the real wage in the new model. When I shut down heterogeneity in the degree of differentiation, the gains are only around 5\%. Further, when I also lower $\eta$ to (approximately) one the gains are only $1 \%$ of the real wage. Mathematically, I can show that if one fits the new model to match observed trade shares the underlying

\footnotetext{
${ }^{69}$ In the CES context the model implies gains from trade for all households. In general, the CES framework with identical consumers has no implications about the distribution of the gains from trade (since everyone gains the same). The CES interpretation behind the demand function in equation (1), is one extreme interpretation. The other extreme is the logit interpretation where every consumer draws taste from a GEV distribution and spends all of his income on only one variety. In appendix B I show that according to the logit interpretation, the model implies that when trade is liberalized, consumers of the cheap less differentiated products lose, while the consumers of expensive highly differentiated products gain substantially. It is worth mentioning that if the per-product cost of exporting- $f$-is lowered to zero, the pro-variety effects of trade and consequently the gains will be seen across all product categories.

${ }^{70}$ The reason I define the baseline as a model in which $\eta \rightarrow 1$ (rather than $\eta=1$ ) is to avoid the no-trade knife-edge equilibrium.
} 
gains from trade would be larger than the baseline model with no heterogeneity in demand elasticities. This result is summarized in proposition 2 for a symmetric global economy where all countries are similar. ${ }^{71}$

$$
\text { Autarky } \rightarrow \text { Trade }
$$

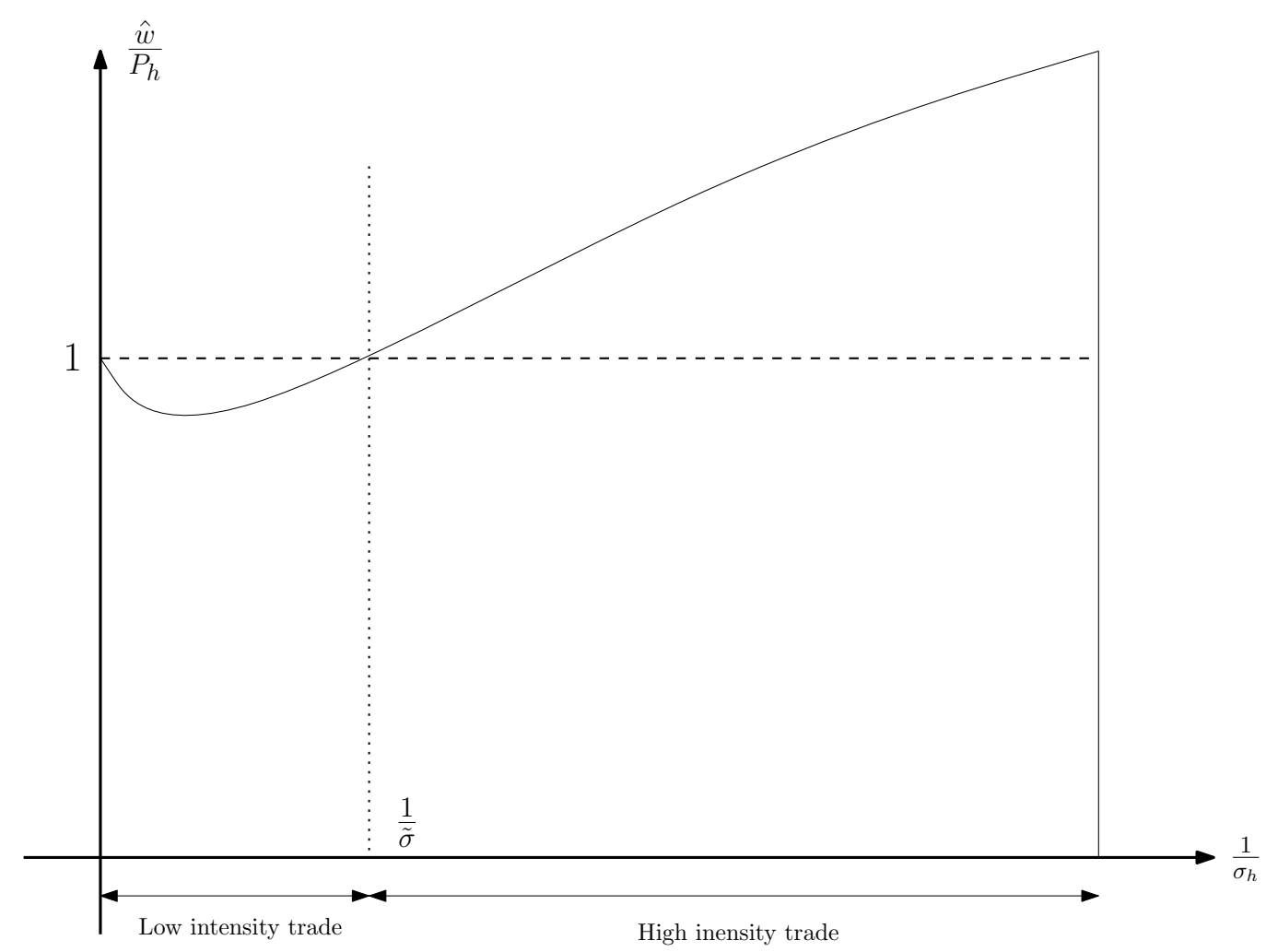

Figure 13: A simple demonstration of changes in purchasing power across different products $\left(\frac{w_{i}}{P_{h}^{i}}\right)$ when a country opens up to trade from autarky.

Proposition 1. Conditional on (the same) observed import shares (i.e. $\sum_{j \neq i} \lambda_{j}^{i}=1-\lambda_{i}^{i}$ ), the underlying gains from trade are larger in the new model relative to the baseline Krugman-Armington model (in the baseline model $\eta \rightarrow 1$ and the cross-country elasticity is constant across all products and equal to the average economy-wide elasticity $\left.\sigma=\int_{h} \sigma_{h} \lambda_{h}^{i} d h, \quad \forall h \in H\right) .^{72}$

Step 1 I first show that the change in the number of domestic varieties, and the share of exports in total spending are sufficient statistics to measure the gains from trade. As in Arkolakis et al. [2012] take the wage in country $i$ as the numeraire, then the change in welfare in country $i$ from a small change in trade costs is given by the change in the aggregate price index

\footnotetext{
${ }^{71}$ Extending proposition 2 to hold for a non-symmetric global economy follows the same intuition provided in the proof of proposition 2. However, it requires looking at many possible cases that arise in equilibrium one by one.

${ }^{72}$ For proposition 2 to hold, the choice of weights when calculating the baseline $\sigma$ do not necessarily need to be expenditure shares in the trade equilibrium (i.e $\lambda_{h}^{i}$ ). They may, as well, be expenditure shares in the autraky equilibrium, i.e. $\sigma=\int_{h} \sigma_{h} \lambda_{h}^{i, A} d h, \forall h$
} 


$$
d \ln \frac{w_{i}}{P^{i}}=-\frac{1}{1-\epsilon} d \ln \left\{\int_{h \in H}\left(P_{h}^{i}\right)^{1-\epsilon} d h\right\}
$$

Given that $d\left(P_{h}^{i}\right)^{1-\epsilon}=(1-\epsilon) d \ln P_{h}^{i}\left(P_{h}^{i}\right)^{1-\epsilon}$, the above equation can be re-written as

$$
d \ln \frac{w_{i}}{P^{i}}=-\int_{h} d \ln P_{h}^{i}\left(\frac{P_{h}^{i}}{P^{i}}\right)^{1-\epsilon}
$$

where

$$
d \ln P_{h}^{i}=\sum_{j} d \ln P_{j h}^{i}\left(\frac{P_{j h}^{i}}{P_{h}^{i}}\right)^{1-\sigma_{h}}
$$

and

$$
P_{j h}^{i}=\tau_{j i} w_{i}\left(\mu_{j} M_{j h}^{i}\right)^{\frac{1}{1-\eta \sigma_{h}}}
$$

Plugging (21) and (20) into equation (19) we will have

$$
d \ln \frac{w_{i}}{P^{i}}=\sum_{j} d \ln w_{j} \tau_{j i} \lambda_{j h}^{i}+\int_{h} \sum_{j} \frac{1}{1-\eta \sigma_{h}} d \ln M_{j h}^{i} \lambda_{j h}^{i}
$$

where the above equation follows from the fact that $\lambda_{j h}^{i}=\lambda_{j \mid h}^{i} \lambda_{h}^{i}=\left(\frac{P_{j h}^{i}}{P_{h}^{i}}\right)^{1-\sigma_{h}}\left(\frac{P_{h}^{i}}{P^{i}}\right)^{1-\epsilon}$. From the lowertire gravity described by equation (8), we have

$$
d \ln \lambda_{j \mid h}^{i}-d \ln \lambda_{i \mid h}^{i}=\left(1-\sigma_{h}\right)\left[d \ln w_{j}+d \ln \tau_{j i}\right]+\frac{1-\sigma_{h}}{1-\eta \sigma_{h}}\left[\ln M_{j h}^{i}-\ln M_{i h}^{i}\right]
$$

Plugging (23) into equation (22) and we will have

$d \ln \frac{w_{i}}{P^{i}}=-\left\{\int_{h} \sum_{j} \frac{\left(d \ln \lambda_{j \mid h}^{i}-d \ln \lambda_{i \mid h}^{i}\right)}{1-\sigma_{h}} \lambda_{j \mid h}^{i} \lambda_{h}^{i}+\int_{h} \frac{1}{1-\eta \sigma_{h}} d \ln M_{i}^{i} \lambda_{h}^{i} d h\right\}=\int_{h} \frac{d \ln \lambda_{i \mid h}^{i} \lambda_{h}^{i}}{1-\sigma_{h}} d h+\int_{h} \frac{1}{\eta \sigma_{h}-1} d \ln M_{i}^{i} \lambda_{h}^{i} d h$ given that $\sum_{j} \lambda_{j \mid h}^{i}=1$ the above equation simplifies to

$$
d \ln \frac{w^{i}}{P^{i}}=\int_{h} \frac{-d \ln \lambda_{i \mid h}^{i} \lambda_{h}^{i}}{\sigma_{h}-1} d h+\left[\int_{h} \frac{1}{\eta \sigma_{h}-1} \lambda_{h}^{i} d h\right] d \ln M_{i}^{i}
$$

and for every product $h$ the change in purchasing power will be 


$$
d \ln \frac{w_{i}}{P_{h}^{i}}=\frac{-d \ln \lambda_{i \mid h}^{i}}{\sigma_{h}-1}+\frac{d \ln M_{i}^{i}}{\eta \sigma_{h}-1}
$$

Step 2 In this step I will first show that gains from trade in my model are larger than the baseline in a symmetric economy where wages are equalized. The fact that gains from trade are larger in my model follows from the same argument presented in the main text. Consider the change in welfare equation

$$
d \ln \frac{w^{i}}{P^{i}}=\int_{h} \frac{-d \ln \lambda_{i \mid h}^{i} \lambda_{h}^{i}}{\sigma_{h}-1} d h+\left[\int_{h} \frac{1}{\eta \sigma_{h}-1} \lambda_{h}^{i} d h\right] d \ln M_{i}^{i}
$$

From the entry condition we have

$$
\left(\frac{1}{M_{i}^{i}} \int_{h \in H} \frac{\lambda_{i \mid h}^{i} \lambda_{h}^{i}}{\sigma_{h}-1} d h\right) L_{i}=f^{e}
$$

Then

$$
d \ln M_{i}^{i}=d \ln \int_{h \in H} \frac{\lambda_{i h}^{i}}{\sigma_{h}-1} d h \Longrightarrow d \ln M_{i}^{i}=\left\{\frac{\int_{h \in H} \frac{d \lambda_{i h}^{i}}{\sigma_{h}-1} d h}{\int_{h \in H} \frac{\lambda_{i h}^{i}}{\sigma_{h}-1} d h}\right\}
$$

The above inequality follows from writing the FE condition as $\frac{M_{i}^{i} f^{e}}{L_{i}}=\int_{h \in H} \frac{d \lambda_{i h}^{i}}{\sigma_{h}-1} d h$, which in turn implies

$$
d \ln \frac{w^{i}}{P^{i}}=\int_{h} \frac{-d \ln \lambda_{i \mid h}^{i} \lambda_{h}^{i}}{\sigma_{h}-1} d h-\left[\int_{h} \frac{1}{\eta \sigma_{h}-1} \lambda_{h}^{i} d h\right] d \ln \int_{h \in H} \frac{\lambda_{i h}^{i}}{\sigma_{h}-1} d h
$$

In autarky, and close to autarky a good approximation will be $\lambda_{i \mid h}^{i} \approx 1$ which allows me to write the above equation as

$$
d \ln \frac{w^{i}}{P^{i}}=\int_{h} \frac{-d \ln \lambda_{i \mid h}^{i} \lambda_{h}^{i}}{\sigma_{h}-1} d h\left\{1-\left[\frac{\int_{h} \frac{1}{\eta \sigma_{h}-1} \lambda_{h}^{i} d h}{\int_{h} \frac{1}{\sigma_{h}-1} \lambda_{h}^{i} d h}\right]\right\}
$$

to prove the proposition I need to show that if parameters in the two models where somehow that import penetration was the same for both models (i.e. $\int_{h}-d \ln \lambda_{i \mid h}^{i} \lambda_{h}^{i} d h=\left(\int_{h}-d \ln \lambda_{i \mid h}^{i} \lambda_{h}^{i} d h\right)^{\text {baseline }}$ ), the new model would generates more gains. Note that in the symmetric equilibrium $p_{i h}^{i}>p_{j h}^{i} \forall h$ and hence domestic firms have competitive advantage in the less differentiated products. In the baseline model domestic firms do not have the same level of competitiveness in all products. Hence, it follows that (i) $\frac{d \ln \lambda_{i \mid h}^{i}}{\left(d \ln \lambda_{i \mid h}^{i}\right)^{\text {baseline }}}$ is increasing in $\frac{1}{\sigma_{h}-1}$, and (ii) $\frac{\lambda_{\mathbf{h}}^{\mathbf{i}}}{\left(\lambda_{h}^{i}\right)^{\text {baseline }}}$ is non-decreasing in $\frac{1}{\sigma_{h}-1}$. (i) and (ii) together imply that $\int_{h} \frac{-d \ln \lambda_{i \mid h}^{i} \lambda_{h}^{i}}{\sigma_{h}-1} d h>\left(\int_{h} \frac{-d \ln \lambda_{i \mid h}^{i} \lambda_{h}^{i}}{\sigma_{h}-1} d h\right)^{\text {baseline }}$. Moreover the term in the parenthesis on the RHS goes to zero as $\eta \rightarrow 1$ which is another channel which pushes down the gains in the baseline model. 


\section{A.2 Proof of Proposition 1}

Consider the labor market clearing condition

$$
\alpha L^{i}=\underbrace{\left(M_{i}^{i} f^{e}+\int_{h \in H} q_{i h}^{i} M_{i}^{i} \nu_{i}^{i}(h) d h\right)}_{\text {Home sales }}+\underbrace{\left(\sum_{k \neq i} M_{i}^{k} f^{e}+\int_{h \in H}\left(\tau_{i k} q_{i h}^{k}+f\right) M_{i}^{k} \nu_{i}^{k}(h) d h\right)}_{\text {Exports }}
$$

The assumption is that $\left\{\tau_{i k}\right\}_{k \in C}=\left\{\tau_{j k}\right\}_{k \in C}, L_{i}=L_{j}$, and $\mu_{i}>\mu_{j}$. I will prove the proposition by contradiction; suppose $w_{i} \leq w_{j}$ then

$$
\left\{\begin{array}{l}
\tau_{i k} q_{i h}^{k}>\tau_{j k} q_{j h}^{k} \\
M_{i}^{k} \nu_{i}^{k}(h)>M_{j}^{k} \nu_{i}^{k}(h) \quad, \quad \forall h \in H ; \forall k \neq j, i \\
M_{i}^{k}>M_{j}^{k}
\end{array}\right.
$$

which implies that there is more demand for labor in country $i$ while supply of labor in both countries is the same which is a contradiction. Therefore, $w_{i}>w_{j}$. Moreover, there exists some $\sigma^{*}$ such that for $\sigma_{h}>\sigma^{*}$ then $\mu_{j} w_{j}^{1-\sigma_{h}}>\mu_{i} w_{i}^{1-\sigma_{h}}$-otherwise there the (LMC) will be contradicted because there would be more demand for labor in $i$ while the supply of labor is the same in both countries.

An increase in $w_{i}$ affects home sales more than exports because (i) $\nu_{i}^{i}(h)=1>\nu_{i}^{k}(h) \forall k \neq i$ and (ii) $\frac{q_{i h}^{i}}{q_{i h}^{k}}$ is decreasing in $h$ for all $k \neq i$ because firms charge lower prices at home than in foreign markets. Hence, in equilibrium for demand to be equalized for labor between $i$ and $j$ we will have

$$
\left\{\begin{array}{l}
w_{i}>w_{j} \\
M_{i}^{i} f^{e}+\int_{h \in H_{i}^{i}} q_{i h}^{i} M_{i}^{i} d h<M_{j}^{j} f^{e}+\int_{h \in H} q_{j h}^{j} M_{j}^{j} d h \\
\sum_{k \neq i} M_{i}^{k} f^{e}+\int_{h \in H}\left(\tau_{i k} q_{i h}^{k}+f\right) M_{i}^{k} \nu_{i}^{k}(h) d h>\sum_{k \neq i} M_{j}^{k} f^{e}+\int_{h \in H}\left(\tau_{j k} q_{j h}^{k}+f\right) M_{j}^{k} \nu_{j}^{k}(h) d h
\end{array}\right.
$$

Given that labor requirement for production is the same in both $i$ and $j$ (it is the same for all countries by assumption). The free entry (FE) condition and the second inequality above imply

$$
\int_{h \in H} \frac{\sigma_{h}}{\sigma_{h}-1} M_{j}^{j} q_{j h}^{j} d h>\int_{h \in H} \frac{\sigma_{h}}{\sigma_{h}-1} M_{i}^{i} q_{i h}^{i} d h
$$

Since $L_{i}=L_{j}$, the above inequality can be written as 


$$
\lambda_{j}^{j}=\frac{\int_{h \in H} \frac{\sigma_{h}}{\sigma_{h}-1} w_{j} M_{j}^{j} q_{j h}^{j} d h}{w_{j} L_{j}}>\frac{\int_{h \in H} \frac{\sigma_{h}}{\sigma_{h}-1} w_{i} M_{i}^{i} q_{i h}^{i} d h}{w_{i} L_{i}}=\lambda_{i}^{i}
$$

Form the balance of payments equation, the above conditions implies that country $i$ exports a higher share of the value added in its country, relative to $j$. The fact that country $i$ exports more differentiated (and expensive) products follows from the argument in the text.

\section{B Market Size and the Price of a Country's Consumption}

A salient future of the upper tier gravity (equation (9)) is that love of variety is stronger in more differentiated product categories. Therefore, if the number of varieties in a country rises, spending will be redirected towards more differentiated products, so consumers can benefit from the extra variety. For example, in country $i$ spending on product $h$ relative to $h^{\prime}$ would be

$$
\frac{\lambda_{h}^{i}}{\lambda_{h^{\prime}}^{i}}=\frac{\left[\frac{\eta \sigma_{h}}{\eta \sigma_{h}-1}\right]^{(1-\epsilon)}\left\{\sum_{k \in C} \mu_{k}\left(M_{k h}^{i}\right)^{\frac{\sigma_{h}-1}{\eta \sigma_{h}-1}}\left(w_{k} \tau_{k i}\right)^{\left(1-\sigma_{h}\right)}\right\}^{\frac{\epsilon-1}{\sigma h^{-1}}}}{\left[\frac{\eta \sigma_{h^{\prime}}}{\eta \sigma_{h^{\prime}}-1}\right]^{(1-\epsilon)}\left\{\sum_{k^{\prime} \in C} \mu_{k^{\prime}}\left(M_{k^{\prime} h^{\prime}}^{i}\right)^{\frac{\sigma_{h^{\prime}}-1}{\eta \sigma_{h^{\prime}}-1}}\left(w_{k^{\prime}} \tau_{k^{\prime}}\right)^{\left(1-\sigma_{h^{\prime}}\right)}\right\}^{\frac{\epsilon-1}{\sigma_{h^{\prime}-1}}}}
$$

Suppose the total number of varieties in market $i$ increase by a factor $t>1$ (i.e. $\left(\sum_{j \in C} M_{j h}^{i}\right)^{\prime}=$ $\left.t \sum_{j \in C} M_{j h}^{i}, \forall h\right)$ then

$$
\left(\frac{\lambda_{h}^{i}}{\lambda_{h^{\prime}}^{i}}\right)^{\prime}=t^{\frac{\epsilon-1}{\eta}\left(\frac{\sigma_{h^{\prime}}-\sigma_{h}}{\left(\sigma_{h}-1\right)\left(\sigma_{h^{\prime}}-1\right)}\right)} \frac{\lambda_{h}^{i}}{\lambda_{h^{\prime}}^{i}}
$$

if $\sigma_{h}<\sigma_{h^{\prime}}$ if follows that $\left(\frac{\lambda_{h}^{i}}{\lambda_{h^{\prime}}^{i}}\right)^{\prime}>\frac{\lambda_{h}^{i}}{\lambda_{h^{\prime}}^{i}}$. Putting it differently; if the number of supplied varieties in country $i$ increases, then country $i$ will spend relatively more on highly differentiated products. ${ }^{73}$

\section{Isomorphism between CES and Nested logit}

I will describe the nested logit demand first. Each consumer in country $i$ buys only one variety of the differentiated good, and spends all of his income on that particular variety. If consumer $n$ consumes variety $f j$ of product $h$ then he gets utility $V_{\omega j h}$

\footnotetext{
${ }^{73}$ This factor in equilibrium prompts consumers in high-wage countries to spend relatively more on expensive differentiated products; a novel result that comes without the need to assume some type of non-homotheticity in demand. However, Unlike nonhomothetic preferences, this channel does not disentangle the effect of population from wage on the patterns of spending.
} 


$$
V_{\omega j h}^{n}=\ln \left(\frac{w_{i}}{p_{\omega j h}^{i}}\right)+\ln \mu_{j}+\nu_{\omega j h}^{n}
$$

Where $p_{\omega j h}^{i}$ is the price of variety $\omega j h$ in country $i$, and $\frac{w_{i}}{p_{\omega j h}^{i}}$ is the amount of the variety $\omega j h$, consumer $n$ in country $i$ with income $w_{i}$ can purchase. Every household is endowed with one units of effective labor so that income is equal to wage $w_{i}$ in country $i . \mu_{j}$ is the common value all households attach to varieties produced in country $j$. Consumer $n$ also has a personal evaluation of each variety which I call "taste", and is captured by the term $\nu_{\omega j h}^{n}$. I assume that every consumer independently and separately draws (a continuum of) taste shocks from the following general extreme value (GEV) distribution

$$
H_{\nu}(\nu)=\frac{1}{\epsilon-1} \exp \left[\int_{h \in H}\left[\sum_{j \in C_{h}}\left(\sum_{\omega \in F_{j h}}\left(1-\eta \sigma_{h}\right) \nu_{\omega j h}\right)^{\frac{1}{\eta \sigma_{h}-1}} \sigma_{h}\right]^{\frac{\epsilon-1}{\sigma_{h-1}}} d h\right]
$$

The consumer then ranks all the varieties, chooses only one (utility maximizing) variety, and allocates all her income to that variety. $\sigma_{h}$ is the correlation between taste of consumers for country-level composite varieties of product $h . \eta \sigma_{h}$ is the correlation of consumers' tastes for firm-level varieties of product category $h$ produced in the same country. $\epsilon$ is the correlation between consumers' taste for different product categories in $H$. As Anderson, De Palma, and Thisse [1992] show, the nested-logit demand structure (described above) is equivalent to a nested CES demand structure. The aggregate demand for variety $f j h$ in country $i$ resembles that of a nested CES demand and is given by

$$
q_{\omega j h}^{i}=\left(\frac{p_{f j h}^{i}}{P_{j h}^{i}}\right)^{1-\eta \sigma_{h}}\left(\frac{P_{j h}^{i}}{P_{h}^{i}}\right)^{-\sigma_{h}}\left(\frac{P_{h}^{i}}{P^{i}}\right)^{-\epsilon} \frac{w^{i} L^{i}}{p_{\omega j h}}
$$

where $q_{\omega j h}^{i}$ is the "quantity" demanded of variety $\omega j h$ in country $i$. The above demand equation is a simple reformulation of the demand equation derived by McFadden et al. [1978], and the (quality adjusted) price indexes are given by

$$
\begin{aligned}
P_{j h}^{i} & =\left\{\sum_{\omega^{\prime} \in F_{j h}^{i}}\left(p_{\omega^{\prime} j h}^{i}\right)^{1-\eta \sigma_{h}}\right\}^{\frac{1}{1-\eta \sigma_{h}}} \\
P_{h}^{i} & =\left\{\sum_{k \in C_{h}^{i}} \mu_{k}\left(P_{k h}^{i}\right)^{1-\sigma_{h}}\right\}^{\frac{1}{1-\sigma_{h}}} \\
P^{i} & =\left\{\int_{h \in H}\left(P_{h}^{i}\right)^{1-\epsilon} d h\right\}^{\frac{1}{1-\epsilon}}
\end{aligned}
$$


McFadden et al. [1978] show the expected utility of an average consumer

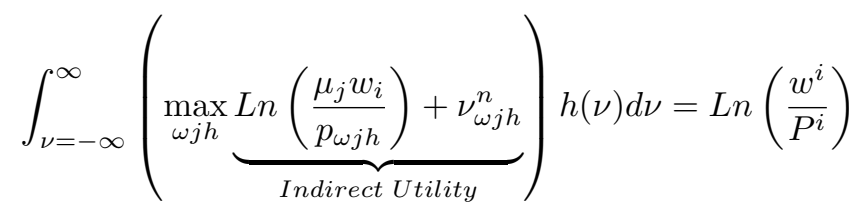

However the realized welfare for consumers buying product $h$ in country $i$ will be $L n\left(\frac{w^{i}}{P_{h}^{i}}\right)$. This leads to asymmetric gains from trade across consumers in my model.

\section{Empirical Appendix}

\section{D.1 Estimated Elasticities versus Estimates in the Literature}

Table 7 compares the average elasticity estimates to the existing studies. The closest study to mine (in terms of the patterns of product substitution) is Feenstra, Obstfeld, and Russ [2012]. They estimate a microelasticity between foreign varieties in each SIC-2 sector, and a macro-elasticity between the composite imported good and the composite domestic good. They estimate the cross-exporter micro elasticity to be around 3.1 times higher than the macro elasticity. The ratio is somehow close to the relative scale of the within-country to cross-country elasticity in this paper, which is 2.15 on average.

It is not surprising that my estimates are the closest to Feenstra et al. [2012] - the estimated elasticities are quite lower than the remaining studies. Apart from the fact that their estimation methods differ substantially from this paper, the difference is due to the following. In these studies the mass of firms (varieties) from each country is exogenously assumed to be one-or the within-country elasticity is assumed to be infinity. The approach taken here is that the number of firms is an endogenous variable and I use data to approximate it when estimating the trade elasticities. The take-away message is that not controlling for hidden varieties (or the extensive margin of trade) could result in over-estimating trade elasticities. To see this, suppose we exogenously force $\gamma_{h}$ to be infinity so that $M_{j h}=1 \forall j \in C$ and $\forall h \in H$. Then, instead of (15), I will be estimating the following micro-gravity equation

$$
\ln X_{j h t}=-\left(\sigma_{h}-1\right) \ln p_{j h t}+\psi_{h, t}+\ln \mu_{j h t}
$$

A country with lower prices within an HS-10 product category will most likely have more exporting firms (or varieties). Suppressing the effect of varieties means we are matching trade flows with only price variations. As a result, the elasticity of trade values with respect to prices will be over-estimated. ${ }^{74}$

\footnotetext{
${ }^{74}$ Helpman et al. [2008] make a similar argument, but implement their argument differently. Their estimates also indicate a upward
} 
Even though I control for the extensive margin of trade (or hidden varieties), however, like most of the existing studies I do not control for selection of countries into HS-10 product codes. Helpman et al. [2008] find that the selection bias is small compared to the extensive margin bias. Moreover, the selection bias problem arises because I might not be controlling for all the variables influencing the import flows. There is no selection problem if every variable influencing selection is controlled in the outcome equation (15) (Achen [1986], pages 78-79). It is very likely that other variables apart from price and the mass of firms affect selection. To avoid selection bias I either have to add controls or make sure my instruments are not correlated with the omitted control variables. ${ }^{75}$

\section{D.2 Additional Patterns}

Pattern 1: The US import basket is more (horizontally) diversified for HS-10 products that exhibit high degrees of differentiation

A more evident result arising from the estimation is the strong positive association between product differentiation and the number of imported varieties. My theory indicates that the gains from variety are mostly due to highly differentiated products that are subject to low elasticities of substitution. To assess my claim, I plot the number of country-specific varieties per dollar imported in each HS-10 product code against the estimated degree of differentiation in that HS-10 code (i.e $\frac{1}{\sigma_{h}}$ ). As the results presented in figure 14 suggest, for every dollar the US imports the imported bundle contains more country-specific varieties for HS-10 products that are more differentiated and more f.o.b expensive. Given that the gains from variety (post trade liberalization) are proportional to $\frac{1}{\sigma_{h}}$, figure 14 suggests that the gains from removing trade barriers would be larger in a model where differences in the degree of differentiation are taken into account.

Pattern 2: US Employment is insulated from low-wage import penetration in highly differentiated industries

To examine my claim I first run the following regression with NAICS industry fixed effects ${ }^{76}$

$$
\ln \text { employment }_{S, t}=\underset{(.006)}{.0513} \ln L W P_{S, t}+\underset{(.010)}{0.046} \ln L W P_{S, t} * \ln \frac{1}{\hat{\sigma}_{S}}+\underset{(.064)}{2.78}
$$

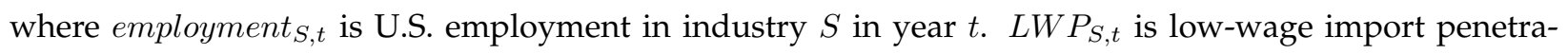
tion index calculate by Bernard et al. [2006a] for industry $S$ in year $t$, and $\ln \frac{1}{\hat{\sigma}_{S}}$ is the average degree of

bias in traditional elasticity estimates.

${ }^{75}$ This paper is in the process of development. I plan to rerun the estimation with additional controls and examine how robust the results are to these variations.

${ }^{76}$ NAICS stands for North American Industry Classification System. The reason I use the NAICS classification is that employment is reported according to the NAICS rather than the SITC classification. 


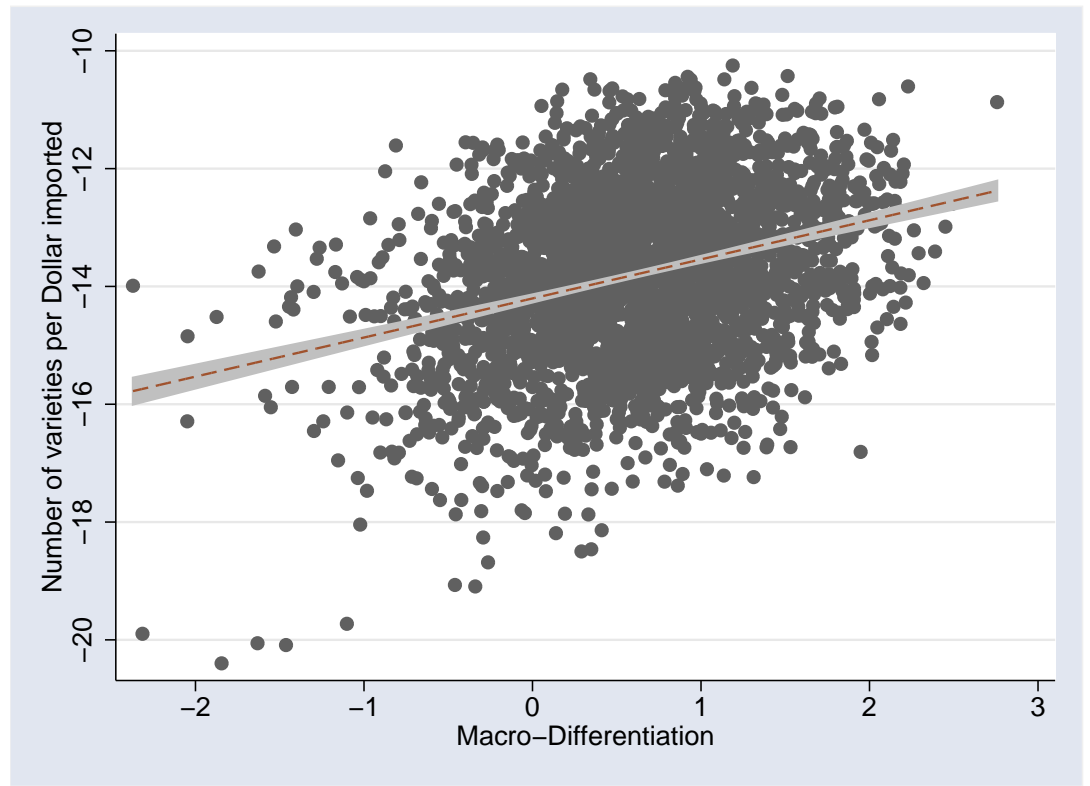

Figure 14: The positive relation between product differentiation (in logs) and the number of country-specific varieties per dollar imported - in an HS-10 product code. All values are reported in logs. Each point in the graph corresponds to an HS-10 product code. The shaded area indicates 95\% confidence intervals for the best-fitted linear relationship. Macro-differentiation for HS-10 code $h$ is measured as $\frac{1}{\sigma_{h}}$.

differentiation in industry $S$-based on the estimated elasticities. All the coefficients are significant at the $99 \%$ confidence level and the $R^{2}$ is 0.120 for 240 NAICS industries-the robust standard errors are given in the parenthesis. The above regression indicates that the effect of low-wage import penetration on US (industry-level) employment diminishes significantly with the degree of differentiation in the industry. 


\section{E Additional Tables and Figures}

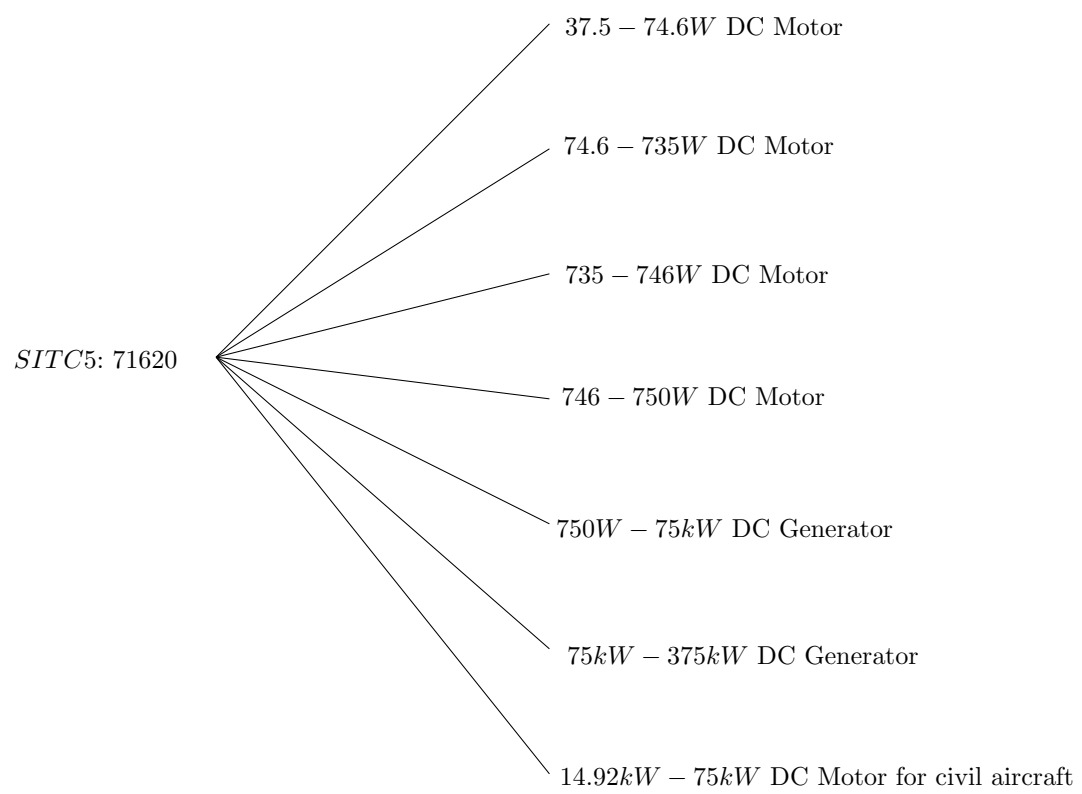

Figure 15: An example of and SITC-5 industry in the US import data (compiled by Feenstra et al. [2002]). The figure only displays a representative group of HS-10 codes that belong to SITC-5 industry 71620.

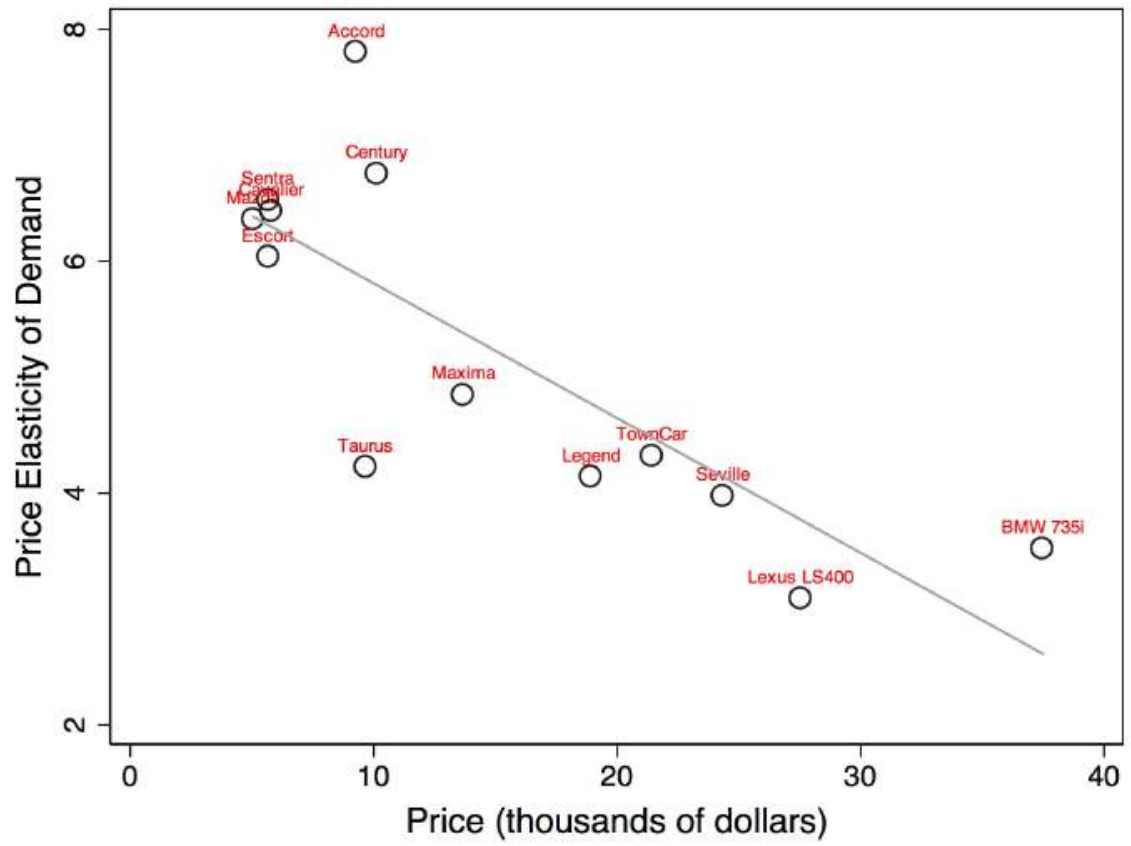

Figure 16: Price elasticity of demand for various car products in the U.S. (source: Berry, Levinsohn, and Pakes [1995]). 


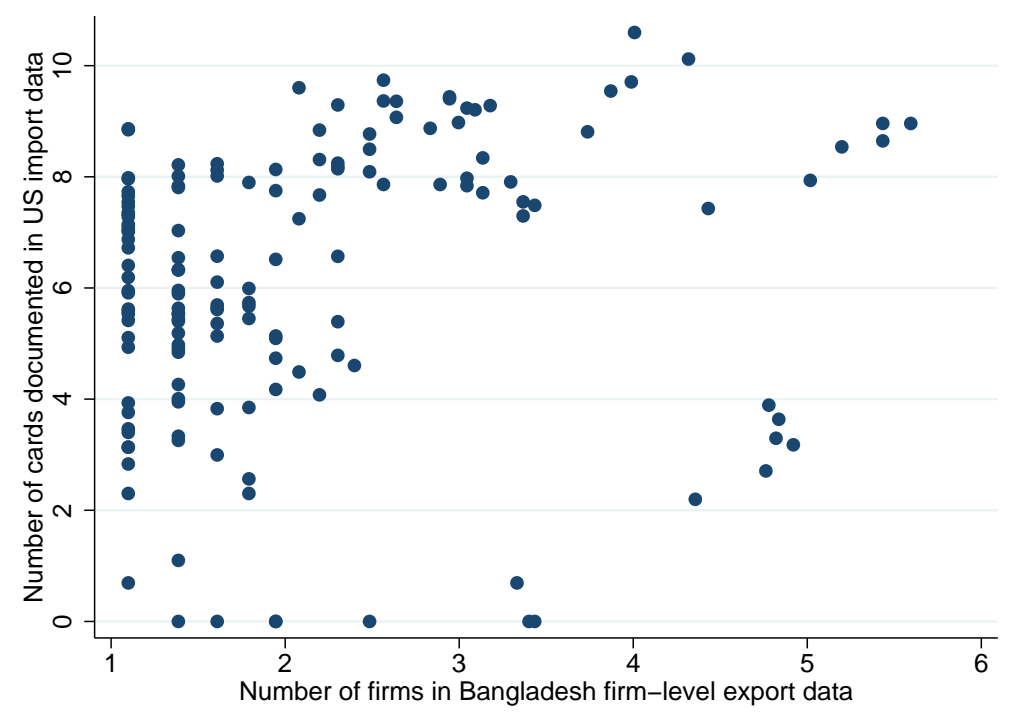

Figure 17: Scatter plot of the number of cards reported in the public US import data and the number of exporting firms from the Bangladesh firm-level export data. The correlation between the cards and the number of firms is 0.415 and is significant at the 99\% confidence level. For six of the HS-10 products, the Bangladesh export data reports multiple exporters while the US import data reports only one invoice (export card). This can be due to the fact that HS-8 codes in the Bangladesh export data do not map one-to-one into HS-8 codes in the US import data.
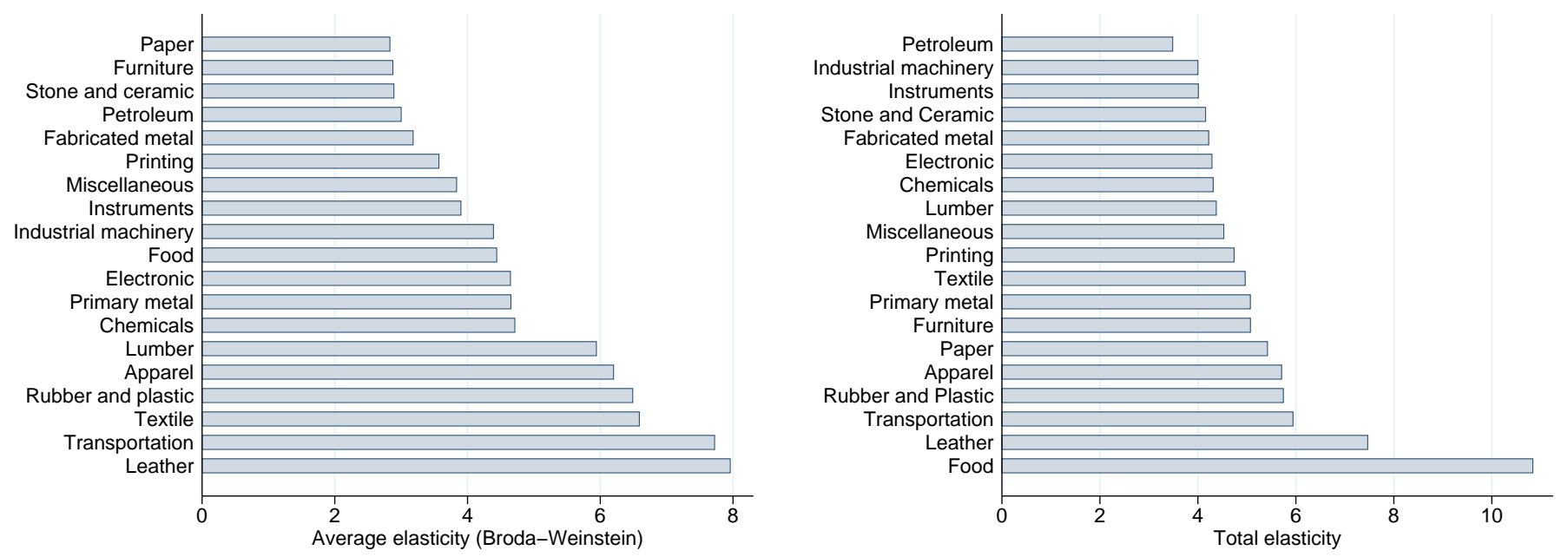

Figure 18: Average estimated elasticity by SIC-2 sector from Broda and Weinstein [2006] versus total elasticity $\left(\gamma_{h}+\sigma_{h}\right)$ as estimated in the present paper. 


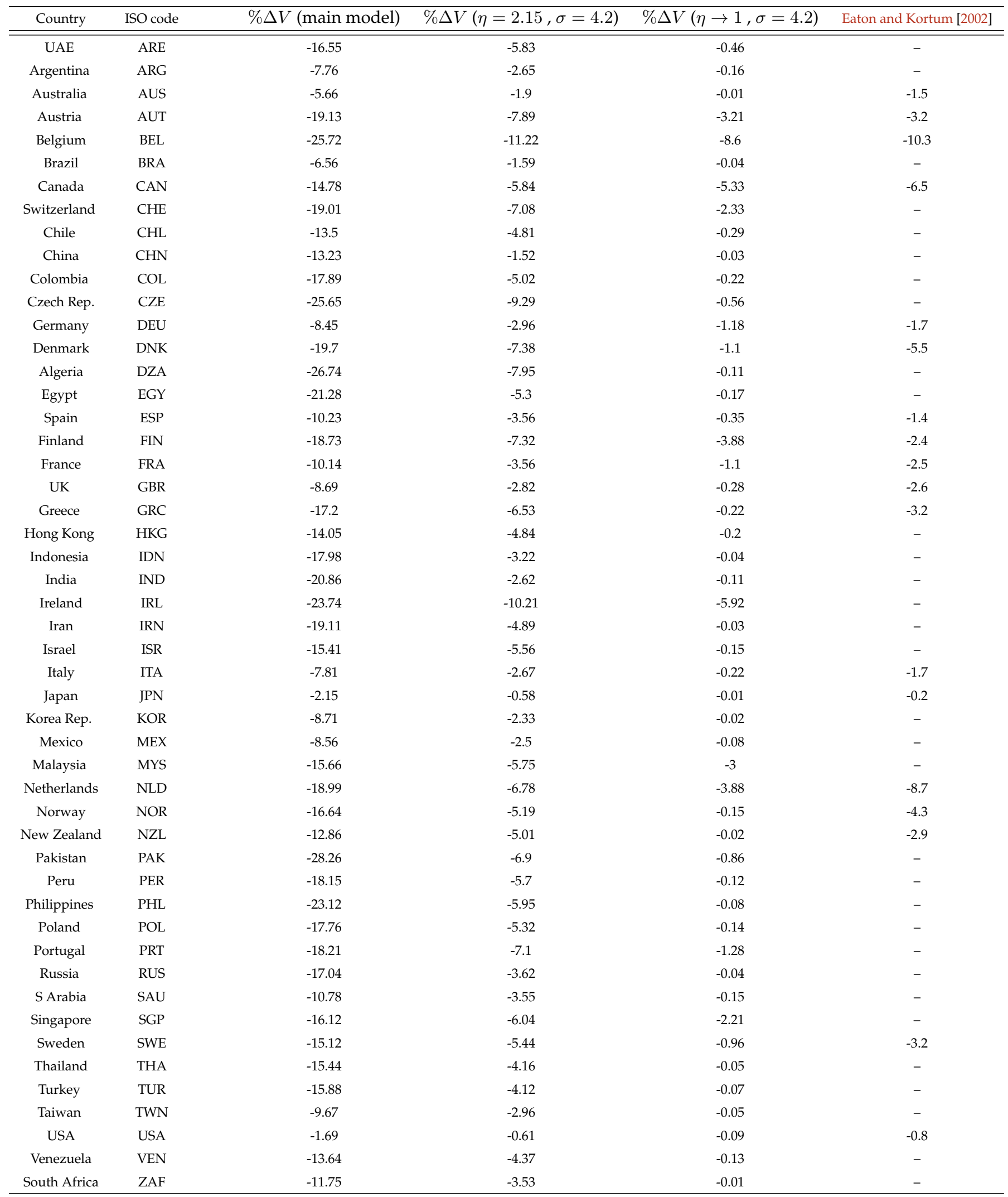

Table 6: The gains from opening to trade from autarky under different specifications. I am comparing changes in real wage when switching from the calibrated trade equilibrium to the counter-factual autarky equilibrium. Notice that $V=Q_{N}^{1-\alpha} U_{M}^{\alpha}$, and hence $d \ln V^{i}=\alpha d \ln U_{M}^{i}=\alpha d \ln \frac{w_{i}}{P^{i}}$. 


\begin{tabular}{|c|c|c|c|c|}
\hline Study & Setting & Structure & Micro-elasticity & Macro-elasticity \\
\hline \multirow[t]{2}{*}{ Feenstra et al. [2012] } & Armington / Melitz & Micro: across foreign var. & 3.1 & 1 \\
\hline & & $\begin{array}{l}\text { Macro: between comp. domestic and } \\
\text { comp. foreign var. }\end{array}$ & & \\
\hline Simonovska and Waugh [2011] & Ricardian & $\begin{array}{l}\text { Trade elasticity: Pareto shape } \\
\text { parameter } \theta\end{array}$ & $3.79-5.46$ & - \\
\hline Broda and Weinstein [2006] & Armington & Different elasticity for each HS-10 product & 12.6 & - \\
\hline Imbs and Méjean [2010] & Armington / Melitz & different elasticity for each SIC-3 & 6.7 & - \\
\hline My estimates & Krugman & $\begin{array}{l}\text { Micro: across firms within country } \\
\text { Macro: between countries }\end{array}$ & 3.334 & 1.675 \\
\hline
\end{tabular}

Table 7: Comparison of estimated trade elasticities to existing estimates in the literature. For studies that estimate elasticities at disaggregated product levels, the table reports the average estimated elasticity.

\begin{tabular}{cccc}
\hline Afghanistan & Chad & Haiti & Niger \\
Albania & China & India & Pakistan \\
Angola & Congo & Kenya & Rwanda \\
Armenia & Equatorial Guinea & Lao PDR & Samoa \\
Azerbaijan & Ethiopia & Madagascar & Sierra Leone \\
Bangladesh & Gambia & Malawi & Sri Lanka \\
Benin & Georgia & Mali & Sudan \\
Burkina Faso & Ghana & Mauritania & Togo \\
Burundi & Guinea & Moldova & Uganda \\
Cambodia & Guinea-Bissau & Mozambique & Vietnam \\
Central African Republic & Guyana & Nepal & Yemen \\
\hline
\end{tabular}

Table 8: Notes: The table provides the list of low-wage countries used in the paper. Low-wage countries are defined as countries with less than 5\% of US per capita GDP. (source: Bernard et al. [2006a]) 


\begin{tabular}{|c|c|c|c|c|c|c|c|c|c|c|}
\hline \multicolumn{2}{|c|}{ HS } & \multicolumn{2}{|c|}{ SITC (rev.3) } & \multicolumn{7}{|c|}{ Description } \\
\hline \multicolumn{2}{|c|}{6302322060} & \multicolumn{2}{|c|}{58439} & \multicolumn{7}{|c|}{ BED LINEN NESOI OF MANMADE FIBER } \\
\hline year & \multicolumn{2}{|c|}{ Country } & \multicolumn{2}{|c|}{ Entry City } & \multicolumn{3}{|c|}{ Unloading city } & Unit 1 & Unit 2 & Cards \\
\hline \multirow[t]{5}{*}{90} & \multicolumn{2}{|c|}{ CHINA M } & \multicolumn{2}{|c|}{ CHICAGO } & \multicolumn{3}{|c|}{ LOS ANG } & $\mathrm{NO}$ & KG & 1 \\
\hline & & Value & \multicolumn{2}{|c|}{ Quantity 1} & & uantity 2 & \multicolumn{2}{|c|}{ Charge } & Duty & \\
\hline & \multicolumn{2}{|r|}{3634} & \multicolumn{2}{|c|}{920} & & 417 & \multicolumn{2}{|c|}{198} & 472 & \\
\hline & \multicolumn{2}{|c|}{ Air value } & \multicolumn{3}{|c|}{ Vessel value } & \multicolumn{2}{|c|}{ Air weight } & \multicolumn{2}{|c|}{ Vessel weight } & \\
\hline & \multicolumn{2}{|r|}{0} & \multicolumn{2}{|c|}{3634} & & \multicolumn{2}{|c|}{0} & \multicolumn{2}{|c|}{483} & \\
\hline
\end{tabular}

Table 9: Layout of the US import data compiled bySchott [2008]

\begin{tabular}{cccccc}
\hline & $\begin{array}{c}\text { Industry } \\
\text { (SITC-5) }\end{array}$ & $\begin{array}{c}\text { Products } \\
(\text { HS-10) }\end{array}$ & $\begin{array}{c}\text { Average } \\
\text { GDP }\end{array}$ & $\begin{array}{c}\text { Skill } \\
\text { Intensity }\end{array}$ & $\begin{array}{c}\text { Capital } \\
\text { intensity }\end{array}$ \\
Sector (SIC-2) & $(1)$ & $(2)$ & $(3)$ & $(4)$ & $(5)$ \\
\hline 20 Food & 8 & 37 & 16,881 & 0.39 & 81.4 \\
22 Textile & 85 & 1,642 & 13,304 & 0.15 & 48.7 \\
23 Apparel & 68 & 2,560 & 7120 & 0.18 & 11.2 \\
24 Lumber & 20 & 262 & 12,634 & 0.20 & 36.3 \\
25 Furniture & 5 & 72 & 11,849 & 0.25 & 22.1 \\
26 Paper & 38 & 216 & 19,766 & 0.30 & 126.0 \\
27 Printing & 16 & 55 & 17,574 & 0.87 & 33.2 \\
28 Chemicals & 231 & 2,588 & 20,094 & 0.75 & 166.1 \\
29 Petroleum & 7 & 21 & 10,952 & 0.51 & 509.1 \\
30 Rubber and plastic & 45 & 515 & 14,119 & 0.29 & 48.5 \\
31 Leather & 17 & 403 & 6088 & 0.19 & 18.6 \\
32 Stone and ceramic & 57 & 357 & 15,133 & 0.29 & 78.6 \\
33 Primary metal & 98 & 1,372 & 16,864 & 0.29 & 157.1 \\
34 Fabricate metal & 78 & 599 & 17,364 & 0.35 & 53.0 \\
35 Industrial machinery & 169 & 1,632 & 21,035 & 0.57 & 63.1 \\
36 Electronics & 100 & 1,325 & 15,551 & 0.56 & 57.7 \\
37 Transportation & 43 & 372 & 23,096 & 0.52 & 68.6 \\
38 Instruments & 60 & 715 & 21,843 & 0.96 & 45.3 \\
39 Miscellaneous & 76 & 375 & 10,804 & 0.38 & 29.7 \\
\hline
\end{tabular}

Table 10: The table provides summary statistics for SIC-2 (1987 revision) sectors. Column 1 reports the number of SITC-5 (revision 2) industries. Column 2 reports the total number of HS-10 products. Column 3 reports the weighted average of exporter per capita GDP. Columns 4 and 5 report skill (ratio of production to non-production workers) and capital intensity. (Source: Khandelwal [2010]) 


\begin{tabular}{|c|c|c|c|c|c|c|c|c|c|c|c|}
\hline Country & $\tilde{\mu}_{i}$ & $w_{i}$ & Country & $\tilde{\mu_{i}}$ & $w_{i}$ & Country & $\tilde{\mu}_{i}$ & $w_{i}$ & Country & $\tilde{\mu_{i}}$ & $w_{i}$ \\
\hline USA & 100 & 100 & Russia & 1.52 & 5.13 & Greece & 10.15 & 30.34 & Taiwan & 20.19 & 41.96 \\
\hline Japan & 94.14 & 105.92 & Switzerland & 37.28 & 98.99 & Portugal & 10.23 & 31.84 & Venezuela & 4.80 & 13.93 \\
\hline Germany & 44.45 & 66.80 & Sweden & 37.28 & 78.86 & Iran & 1.10 & 4.60 & New Zealand & 12.92 & 39.46 \\
\hline UK & 44.28 & 69.80 & Belgium & 20.49 & 65.38 & Egypt & 0.92 & 4.29 & Argentina & 10.87 & 22.26 \\
\hline France & 39.43 & 65.17 & Turkey & 2.77 & 8.54 & Ireland & 20.95 & 73.04 & Israel & 19.09 & 53.07 \\
\hline China & 1.03 & 2.74 & Austria & 25.11 & 69.93 & Singapore & 22.80 & 66.70 & Netherlands & 28.28 & 70.14 \\
\hline Italy & 34.22 & 55.69 & S Arabia & 11.12 & 26.36 & Malaysia & 3.50 & 11.35 & Finland & 22.53 & 67.32 \\
\hline Canada & 32.49 & 67.109 & Poland & 4.07 & 12.88 & Colombia & 1.47 & 5.81 & Peru & 1.41 & 5.93 \\
\hline Brazil & 5.84 & 10.71 & Hong Kong & 28.74 & 73.18 & Philippines & 0.52 & 2.89 & Australia & 32.63 & 60.31 \\
\hline Mexico & 8.81 & 17.15 & Norway & 39.60 & 107.41 & Chile & 4.59 & 14.10 & Thailand & 1.70 & 5.77 \\
\hline Spain & 21.59 & 41.68 & Indonesia & 0.53 & 18.03 & Pakistan & 0.19 & 1.53 & Algeria & 0.86 & 5.20 \\
\hline Korea Rep. & 16.62 & 31.46 & Denmark & 29.80 & 2.31 & UAE & 20.11 & 62.83 & & & \\
\hline India & 0.26 & 1.31 & South Africa & 3.09 & 8.73 & Czech Rep. & 3.49 & 15.96 & & & \\
\hline
\end{tabular}

Table 11: The calibrated country-specific quality parameters. $\mu_{i}$ is adjusted by the average elasticity of substitution, i.e. $\tilde{\mu}_{i}=\mu_{i}^{1 /\left(\sigma^{a v g}-1\right)}$.

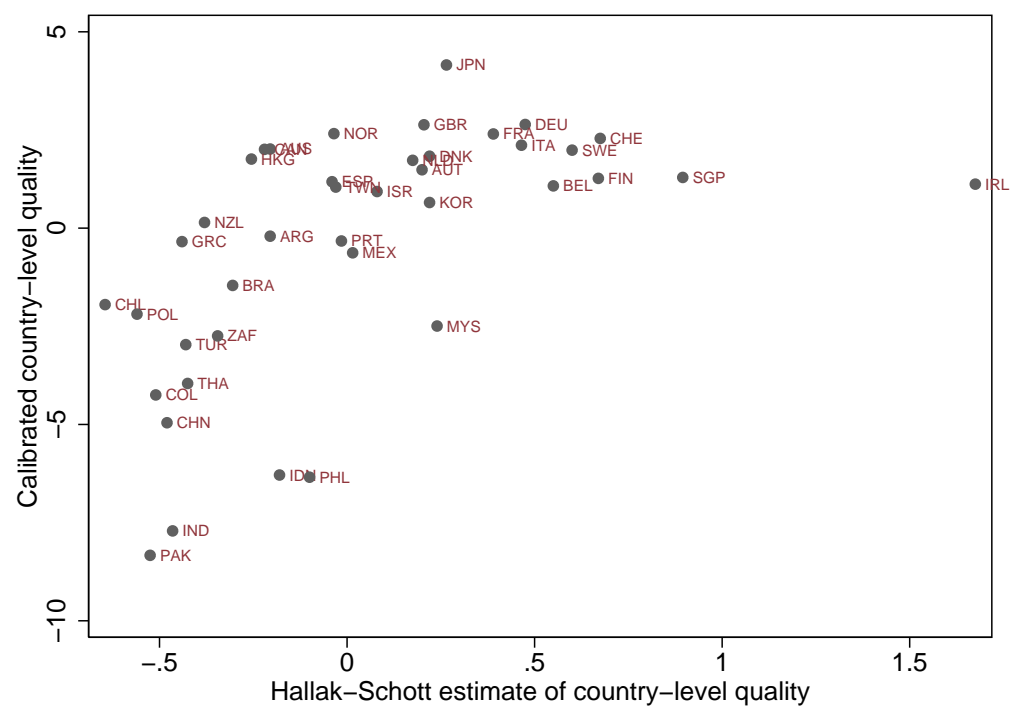

Figure 19: Comparison of country-specific quality estimates by Hallak and Schott [2011] with the calibrated country-specific quality in this paper. I use the average value estimated by Hallak and Schott [2011] for years 1998 and 2003, and normalize the quality of Argentina to zero. 


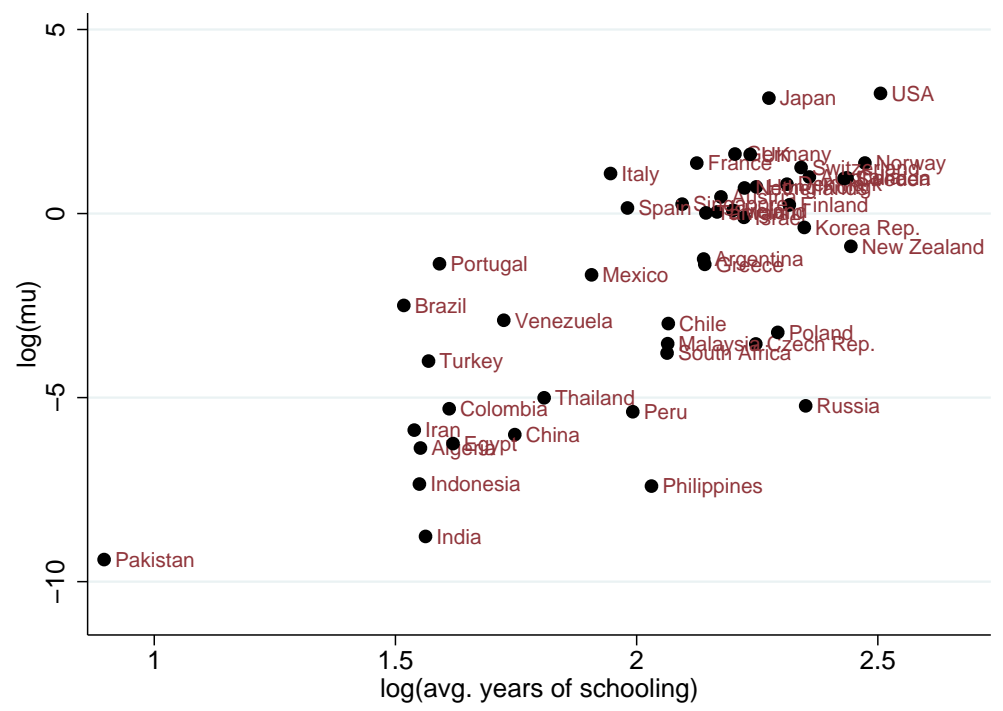

Figure 20: The scatter plot of the country-specific quality $\mu_{j}$ against the average years of schooling in each country (in benchmark year 2000) as reported by Barro and Lee [2001] $\left(R^{2}=0.55\right)$. The average years of schooling can be thought of as a proxy for skill of labor force in a country. This graph partially explains why a car produced by labor in the US is more valued by consumers than a car produced in India.

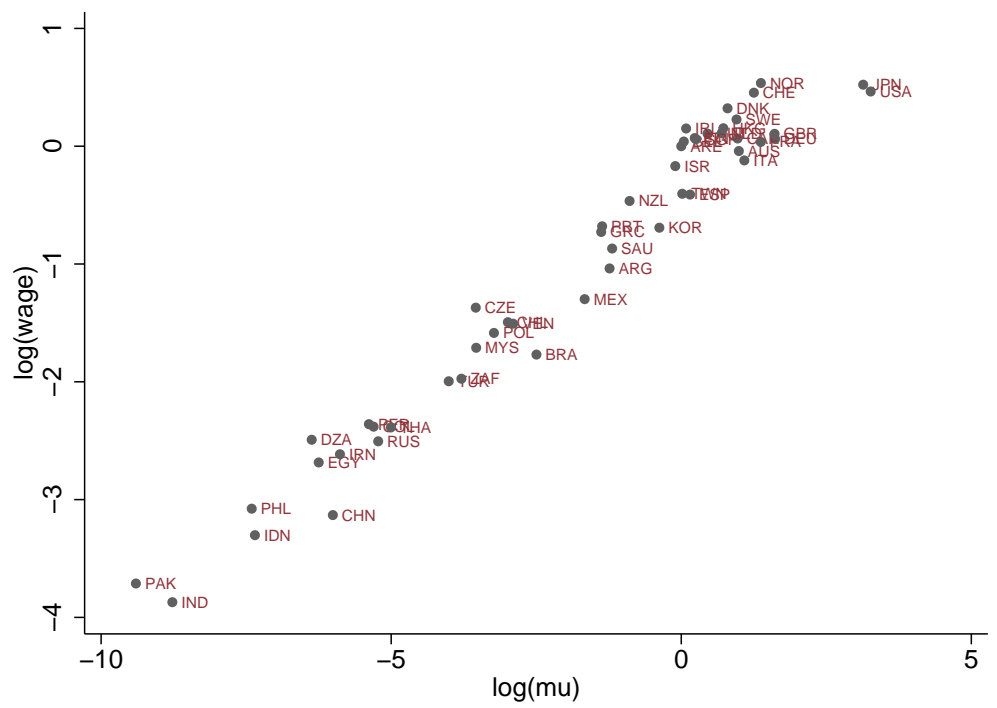

Figure 21: Scatter plot of the calibrated country-specific quality $\ln \mu_{i}$ against nominal country wage $\ln w_{i}$ in 2000. 


\begin{tabular}{|c|c|c|c|c|c|c|}
\hline Country & ISO code & $\left.\% \Delta V_{h}\right|_{h=1}$ & $\left.\% \Delta V_{h}\right|_{h=2}$ & $\left.\% \Delta V_{h}\right|_{h=3}$ & $\left.\% \Delta V_{h}\right|_{h=4}$ & $\left.\% \Delta V_{h}\right|_{h=5}$ \\
\hline UAE & ARE & -11.51 & -9.4 & -13.24 & -18.64 & -24.36 \\
\hline Argentina & ARG & -0.55 & -1.3 & -5.19 & -10.51 & -16.65 \\
\hline Australia & AUS & -2.59 & -1.71 & -3.68 & -6.66 & -10 \\
\hline Austria & AUT & -10.53 & -12.49 & -16.99 & -22 & -26.96 \\
\hline Belgium & BEL & -13.8 & -18.35 & -24.12 & -29.8 & -35.3 \\
\hline Brazil & BRA & 1.19 & 0.85 & -3.43 & -9.82 & -17.49 \\
\hline Canada & CAN & -5.24 & -8.22 & -12.86 & -17.56 & -22.05 \\
\hline Switzerland & CHE & -12.72 & -13.84 & -17.14 & -20.84 & -24.52 \\
\hline Chile & CHL & 0.42 & -2.95 & -10.58 & -20.04 & -29.93 \\
\hline China & $\mathrm{CHN}$ & 2.07 & 1.59 & -8.4 & -22.67 & -37.63 \\
\hline Colombia & $\mathrm{COL}$ & 2.03 & -2.82 & -14.99 & -29.37 & -43.7 \\
\hline Czech Rep. & CZE & -3.41 & -12.12 & -24.22 & -36.51 & -48.29 \\
\hline Germany & DEU & -4.18 & -4.82 & -7.11 & -9.63 & -12.23 \\
\hline Denmark & DNK & -12.12 & -13.39 & -17.54 & -22.18 & -26.76 \\
\hline Algeria & DZA & 1.8 & -9.29 & -26.48 & -43.93 & -60.53 \\
\hline Egypt & EGY & 2.37 & -4.4 & -19.26 & -35.81 & -51.86 \\
\hline Spain & ESP & -1.49 & -4.02 & -8.22 & -13.07 & -18.04 \\
\hline Finland & FIN & -10.94 & -11.45 & -16.13 & -21.63 & -27.14 \\
\hline France & FRA & -4.56 & -5.86 & -8.62 & -11.68 & -14.76 \\
\hline UK & GBR & -4.36 & -4.81 & -7.16 & -9.91 & -12.69 \\
\hline Greece & GRC & -4.6 & -7.68 & -14.55 & -22.42 & -30.29 \\
\hline Hong Kong & HKG & -13.98 & -8.51 & -10.42 & -14.5 & -18.78 \\
\hline Indonesia & IDN & 2.41 & -0.24 & -14.46 & -32.23 & -49.94 \\
\hline India & IND & 2.6 & -0.39 & -17.74 & -38.66 & -59.04 \\
\hline Ireland & IRL & -12.73 & -15.8 & -21.6 & -27.69 & -33.58 \\
\hline Iran & IRN & 1.97 & -2.99 & -16.26 & -31.96 & -47.38 \\
\hline Israel & ISR & -9.9 & -7.97 & -12.12 & -17.79 & -23.6 \\
\hline Italy & ITA & -2.5 & -3.49 & -6.15 & -9.38 & -12.76 \\
\hline Japan & JPN & -4.62 & -1.31 & -1.23 & -1.67 & -2.18 \\
\hline Korea Rep. & KOR & -3.54 & -2.02 & -5.65 & -10.86 & -16.51 \\
\hline Mexico & MEX & 1.24 & -0.3 & -5.46 & -12.5 & -20.08 \\
\hline Malaysia & MYS & -1.83 & -3.7 & -12.16 & -22.93 & -33.91 \\
\hline Netherlands & NLD & -10.21 & -12.99 & -17.26 & -21.73 & -26.12 \\
\hline Norway & NOR & -12.32 & -11.42 & -14.29 & -18.01 & -21.76 \\
\hline New Zealand & NZL & -2.93 & -4.34 & -9.99 & -16.95 & -24.08 \\
\hline Pakistan & PAK & 0.43 & -7.42 & -27.71 & -50.3 & -72.16 \\
\hline Peru & PER & 1.94 & -3.13 & -15.42 & -29.86 & -44.28 \\
\hline Philippines & PHL & 2.2 & -4.48 & -21.3 & -40.25 & -58.54 \\
\hline Poland & POL & 0.36 & -5.16 & -15.27 & -26.44 & -37.4 \\
\hline Portugal & PRT & -3.4 & -8.55 & -16.08 & -24.12 & -32.04 \\
\hline Russia & RUS & 2.21 & -1.71 & -13.75 & -28.1 & -42.3 \\
\hline S Arabia & SAU & -1.85 & -2.74 & -7.79 & -14.48 & -21.57 \\
\hline Singapore & SGP & -15.53 & -10.5 & -12.19 & -16.61 & -21.62 \\
\hline Sweden & SWE & -8.82 & -9.39 & -12.91 & -17.14 & -21.37 \\
\hline Thailand & THA & 1.42 & -1.34 & -11.77 & -25.2 & -38.86 \\
\hline Turkey & TUR & 1.53 & -2.55 & -12.85 & -24.9 & -36.92 \\
\hline Taiwan & TWN & -5.9 & -3.37 & -6.6 & -11.35 & -16.36 \\
\hline USA & USA & -1.82 & -1.07 & -1.25 & -1.64 & -2.1 \\
\hline Venezuela & VEN & 0.58 & -2.45 & -10.48 & -20.38 & -30.53 \\
\hline South Africa & ZAF & 1.66 & 0.15 & -8.05 & -18.83 & -30.17 \\
\hline
\end{tabular}

Table 12: The gains from trade for different countries in various product categories. The table reports changes in purchasing power in each product category, i.e. $\frac{w_{i}}{P_{h}^{i}}$, when switching from the calibrated trade equilibrium to the counter-factual autarky equilibrium. Notice that $V=Q_{N}^{1-\alpha} U_{M}^{\alpha}$, and hence $d \ln V^{i}=\alpha d \ln U_{M}^{i}=\alpha d \ln \frac{w_{i}}{P^{i}}$. 